\title{
Exploring How Experts in Interdisciplinary Teams Express and Share Ideas through Sketching
}

\author{
by
}

Diana Wilhelm

A thesis submitted to the Faculty of Graduate and Postdoctoral Affairs in partial fulfillment of the requirements for the degree of

Master of Design

in

Industrial Design

Carleton University

Ottawa, Ontario

(C) 2011

Diana Wilhelm 
Library and Archives

Canada

Published Heritage

Branch

395 Wellington Street

Ottawa ON K1A ON4

Canada
Bibliothèque et

Archives Canada

Direction du

Patrimoine de l'édition

395, rue Wellington

Ottawa ON K1A ON4

Canada
Your file Votre référence

ISBN: 978-0-494-81610-3

Our file Notre référence

ISBN: 978-0-494-81610-3
NOTICE:

The author has granted a nonexclusive license allowing Library and Archives Canada to reproduce, publish, archive, preserve, conserve, communicate to the public by telecommunication or on the Internet, loan, distribute and sell theses worldwide, for commercial or noncommercial purposes, in microform, paper, electronic and/or any other formats.

The author retains copyright ownership and moral rights in this thesis. Neither the thesis nor substantial extracts from it may be printed or otherwise reproduced without the author's permission.

\section{AVIS:}

L'auteur a accordé une licence non exclusive permettant à la Bibliothèque et Archives Canada de reproduire, publier, archiver, sauvegarder, conserver, transmettre au public par télécommunication ou par l'Internet, prêter, distribuer et vendre des thèses partout dans le monde, à des fins commerciales ou autres, sur support microforme, papier, électronique etlou autres formats.

L'auteur conserve la propriété du droit d'auteur et des droits moraux qui protège cette thèse. $\mathrm{Ni}$ la thèse ni des extraits substantiels de celle-ci ne doivent être imprimés ou autrement reproduits sans son autorisation.
In compliance with the Canadian Privacy Act some supporting forms may have been removed from this thesis.

While these forms may be included in the document page count, their removal does not represent any loss of content from the thesis.
Conformément à la loi canadienne sur la protection de la vie privée, quelques formulaires secondaires ont été enlevés de cette thèse.

Bien que ces formulaires aient inclus dans la pagination, il n'y aura aucun contenu manquant. 


\begin{abstract}
Research into design methodologies has examined the benefits of visualization tools to facilitate ideation for solo and groups of designers. This thesis looks at how experts from outside of design-studio syllabus use visualization tools natively to design in an interdisciplinary team setting, to explore how to adapt visualization tools. Structured workshops using experts from diverse backgrounds were conducted and then analyzed. The study revealed that designing solutions to abstract problems is less likely to lead participants to sketch when compared to a more concrete problem. In addition, the content and types of drawings used to explore abstract problems varied significantly, suggesting that abstract problems have more options in how they can be represented. As well, size and positioning of artifacts appeared to affect group dynamics. The next stage of the investigation needs to explore how to adapt sketching methods for expert teams based on the results of this study.
\end{abstract}

Keywords: interdisciplinary, expert teams, sketching, collaboration, abstract problemsolving, turn-taking, brainstorming, story-telling, facilitation 


\section{Acknowledgements}

I would like to thank my professors WonJoon Chung and Gitte Lindegaard for their patience and persistence in helping me complete this thesis. This research project has been challenging in a good way and has pushed me in ways that I never expected.

I would also like to thank my husband Chris Edwards for his understanding and acceptance of my choice to go back to school and for supporting me during the intensity of this endeavour. While he did not always know what I was talking about, he was patient and was always willing to help me.

In memory of my father who passed away during the time that I was working on this thesis. He taught me his "old farmer" approach to logic: If it does not make sense, then there is something missing and you need to discover what that is. I will always cherish all that he shared with me.

Finally, my thanks go to the program graduate administrator Val Daley for her good cheer and helpfulness during my studies. 


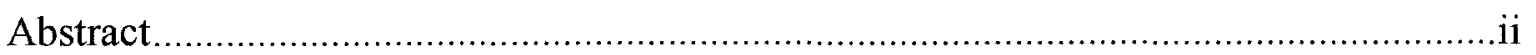

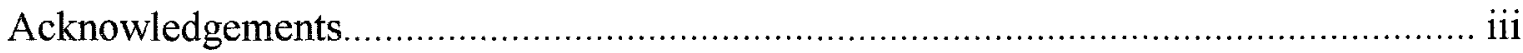

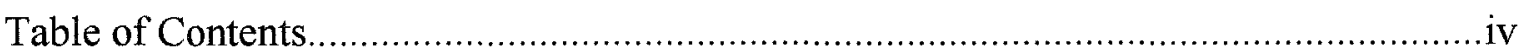

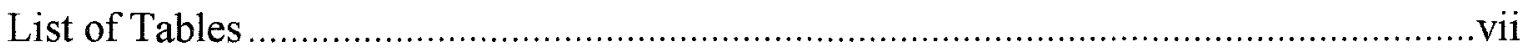

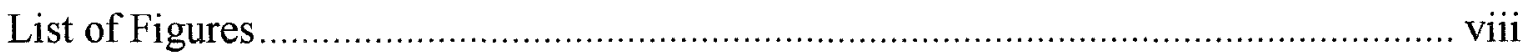

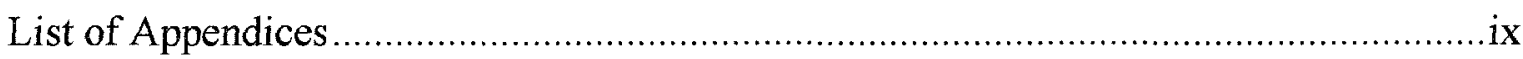

Glossary

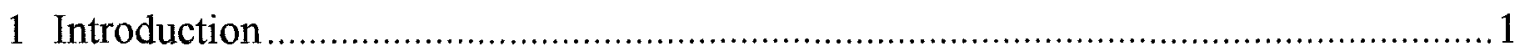

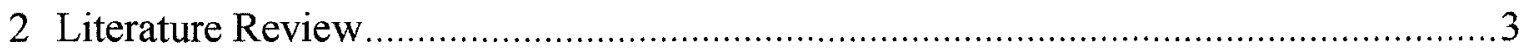

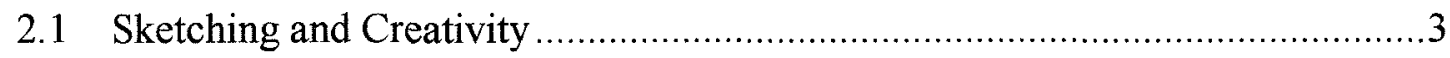

2.2 Expert Knowledge and Creative Problem-solving ........................................4

2.3 Abstract Problem-solving through Visualization.........................................6

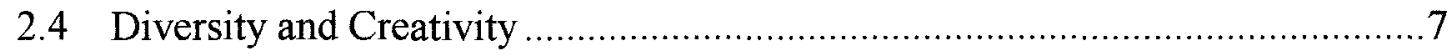

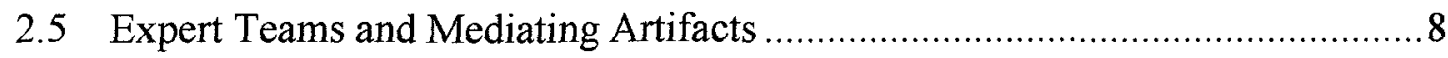

2.6 Collaborative Design Methods and Expert Teams.........................................

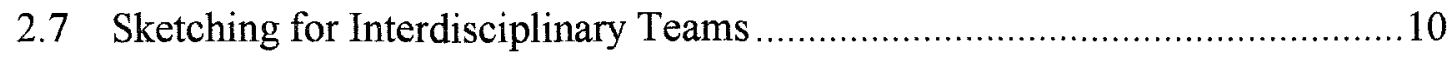


EXPERT GROUP SKETCHING V V

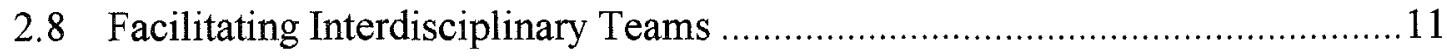

2.9 Summary of Sketching in Expert Groups ............................................. 12

2.10 Investigating Expert Teams and Sketching .....................................13

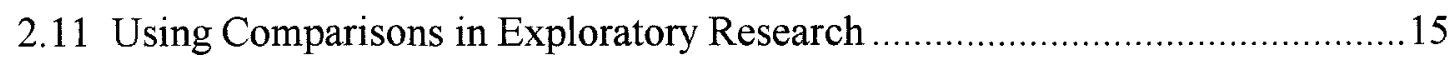

2.12 Analyzing Design Workshop Artifacts ........................................... 16

2.13 Creating Diversity Equivalence in Workshop Groups............................... 18

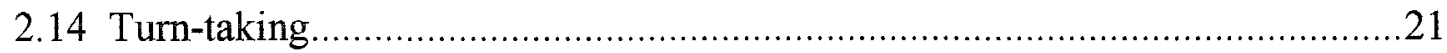

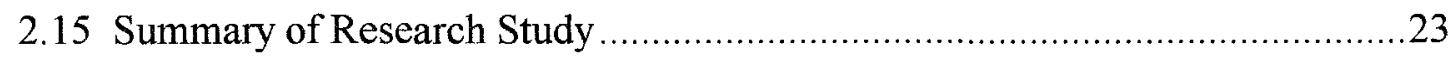

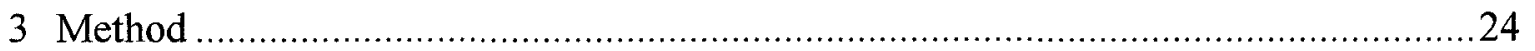

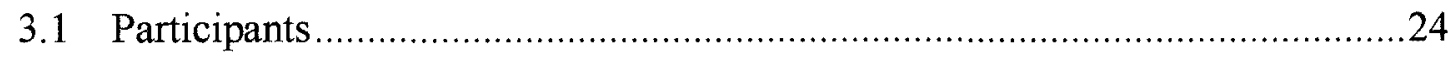

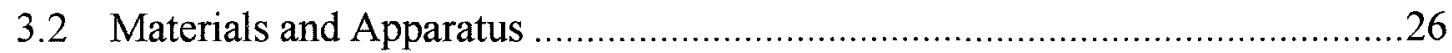

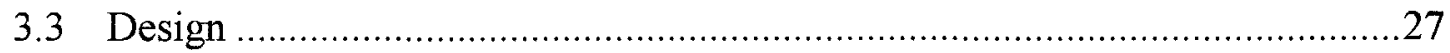

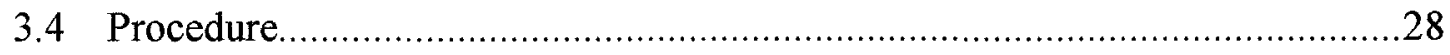

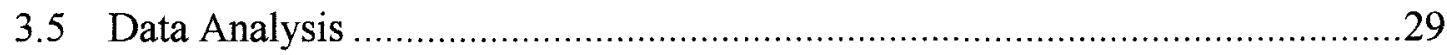

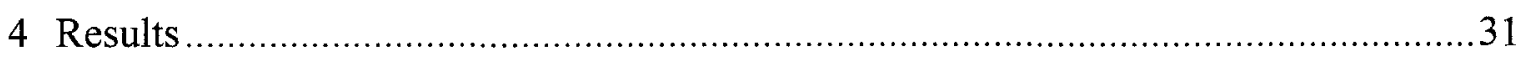

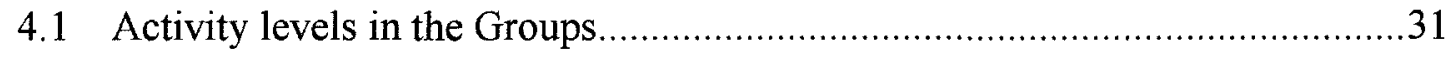

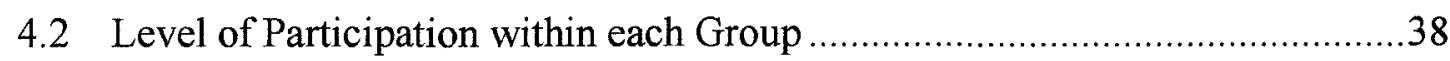

4.3 Results of Verbal Activity Analysis................................................41 
EXPERT GROUP SKETCHING Vi

4.4 Comparing Level of Activity and Occupation ...................................... 44

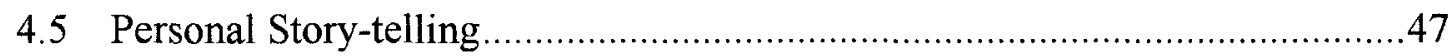

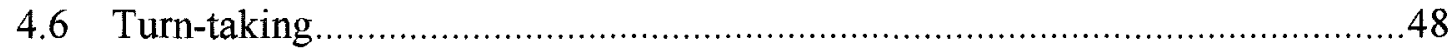

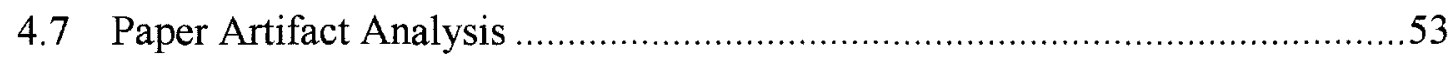

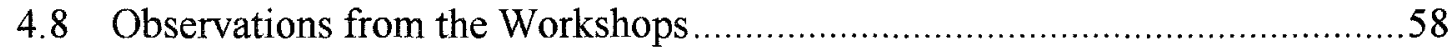

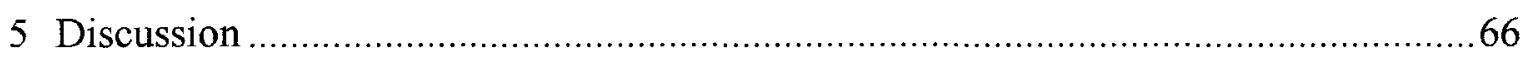

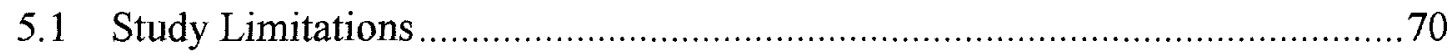

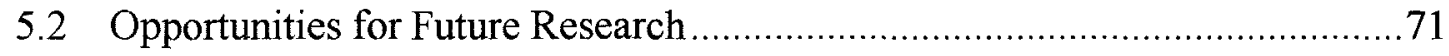

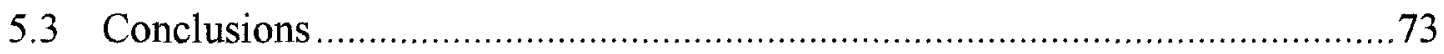

5.4 Suggestions for Designers Facilitating Highly Diverse Expert Teams............74

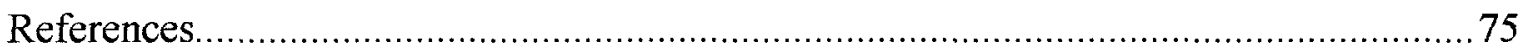


List of Tables

Table 1 Characteristics of the Holland Codes

Table 2 Occupation Categories for Professional Diversity .....

Table 3 Example Professions for Occupation Categories

Table 4 Workshop Participant Assignments with Holland Code Quiz Results. .25

Table 5 Operational Definitions for Workshop Activities

Table 6 Total Word Count and Total Paper Activity Minutes by Participant

Table 7 Drawing/Writing Activity Time by Gender

Table 8 Number of Story-telling Events in each Workshop by Problem

Table 9 Average Turns per Minute by Workshop and Problem.

Table 10 Average Turn-taking Rate During and Following Story-Telling .53

Table 11 Operational Definitions for Paper Artifacts.

Table 12 Operational Definitions for Artifact Location on Paper Sheet .55

Table 13 Operational Definition for Artifact Size. .55

Table 14 Operational Definitions for Artifact Level of Usage .55

Table 15 Paper Artifact Counts by Workshop and Problem .56

Table 16 Artifact Counts for Usage and Size .57

Table 17 Artifact Counts for Usage and Location. .57 


\section{List of Figures}

Figure 1 Holland's Hexagon Model with Prediger's Axes

Figure 2 Four Categories of Occupation based on Holland/Prediger Model .20

Figure 3 Participant Experience Level Distribution .25

Figure 4 Gender Representation by Group. .26

Figure 5 Total Group Drawing Activity Time by Problem.... 33

Figure 6 Total Group Writing Activity Time by Group and by Problem. 34

Figure 7 Total Paper Activity by Group and by Problem. .35

Figure 8 Workshop 1 Event Diagram .37

Figure 9 Total Drawing Time by Participant for Abstract-ebook Problem .38

Figure 10 Total Drawing Time by Participant for Concrete-kitchen Problem .39

Figure 11 Total Writing Time by Participant for Abstract-ebook Problem 40

Figure 12 Total Writing Time by Participant for Concrete-kitchen Problem 40

Figure 13 Total Paper Creation Time by Participant. 41

Figure 14 Total Word Count by Participant .42

Figure 15 Total Paper Activity by Occupation Category .45

Figure 16 Rate of Turn-taking for Workshop 3 for Abstract-ebook Problem .50

Figure 17 Workshop 3 Rate of Turn-taking-Event Diagram for Abstract-ebook Problem

Figure 18 Abstract-ebook Representations from Workshops 1 and 2. .59

Figure 19 Abstract-ebook Representations from Workshops 3 and 4 . .60

Figure 20 Sketch Sequence of Participant Pointing and then Leaning Back .62

Figure 21 Sketch of Workshop Group Crowding around Prototype 


\section{List of Appendices}

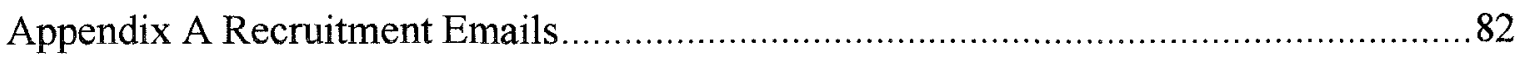

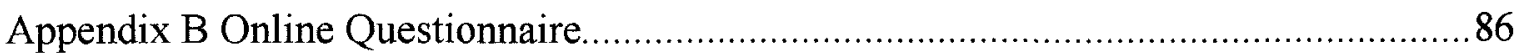

Appendix C Workshop Problem Statement Handouts ...................................................97

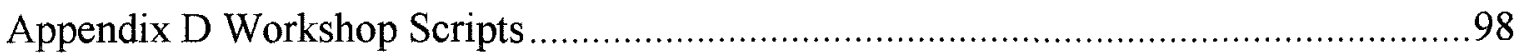

Appendix E Example of Rate of Turn-taking Calculation Method.................................100

Appendix F Holland Code Quiz Results ........................................................................ 101

Appendix G Workshop Activity Event Diagrams ………............................................ 102

Appendix H Rate of Turn-taking with Event Diagrams...............................................105 


\section{Glossary}

Abstract

Abstract Problem

Concrete

Concrete Problem

Designer

Expert

Ill-defined Problem
Is defined as "based on general ideas and not on any particular real person, thing or situation."

Generally refers to problems that do not have physical

manifestations and as a result its components cannot be seen and are oftentimes idea-based rather than specific to an instance.

Is defined as "existing in a material or physical form ; not abstract" (“Oxford Dictionaries Online," 2011)

Are problems that are physical in nature or are visually tangible. These problems exist in a physical domain.

For the purposes of this thesis, the word "designer" refers to individuals who have been trained in a studio-based program such as industrial design, architecture or graphic design, where sketching methodologies are taught as part of the training syllabus.

Is defined as an individual with 10 or more years of experience in their field (Ericsson \& Smith, 1991) and as a result has developed distinct professional skills that are reflected in the way they solve problems in their field. Is defined as a class of problems whereby the parameters of the problem are not all known or are not sufficiently clear and as a result, the problem is considered difficult to solve. 
EXPERT GROUP SKETCHING

Interdisciplinary Is defined as "combining or involving two or more academic disciplines or fields of study" (The Random House Dictionary of the English Language, 1987)

Reflective Practice Reflective practice has been defined as "the capacity to reflect on action so as to engage in a process of continuous learning" (Schön, 1983).

Reflective Sketching Is a term used in this thesis as a short form for describing the use of sketching as part of "reflective practice". Using sketching for reflective practice involves sketching and then looking back on the sketches in an attempt to discern further insights and ideas that will further the design of that being sketched. Design disciplines such as architecture and industrial design are trained to use sketching as part of their reflective practice. Their training involves professors working with students to show them how to reexamine their designs through the sketch to further develop and refine their solution.

Turn-taking Is defined as "one or more streams of speech bounded by speech of another, usually an interlocutor" (Crookes, 1990). More plainly, it means the process by which speakers take turns while conversing.

Visual Analogy The term analogy is defined as "a resemblance in some particulars between things otherwise unlike" ("Free Merriam- 
Webster Dictionary," 2011). A visual analogy refers to identifying common form characteristics between two disparate items based on their visual representations.

Visualization Is defined as "the act or process of interpreting in visual terms or of putting into visible form" ("Free Merriam-Webster Dictionary," 2011)

Wicked Problem Is a type of problem originally defined by Rittel and Webber (1973) to describe problems for which it is difficult to formulate a problem statement, have "no stopping rule" (1973), are unique, and that usually provide no opportunity to test before implementing them. As well, typically solutions to wicked problems once implemented will create new problems that were unforeseen. 
EXPERT GROUP SKETCHING

1 Introduction

Interdisciplinary teams are increasingly being formed to address difficult and complex problems (Klein, 2004; Lélé \& Norgaard, 2005). Rittel and Webber (1973) described certain types of problems as "wicked problems". These are problems that do not have clearly identifiable boundaries about scope, timing and completeness and are likely unique. These problems are the most challenging to design solutions for. The very scope of the problems makes it essential to engage many different types of expertise in an attempt to solve them. While not all problems are "wicked problems", many problems possess "wicked" characteristics.

Pulling together an interdisciplinary team is one way to try to address complex problems. The experts on these teams bring many different types of knowledge, methods and strategies to the team (Newell \& Simon, 1972) but miscommunication often occurs due to differences among team members (Kilker, 1999).

Sanders \& Stappers (2008) noted that a mediating artifact (e.g. sketching or early prototypes) can help designers and users interact as they evolve a design. Casakin and Goldschmidt (2000) investigated how visualization can help in problem-solving, specifically by helping people to find patterns through visual analogies. There is evidence that using sketching during problem-solving can expand the quality of results beyond what each individual can produce (Schwartz, 1995).

Collaborative design methods involve users and designers working together through sketching and/or prototyping to design solutions to problems. In interdisciplinary teams, experts are not "users" of the product being designed. Instead, these experts have knowledge and professional artistry that is seen as valuable for solving 
EXPERT GROUP SKETCHING

the problem. While there are many ways that these experts may choose to express and share their thoughts, not everyone will necessarily choose to use sketches or prototypes. Yet these tools could potentially provide some benefits by leveraging visual thinking as a means for learning and problem-solving (Mathewson, 1999).

With the growing interest in design thinking (Brown \& Katz, 2009; Esslinger, 2009) designers are increasingly being asked to facilitate interdisciplinary teams in the pursuit of innovative solutions (Martin, 2009). While designers use sketching to develop their ideas, other disciplines may not be as skilled or as inclined towards sketching as a tool to represent ideas visually. If designers want to use sketching in an interdisciplinary team, they need to better understand its usage in that context. This thesis explores how interdisciplinary teams use sketching natively as they design solutions to abstract problems and even "wicked" (Rittel \& Webber, 1973) problem spaces. The specific area of interest is sketching as used by experts from outside of the typical design professions such as architecture or industrial design to those disciplines that do not include sketching as part of their professional practice training. The first part of this document presents a review of background literature related to the topic and research approach. The subsequent section describes the study's structured group workshops conducted using expert participants. The results section then provides the detailed findings from the analysis of the activities observed in the workshops. Based on this, the discussion section outlines the major findings, study limitations, and future research. Finally, the conclusions include some useful suggestions for facilitating the use of sketching in an interdisciplinary team environment. 
EXPERT GROUP SKETCHING

2 Literature Review

\subsection{Sketching and Creativity}

In his work on reflective practice, Schön $(1983 ; 1990)$ describes a skill that develops through studio-based training where student and mentor work through projects so that the student will develop the thinking required for professional practice. Sketching plays an integral role in the reflective practice of designers whereby sketches act to facilitate the creative process by leveraging the visual cognitive abilities of the human brain (Goldschmidt, 1991; 1994)\}.

For early concept development, recent research into sketching has highlighted the "dialogue" of the sketch as a means to encourage creativity through reflection of design ideas (Buxton, 2007; Cross, 2006; Lawson, 2005). This "dialogue" is represented by the series of sketches a designer creates as the problem space is explored and the solution emerges during the design process. The nature of the rough sketch with its loose representation and lack of formality provides ambiguity for the designer to see alternative approaches (visual analogies) that then provide mental links to prior knowledge enabling the generation of more ideas (Casakin \& Goldschmidt, 1999).

The study of creativity has investigated the process of idea generation during the early design stage of problem solving (Newell \& Simon, 1972). Literature on creativity refers to the "ambiguity" of ideas leading to other ideas (Finke, Ward, \& S. Smith, 1996), but much of this research appears to be about ambiguity with words rather than with visual material (e.g. sketching). The main premise is that ambiguity triggers the retrieval of similarly patterned information from long term memory creating a generative process 
EXPERT GROUP SKETCHING

where new combinations of elements emerge (Ericsson, 1998; Gick \& Holyoak, 1980; 1983; Newell \& Simon, 1972; Schwartz \& Heiser, 2006).

Creativity has been linked with people's ability to find analogies (Finke, Ward, \& S. Smith, 1996) as well as more recent research into visual analogies (Casakin, 2004; Casakin \& Goldschmidt, 1999; Tversky, 2005).

Rough sketching which often triggers visual analogies, has been linked to creative idea development (Kavakli \& Gero, 2001; Vanderlugt, 2002; Verstijnen, Vanleeuwen, Goldschmidt, Hamel, \& Hennessey, 1998), but much of the literature focuses on sketching as used by architects, industrial designers, graphic designers and other disciplines that develop products.

While graduates from other disciplines may not be trained in reflective practice using sketching, there may still be benefits for them in exploring ideas through sketching to take advantage of their cognitive system's ability to find visual analogies.

\subsection{Expert Knowledge and Creative Problem-solving}

Prior knowledge allows the expert to retrieve analogous information from their knowledge base and use it to find more creative solutions than the novice (Ericsson, 1998). Studies into creativity have revealed that an expert will typically produce more ideas and more successful ideas than those without expertise in that area (Akin, 1990). The explanation is that with more knowledge of problem spaces the expert is more adept at identifying possible solution strategies (Simon, 1959; Newell \& Simon, 1972).

Similarly, studies of designers sketching have demonstrated that the expert designer will generally produce more and better ideas than the novice (Suwa \& Tversky, 1997) and be more thorough and rigorous in the exploration of the problem space (Kavakli, Suwa, 
Gero, \& Purcell, 1999).

Studies have shown that typically it takes about 10 years of practice for the skill to develop to an expert level (Ericsson \& J. Smith, 1991). While the amount of experience may vary somewhat, it does take a significant amount of time to develop and integrate professional skills so that the expert level is attained. With experts, the professional judgment they use for appraising ideas appears to be effortless (Csikszentmihalyi, 1997; Gladwell, 2005).

Experts can be considered a distinct demographic group and yet many studies on group creativity have used younger, less experienced participants in their studies which may have affected the results (Dunbar, 1997). Paulus and Dzindolet (1993) investigated social influences in group creativity using novices in an attempt to understand how these influences might impact brainstorming. Diehl and Stroebe $(1987 ; 1991)$ did a series of experiments on blocking effects in brainstorming sessions and used students as their subjects.

Studies have shown that experts have distinct well-developed strategies for problem solving based on their experience and that the style of problem-solving will vary by discipline (Ericsson, 1998). These strategies are quite different from those used by novices. Idea generation has been shown to be linked to metaphors and analogies (Holyoak \& Thagard, 1996). The act of comparing disparate things through an analogy is a form of pattern-matching between the perceived structural aspects of one thing as compared to another. This would suggest that an expert's knowledge will influence their analogical capabilities because it is structured differently and is more extensive than the novice's which in turn will influence the ideas experts will generate. Thus, any research 
EXPERT GROUP SKETCHING

that focuses on experts and their ability to generate ideas and problem-solve must use experts and should not use surrogate subjects such as students.

\subsection{Abstract Problem-solving through Visualization}

Industrial designers and architects typically design for a 3-dimensional world. Graphic designers and User Interface designers most often deal with 2-dimensional solutions. Their work product is clearly visible and tangible. In other disciplines outside of these design practices, the work product may be less visible and less tangible.

The reason an interdisciplinary team is formed is likely due to the complexity and vagueness of a problem. The problem likely has many facets and thus requires a multifaceted solution. This usually means that it needs expert knowledge from many different disciplines.

In the present thesis, the term "abstract problem" is used instead of ill-defined or “wicked" problem. The Oxford Advanced Learner's Dictionary (2010) defines "abstract" as "based on general ideas and not on any particular real person, thing or situation". Not all ill-defined and wicked problems are abstract. Exploring solutions to these problems however often requires exploring the problem space initially in abstract terms before designing a less abstract, more concrete solution. According to Simon (1973), it is necessary to generalize the details and work through the initial problemfinding phase of a design in an abstract form before moving to the more concrete solution space. This is consistent with VanLehn's (1996) description of how the expert's knowledge is represented as structures in their internal long term memory that allow the expert to access their domain knowledge through structural components. Solutions for ill-defined or "wicked" problems are not simply copies of previous solutions to other 
problems but require a solution to be crafted through careful examination of the problem's characteristics. The structural nature of the expert's knowledge facilitates their ability to find components for a solution of these difficult problems in an abstract domain. Once the abstract direction is determined, it becomes easier to then construct the solution. As an example, to design a strategy for solving a business problem requires initial work through abstract goals. Then as the direction for the strategy emerges, individual applied tactics can be identified and these are usually quite concrete.

Thus, there is a class of exploration for problem-solving that involves looking first at the generalized (i.e. abstract) form of a problem even where the solution ends up being quite concrete. While abstractions are likely difficult to represent on paper because they are not visual, expressing abstract ideas on paper does appear to offer some advantages for problem-solving (Schwartz, 1995). As well, Casakin (2004) investigated the use of visual analogies during the early phase of design problem-finding where architects were investigating the constraints around a design problem. The study found that both novice and expert architects were able to more effectively explore using visual analogies referencing other problem domains.

\subsection{Diversity and Creativity}

Today's technology makes it much easier to solve many problems. In a sense it frees up human capital to take on more difficult and challenging problems. This trend is seen with the increased use of interdisciplinary groups (Rhoten, 2004) as a way to tackle complex issues and problems.

Studies have shown that the diversity of expertise in interdisciplinary teams enables creativity. Innovative solutions are often instigated because of an exploration at 
EXPERT GROUP SKETCHING

the crossover of disciplines (Amabile, 1996; Johansson, 2004; Kaufmann \& Tödtling, 2001; Paulus, 2000), and as such, there has been keen interest in both academia and industry to find out how to encourage and facilitate teams with diverse backgrounds (West, 2002).

Each expert in an interdisciplinary team brings their knowledge of problem solving, judgment and perspectives to the group. This knowledge, if shared, can be key to developing new insights as information is combined in new ways (Johansson, 2004; Leonard \& Swap, 2005). But the approach to examining a problem can vary significantly between professional disciplines (Newell and Simon 1972). As well, among the disciplines there can be significant differences in communication styles (terminology) and etiquette (Clark, Dodd, \& Coll, 2008). Each expert may have a different way to represent information (Ericsson \& J. Smith, 1991) and have different perspectives and biases (Campbell, 1969; Kilker, 1999). These all represent potential sources of conflict, but in fact conflict provides the very material necessary for groups to be creative and to avoid groupthink (Janis, 1982; Paulus \& Dzindolet, 1993).

\subsection{Expert Teams and Mediating Artifacts}

When a group of experts get together, dynamics and individual differences can make it difficult to communicate within the group. C. P. Snow (1959) wrote about the division between the literary intellectuals and scientists in his influential paper "Two cultures". Since then there seems to be a continual struggle between different disciplines that in part is caused by language but also cultural training and the ways each discipline is trained to think. The dynamics of the group, especially with experienced professionals can be a challenge because of stylistic as well as professional methodology differences 
among the team. Because language is often used in different ways between disciplines, there is a need for something that acts to symbolize information differently than that achieved through words. When problems are abstract, there is no common convention of a visual representation of the solution across different disciplines. In a sense, there is no common "visual dictionary" that documents the symbols people use for abstract ideas and concepts. While some disciplines have developed their own lexicography of symbols, they are often not universally known (Goel, 1995) and this can cause confusion for other professions. So simply asking people to draw out the solution to an abstract problem would result in many different types of drawings. A mediating artifact such as a sketch can help communication and sharing in collaborative design with users and designers (Vanderlugt, 2002; 2005) but there appears to be limited research into the use of sketching as a mediator for diverse interdisciplinary teams. The creation and use of mediating material can provide a way to bridge a gap and facilitate communication (Erickson, 1995; Fischer, 1999). The use of artifacts that act as mediators has been researched to try to identify how these facilitate communication within groups. The more polarized the opinions are between the parties, the more need for mediating material to allow for the "transformation" of information between parties (Carlile, 2004). The mediation object allows both parties to represent their perspective to the other party and enables better communication and learning (Fischer, 2005).

\subsection{Collaborative Design Methods and Expert Teams}

Collaborative design methods have been increasingly used as a way to achieve a good design (Sanders \& Stappers, 2008). Several designers may work together on sketches as a means of exchanging ideas and building upon each others' insights (Buxton, 
EXPERT GROUP SKETCHING

2007; Cross, 2006). Using quick prototyping and informal sketching for user-designer collaboration provides a mechanism to encourage the generation of ideas from the users as well as providing a means for triggering ideas to further the creative generative process (Cagan \& Vogel, 2002; Fischer \& Giaccardi, 2004; Schrage, 2000; Tohidi, Buxton, Baecker, \& Sellen, 2006; Vyas, Heylen, Nijholt, \& van Der Veer, 2009). For interdisciplinary teams the process of the expert team has the potential to be quite different because these experts are not the "users" of products or services being designed as seen in the collaborative design scenarios. Experts are not test subjects but rather bring their own distinct problem solving strategies, knowledge of subject matter and experience from their mistakes and successes. An economist does not build or use an economy in the same way as a reader uses a book or a driver experiences a car. The expert has developed a keen sense of their subject matter, its qualities, its behaviours and its shortcomings through observation, trial and error, training and reflection.

By the very nature of collaborative design, the designer is the authority in the collaborative process and thus controls the method and direction of the collaborative process. In an interdisciplinary team, where an expert may perceive himself as "the expert", there will likely be different dynamics and thus the methodology may need a different approach than current collaborative design methodologies. There appears to be limited research into the use of collaborative design methodologies applied to highly diverse interdisciplinary teams of experts.

\subsection{Sketching for Interdisciplinary Teams}

Sketching is used as a tool by many design professions. Designers from industrial design, architecture and other reflective-practice design fields are trained to use sketching 
as an effective means to examine, explore, reflect, and refine ideas. Reflective practice through sketch is seen as essential to facilitate the designer's exploration of a problem space to achieve creative solutions (Schön, 1983, 1990). Nigel Cross (Cross, 2006) refers to this as "designerly ways of thinking" and has investigated the differences in problemsolving approaches as a result of the training designers receive.

Research into designers' mental processes has revealed a process by which restructuring and combining of ideas through sketch leads to creative solutions (Verstijnen, Vanleeuwen, Goldschmidt, Hamel, \& Hennessey, 1998). Fish (2004) suggested that the exploration of ideas through sketch is yet another form of communication through symbols similar to human writing.

If thinking through solutions with a sketch is a technique, then it may have applications in other disciplines outside of design practices. However not all experts are necessarily visual thinkers (Gardner, 1983) and attempting to use the designers' reflective practice methodology may not be effective in this context.

\subsection{Facilitating Interdisciplinary Teams}

Designers are often asked to facilitate interdisciplinary teams for creative problem-solving (Martin, 2009). The recent flurry of interest in design thinking books suggests that the training designers receive in "design thinking" (Brown \& Katz, 2009; Esslinger, 2009) has a broader application beyond designing products.

Visual representations may offer some potential to mediate, share and enhance creativity (Erickson, 1995; Larkin \& Simon, 1987; Schwartz, 1995; Schütze, Sachse, \& Römer, 2003) but cannot simply be imposed on an interdisciplinary group without first understanding how these experts natively externalize their ideas in a group setting. For a 
EXPERT GROUP SKETCHING

tool to be effective, it needs to be easy to use and satisfy user requirements. The users in this case are the experts trying to design solutions to difficult problems.

If a designer wants to use sketching as part of facilitating expert groups, they need to understand more about how experts from different disciplines choose to represent their ideas, knowledge and strategies while designing solutions to problems. They can then use this knowledge to adapt their sketching methods to suit this type of group.

\subsection{Summary of Sketching in Expert Groups}

While sketching is part of the training of some disciplines, other disciplines have not developed a rigorous methodology around creative idea development through sketch. Reflective practice through sketching is part of the syllabus of studio-based design disciplines. The use of sketching appears to tap into the brain's visual cognitive functions to enhance the creative generation of ideas through visual analogy. Reflective sketching techniques have also been used for collaborative design where users work with designers to define solutions. The use of sketching also provides a means for mediation within design groups by facilitating communication and sharing. While innovation in diverse teams has been investigated extensively in business and management journal papers there seems to be little research into visualization tools like sketching tailored to team effectiveness for creative problem-solving.

The problems taken on by interdisciplinary teams are often abstract in nature or have some abstract facets to them. Sketching has been linked to improved team-based problem-solving of abstract problems. Since interdisciplinary teams often work on abstract concepts while attempting to solve complex problems, the use of sketching may offer enhancements both to the dynamics within the group as well as the quantity and 
EXPERT GROUP SKETCHING

quality of their creative output.

Typically, designers create sketches and then reflect on them to help trigger further ideas about the problem and/or solution. This in turn may lead to further sketching and reflection as the solution evolves and gets refined. The topic of interest for this thesis is the extent to which the use of the sketching methodology as practiced by design disciplines could benefit other disciplines that currently are not trained in sketching. More specifically, this thesis investigated how interdisciplinary design teams made up of experts from outside of design disciplines (i.e. those where reflective practice through sketching is taught in studio-based curriculums) externally express and share their thoughts and ideas through visual material as they design solutions to ill-defined and abstract problems. The rationale for investigating this topic in a design program is simply that industrial designers are often tasked with facilitating diverse groups in creative problem-solving. This research is intended to help designers better understand how to use sketching in this context.

This thesis can be viewed as the first step in a line of inquiry investigating how to adapt sketching to a broader range of disciplines. For this study, the specific area of interest is the use of sketching in highly diverse interdisciplinary teams working on abstract problems.

2.10 Investigating Expert Teams and Sketching

There are a number of approaches that can be used for researching design group activities. In one sense, this research is User Research looking to find out more about how experts natively sketch in a group. For this study the question is more about "how experts sketch?" rather than "why?" This suggested that the most appropriate way to 
examine the topic was an exploratory research approach to discover first what was going on. For this research, the specific subject matter was not yet well enough understood to investigate a specific variable or aspect since there was not much prior research specifically on expert interdisciplinary teams using sketching. Stebbins noted that "In general, exploration is the preferred methodological approach under at least three conditions: when a group, process, activity, or situation has received little or no systematic empirical scrutiny ..."(Stebbins, 2001, p. 9).

Exploratory research uses an open-ended coding approach to allow the researcher flexibility in their investigation so they can identify the items to examine and analyze after the study has been run. That was done for this study. There are many different research frameworks that advocate open-coding. For example, Grounded Theory (Glaser \& Strauss, 1967) is widely used for qualitative research in the social sciences. With grounded theory, the researcher develops their theory about what is going as the analysis process progresses through a gradual refinement of observing the data and coding it and then reflecting on it. The goal of a Grounded Theory approach is the development of a theory that evolves as the data is analyzed. For this thesis, the intention was to explore the topic in an attempt to identify trends from the data analysis but there was no plan to develop a theory. However, this effort may eventually prove useful in developing a theoretical framework.

To accomplish this, Interaction Analysis was selected as a means to collate and examine the data. Interaction Analysis as defined by Jordan \& Henderson (1995) is a data analysis method rather than a theoretical framework. This analysis method is simply a systematic approach for analyzing video and any related artifacts for qualitative studies. 
Like Grounded Theory, Interaction Analysis uses an open coding scheme that allows the researcher to develop the coding as the analysis process progresses but contrary to Grounded Theory, it does not aim to develop a theory. Its main focus is a suggested approach to video analysis through multiple viewings of the video and emphasizes the need for the researcher to keep a very open mind. It suggests a wide range of possible things to count including some of the items outlined in Conversation Analysis such as turn-taking (Sacks, Schegloff, \& Jefferson, 1974). The aim of interaction analysis is to identify issues that can be counted or observed and to collate them. In that sense, it is simply an open-coding methodology. One of the contributing studies that helped define Interaction Analysis was J.C. Tang's (1989) Ph.D. thesis "Toward an understanding of the use of shared workspaces by design teams". Tang's thesis focused on the topic of design teams and also discussed the need for developing an analysis method for video. In his thesis, Tang videotaped and analyzed a set of design workshops by identifying and coding group interactions, media produced and gestures. While that study's method was considered very useful in terms of its method, it used a case study approach and studied design activities in a real-life scenario. For the present study, it was necessary to control some of the variables such as the professional diversity and the problems with which the groups were tasked and as such a case study was not viewed as suitable for this thesis. Instead, the research approach chosen is based on observing a set of structured group workshops conducted by the researcher.

\subsection{Using Comparisons in Exploratory Research}

Scientific methods for research often use control samples as a reference to set up a strong basis for testing a premise. Social science studies often use comparison groups or 
EXPERT GROUP SKETCHING

control groups to compare different phenomena to ensure a valid research result. The ability to compare items provides the researcher with the ability to test their theories against a reference point.

Exploratory observational research can generate a lot of interesting information about a situation but can also provide the researcher with too much data and too many options to explore. The use of some type of comparison in an exploratory research context was thought to have the potential to provide additional information and insights that would not be possible by simply observing a situation.

This thesis investigated interdisciplinary teams and how they use sketching to design solutions to abstract problems. Because there were so many variables of interest, it was necessary to observe several teams attempting the same tasks. Two problem types were used: one concrete problem that typifies something tangible that the participants could easily envision and a second problem that was more abstract and did not have a physical manifestation in a tangible, visual sense. The concrete problem was intended to act as a reference sample for individual and group activities. Another important factor was to control the diversity within each group so that the results could be compared between groups.

\subsection{Analyzing Design Workshop Artifacts}

External representations created during a design workshop, whether on paper, a whiteboard, or computer screen, have been analyzed by different researchers using different approaches. Some researchers have focused on the sketching process at a very detailed level, where each individual action is interpreted from a cognitive processing perspective. Goldschmidt (1991) explored the design process by having designers use 
the "thinking aloud" protocol where participants talk out loud as they design. Suwa, Tversky (Suwa \& Tversky, 1997) developed a protocol analysis for examining a designer's process by asking the subjects to retrospectively describe their thinking as they watched a previously recorded video of themselves designing. Suwa, Purcell and Gero (1998) further refined the coding scheme to specify more detailed cognitive actions of designers as the subjects sketched. In all cases, the focus of the research was on the individual designer sketching by themselves. For group activities, using such a detailed level of analysis would be extremely difficult due to the complexity of group interactions. There can be multiple activities going on simultaneously which would make it ill-suited for this type of analysis.

For group design research, the thesis of J.C. Tang (1989) as previously mentioned and work by S. Bly (1988) are often referenced because of their approach to analyzing video recordings and artifacts produced during a collaborative design session. In both these studies the artifacts were classified into three categories: drawing, writing and gesturing. The term gesturing was used to indicate either a person's motion to reference a sketch/writing in the discussion or to show an action that mimicked what the person was trying to explain. This set of codings is more suitable for a multi-participant study while still providing a means to explore the overall activity flow of the group during the design session.

In a paper by Larkin and Simon (1987), the differences between diagrammatic and sentential (i.e. written as spoken natural language) representations on paper are discussed from an information processing perspective. They suggest that the positioning of information in a diagram will reduce the need for the viewer to index and cross- 
reference (i.e. correlate) information when compared to written instructions for the same problem. The key message from their work is that natural language when written requires more processing for the reader to link ideas together. This provided useful guidelines for the artifact analysis in this research about how to differentiate between the writing and sketching categories.

\subsection{Creating Diversity Equivalence in Workshop Groups}

For this study, the diversity of interest was related to professional practice. Each of the groups in the study needed somehow to be equivalent in terms of professional diversity to enable comparisons between them. To accomplish this, a combination of the participants' professional and educational background was used coupled with the results of a vocational choice questionnaire ("Holland Code Quiz," 2010) based on the work of Holland (1985). Other types of personality tests were examined such as Myers-Briggs Type Indicator (MBTI) (Myers \& McCaulley, 1985) which measures personality preferences but the Holland Code model was deemed the most suitable because it was specifically developed to measure career dimensions for individuals and thus could be mapped to different types of expert practices.

The Holland Codes consist of 6 types: Realistic (R), Investigative (I), Artistic (A), Social (S), Enterprising (E), and Conventional (C). The characteristics of each of these codes are shown in Table 1. Holland created a hexagonal diagram to represent the 6 types as shown in Figure 1. The proximity of the Holland types in the diagram indicates similarities between the types. Different jobs are classified by combinations of subsets of the 6 Holland Code types. For example, the dominant Holland codes for a Political Scientist are Investigative, Artistic and Enterprising (IAE). Each Holland code 
EXPERT GROUP SKETCHING

combination for an occupation can be plotted within the Holland Hexagon.

Table 1 Characteristics of the Holland Codes

\begin{tabular}{|l|l|}
\hline Holland Code & Characteristics \\
\hline Realistic (R) & practical, physical, hands-on, tool-oriented \\
\hline Investigative (I) & analytical, intellectual, scientific, explorative \\
\hline Artistic (A) & creative, original, independent, chaotic \\
\hline Social (S) & cooperative, supporting, helping, healing/nurturing \\
\hline Enterprising (E) & competitive environments, leadership, persuading \\
\hline Conventional (C) & detail-oriented, organizing, clerical \\
\hline
\end{tabular}

Figure 1 Holland's Hexagon Model with Prediger's Axes

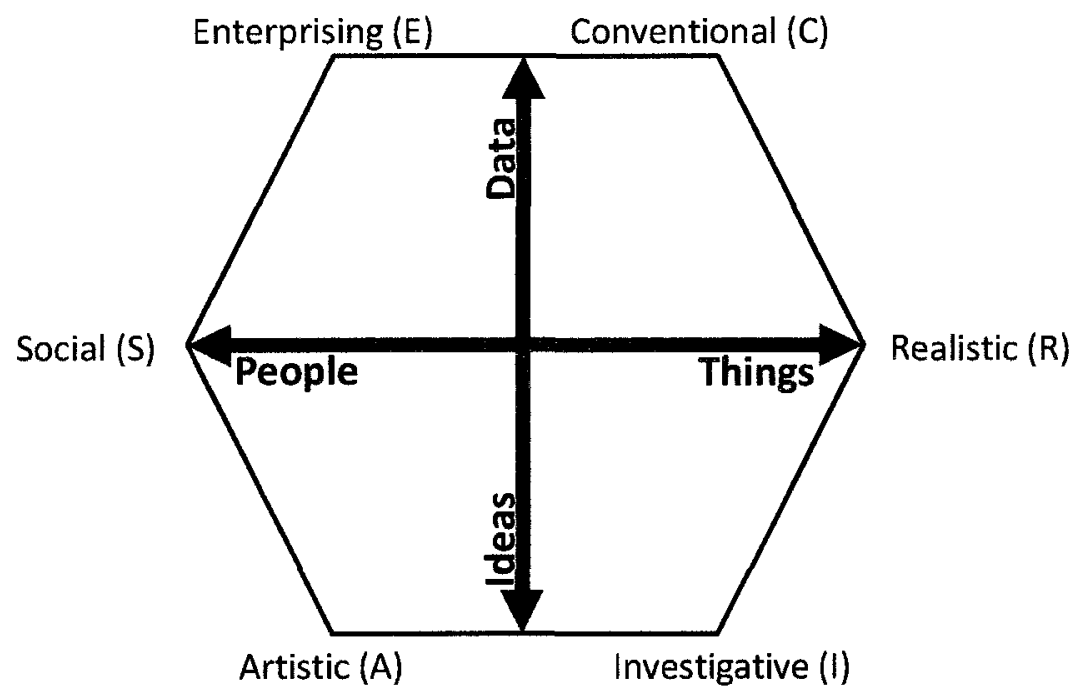

Subsequent work by Prediger (Prediger, 1976; Prediger \& Vansickle, 1992) added two axes to the Holland diagram: a People/Things-oriented axis and an Ideas/Data Axis as shown on Figure 1. Occupations can be categorized as being either people-oriented or thing-oriented along one axis and either ideas-based or data-based along the other axis. In this model, the term "ideas" refers to occupations that require working with theories and insights while the "data" end of the axis involves working with facts and records.

This vocation model was used to create equivalent diversity within each group of 
EXPERT GROUP SKETCHING

experts. Four occupation categories were derived from this model by using the four quadrants from Prediger's model as shown in Figure 2, with each quadrant being labeled for this study with the letters A, B, C or D. A combination of the participant's professional career history in conjunction with their Holland code quiz scores were used to assign participants to one of four occupation categories shown in Table 2. Some examples of professions for each of the occupation categories were extracted from Prediger's model and are shown in Table 3. Note that these letters were used throughout the analysis to distinguish between participants. While it would be virtually impossible to achieve an exact match to these categories, this approach did serve to push the diversity of each group in a consistent way so that all groups would have similar while not necessarily identical professional diversity.

Figure 2 Four Categories of Occupation based on Holland/Prediger Model

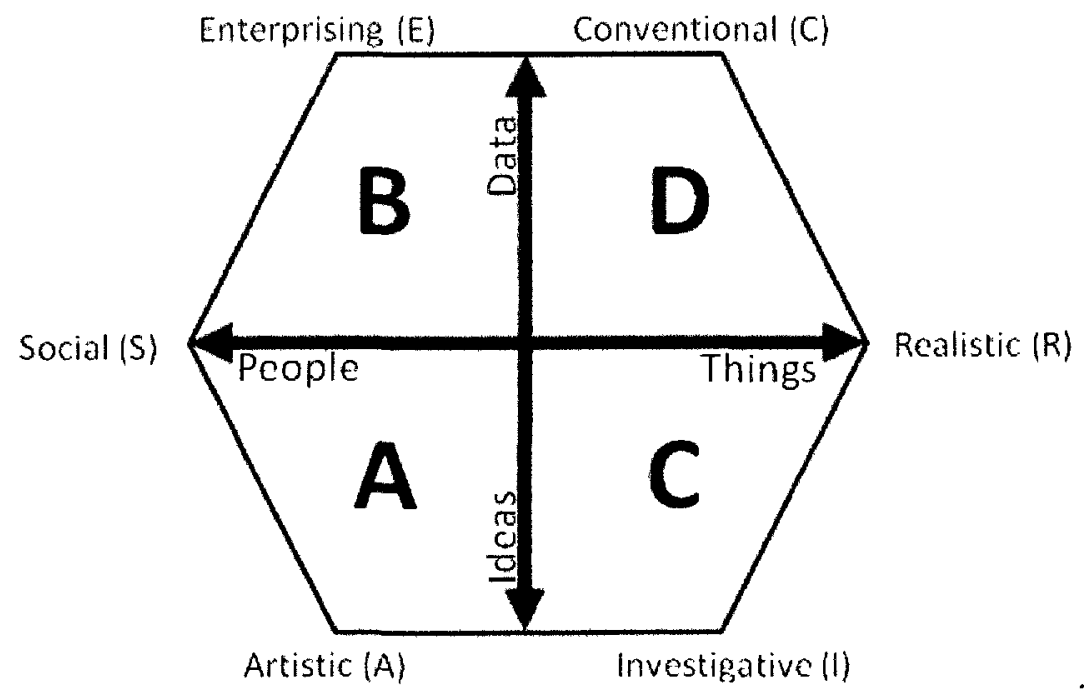


EXPERT GROUP SKETCHING

Table 2 Occupation Categortes for Professional Diversity

\begin{tabular}{|c|l|l|}
\hline $\begin{array}{c}\text { Occupation } \\
\text { Category }\end{array}$ & \multicolumn{1}{|c|}{ Occupation Description } & \multicolumn{1}{|c|}{ Holland Code for category } \\
\hline A & People-oriented- helping & Strong Social (S) and Artistic (A); \\
\hline B & People-oriented - influencing people & $\begin{array}{l}\text { Strong Enterprising (E) and Social } \\
\text { (S) }\end{array}$ \\
\hline C & $\begin{array}{l}\text { Thing-oriented - system thinker, big } \\
\text { picture person }\end{array}$ & $\begin{array}{l}\text { Strong Realistic (R) and } \\
\text { Investigative (I) }\end{array}$ \\
\hline D & $\begin{array}{l}\text { Thing-oriented - day-to-day person, } \\
\text { doer. }\end{array}$ & $\begin{array}{l}\text { Strong Conventional (C) and } \\
\text { Realistic (R) }\end{array}$ \\
\hline
\end{tabular}

Table 3 Example Professions for Occupation Categortes

\begin{tabular}{|c|l|}
\hline $\begin{array}{c}\text { Occupation } \\
\text { Category }\end{array}$ & \multicolumn{1}{|c|}{ Example Professions } \\
\hline A & Doctor, teacher \\
\hline B & Marketing, Business owner \\
\hline C & System Architect, Business Strategist \\
\hline D & Accountant, Software programmer \\
\hline
\end{tabular}

\subsection{Turn-taking}

While sketching can act as a mediator for sharing, verbal exchanges in a group also demonstrate the transfer of information between parties. When people share their drawing or writing they usually also engage in talking. When they have an idea, they may express it with words. To fully understand what was going on in the workshops, some of the characteristics of verbal exchanges needed to be investigated, one of which was turn-taking.

Turn-taking is defined as the process by which people take turns in a conversation. In conversation analysis (Sacks, Schegloff, \& Jefferson, 1974) the natural switching of speakers for turn-taking in conversations is studied. The method has shown that there are inherent social rules dictating when it is appropriate to take over from 
EXPERT GROUP SKETCHING

another speaker. For polite conversation this works very well, but brainstorming does not necessarily follow these conventions. While some rules for brainstorming on the web include a "Do not interrupt the speaker" rule ("ProMentor - Brainstorming Rules," 2010), in fact the original rules set forth by Osborn (1957) do not include this rule. The rule likely migrated from more general rules for business meetings suggested in books on business etiquette and communication for meeting rules (Guffey \& Loewy, 2009). Studies by Diehl and Stroebe $(1987 ; 1991)$ into brainstorming found that when people were asked to wait their turn until someone else had finished speaking, there was a reduction in the number of ideas that person-in-waiting generated, referred to as "production blocking". This would suggest that rules that inhibit spontaneous discourse from occurring may reduce the creative output of a group, and that interjecting ideas during a conversation may indicate a creative action.

Ethnographic research suggests that professional groups in a brainstorming session do not seem to follow the more polite conventions of allowing people to speak in turn (Matthews, 2009; Sawyer, 2007), and that half finished thoughts created by speaker interruptions are part of the creative process. Taking this one step further, this means that those periods of high creative output in a group may result in high rates of interjections and thus high rates of turn-taking in a group. During normal polite conversation, interjecting is usually considered quite rude. Matthews' study (2009) into the dynamics of experienced engineering teams confirmed that teams would interrupt each other frequently and that while it appeared to be rude to the researcher, the group appeared to accept this as an expected behaviour during brainstorming. 


\subsection{Summary of Research Study}

The research study for this thesis involved running a set of four workshops made up of four experts. These experts were selected based on their professional background and career preferences to create equivalent diversity in each group. All groups were asked to design solutions to the same two problems (one concrete and one abstract). The resulting video recordings were examined and coded for both verbal and paper activities, and all paper outputs from each group were analyzed, 


\section{Method}

\subsection{Participants}

Sixteen participants with 10 or more years of professional experience were recruited through email using the researcher's professional and personal network. None of the experts came from the traditional design disciplines where reflective practice using sketching is taught. Each participant was informed that a donation of $\$ 50(\mathrm{CDN})$ would be made on their behalf to a charity of their choice.

Individuals who were willing to take part in the study were asked to complete an online questionnaire about their professional background including questions to identify their Holland Code preferences and their availability for workshops. Based on their responses, 16 participants were assigned to one of the four workshop sessions. Each workshop group was created by assigning one person from each of the 4 occupation categories (A, B, C, or D) based on the quadrants of Holland/Prediger's vocation model as shown earlier in Figure 2 on page 20. Participants who were not selected for the study were notified through email. The participants' results from the Holland Code questionnaire can be found in Appendix F.

Once the workshop times were set up, there was some churn resulting from people becoming unavailable, and some replacements had to be made to some of the groups. As a result, not all groups were quite ideal in terms of their diversity, but all groups still contained similar diversity in their professional makeup. The professions of the experts assigned to each workshop group are shown in Table 4 with their Holland code results shown in brackets Note that the Holland Code results are shown as a set of each participant's top-scored dimensions and includes ties or close values. 
Table 4 Workshop Participant Assignments with Holland Code Quiz Results

\begin{tabular}{|c|c|c|c|c|}
\hline $\begin{array}{c}\text { Workshop } \\
\text { Group }\end{array}$ & $\begin{array}{c}\text { Participant with } \\
\text { Occupation Type }= \\
\text { A }\end{array}$ & $\begin{array}{c}\text { Participant with } \\
\text { Occupation Type }= \\
\text { B }\end{array}$ & $\begin{array}{c}\text { Participant with } \\
\text { Occupation Type }= \\
\text { C }\end{array}$ & $\begin{array}{c}\text { Participant with } \\
\text { Occupation Type }= \\
\text { D }\end{array}$ \\
\hline 1 & $\begin{array}{c}\text { Special needs } \\
\text { teacher } \\
\mathrm{HC}=\text { (Social- } \\
\text { Artistic) }\end{array}$ & $\begin{array}{l}\text { Quality specialist } \\
\text { HC = (Enterprising- } \\
\text { Social-Investigative) }\end{array}$ & $\begin{array}{l}\text { High tech Innovator } \\
\text { HC = (Realistic- } \\
\text { Investigative- } \\
\text { Social-Enterprising) }\end{array}$ & $\begin{array}{c}\text { Project Manager HC } \\
=\text { (Realistic- } \\
\text { Investigative- } \\
\text { Social) }\end{array}$ \\
\hline 2 & $\begin{array}{c}\text { Doctor } \\
\mathrm{HC}=\text { (Social- } \\
\text { Enterprising) }\end{array}$ & \begin{tabular}{|c|} 
Pharmaceutical \\
salesman $\mathrm{HC}=$ \\
(Realistic- \\
Investigative-Social- \\
Enterprising) \\
\end{tabular} & $\begin{array}{l}\text { Technology system } \\
\text { architect HC = } \\
\text { (Realistic-Artistic- } \\
\text { Social-Enterprising) }\end{array}$ & $\begin{array}{c}\text { Software } \\
\text { Programmer HC }= \\
\text { (Conventional- } \\
\text { Social) }\end{array}$ \\
\hline 3 & $\begin{array}{c}\text { Personal Financial } \\
\text { Advisor } \\
\mathrm{HC}=(\text { Artistic- } \\
\text { Social })\end{array}$ & $\begin{array}{c}\text { Medical Device } \\
\text { project coordinator } \\
\text { HC = (Realistic- } \\
\text { Investigative-Social- } \\
\text { Enterprising) }\end{array}$ & $\begin{array}{c}\text { Senior technology } \\
\text { director HC= } \\
\text { (Realistic- } \\
\text { Investigative- } \\
\text { Conventional- } \\
\text { Social) } \\
\end{array}$ & $\begin{array}{c}\text { Software engineer } \\
\mathrm{HC}= \\
\text { (Investigative- } \\
\text { Realistic- } \\
\text { Conventional) }\end{array}$ \\
\hline 4 & $\begin{array}{l}\text { Doctor } \\
\mathrm{HC}=\text { (Social- } \\
\text { Conventional- } \\
\text { Enterprising) }\end{array}$ & $\begin{array}{c}\text { Business owner - } \\
\text { former policeman } \\
\mathrm{HC}=\text { (Realistic- } \\
\text { Enterprising- } \\
\text { Conventional) }\end{array}$ & $\begin{array}{c}\text { Biomedical } \\
\text { researcher } \mathrm{HC}= \\
\text { (Realistic- } \\
\text { Investigative- } \\
\text { Social-Enterprising) }\end{array}$ & $\begin{array}{c}\text { Firmware engineer } \\
\mathrm{HC}= \\
\text { (Investigative- } \\
\text { Social- } \\
\text { Conventional) } \\
\end{array}$ \\
\hline
\end{tabular}

The professional experience for the participants ranged from 12 to 31 years $(\mathrm{M}=$ 23.4, $\mathrm{SD}=6.98$ ). The distribution of experience levels is shown on the graph in Figure 3. The gender breakdown by group is shown in Figure 4.

Figure 3 Participant Experience Level Distribution

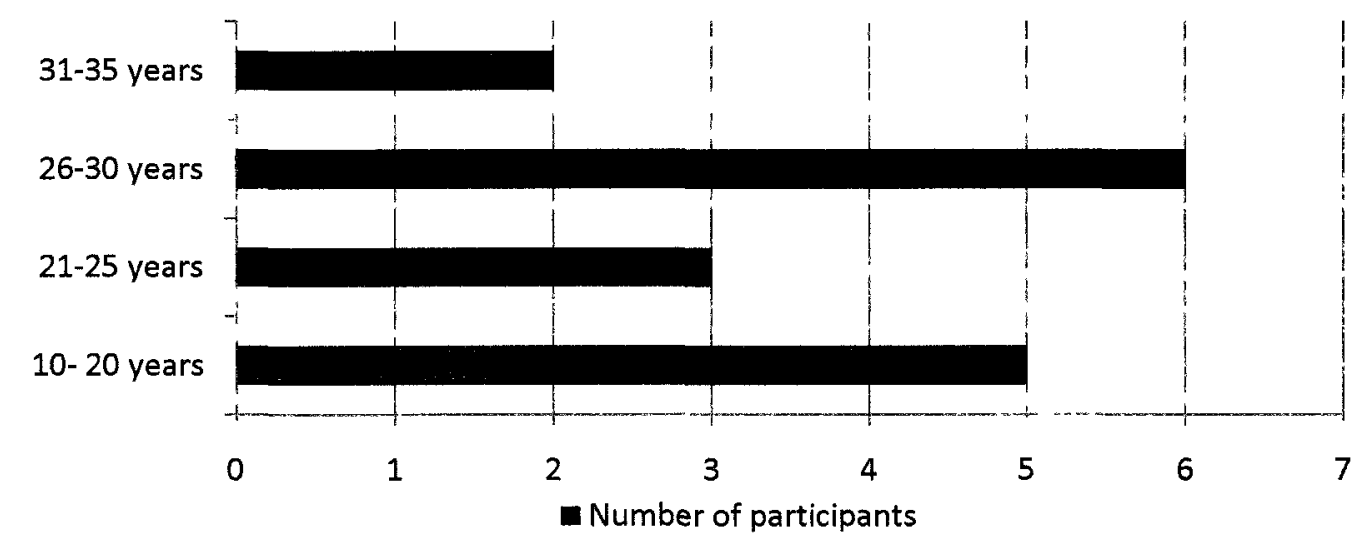


Figure 4 Gender Representation by Group

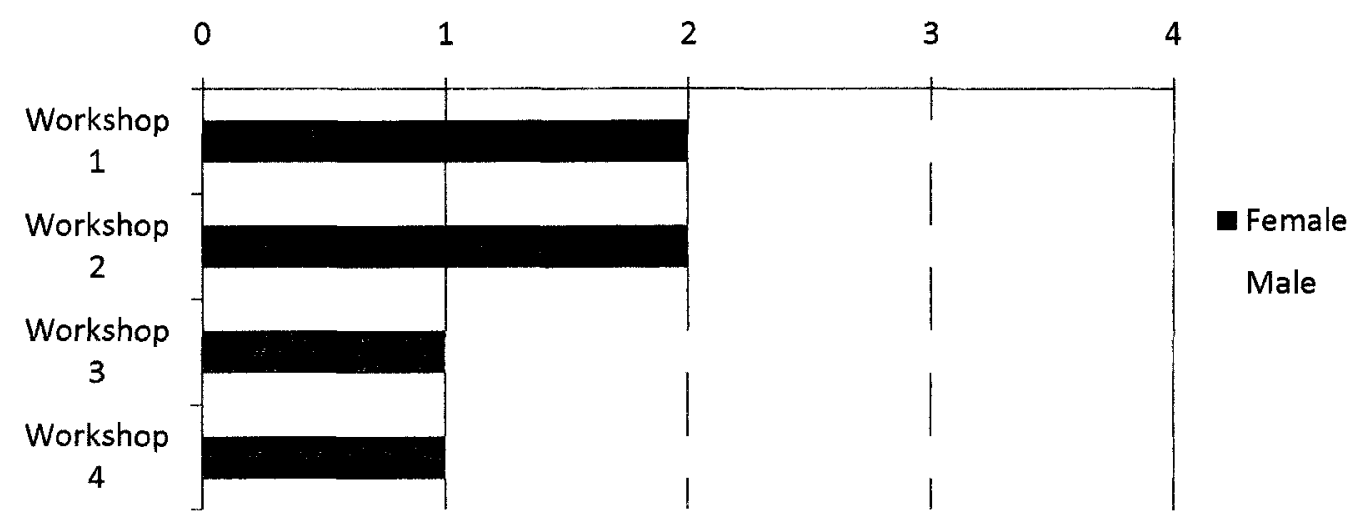

\subsection{Materials and Apparatus}

The questionnaire that potential participants were asked to complete can be found in Appendix B.

The workshops were held at Carleton University in the HOTLab Observation room which has an adjacent control room equipped with audio and video capabilities and a one-way mirror. The observation room looks like any typical meeting room which was important to satisfy the study's objective of observing the participants in a quasi-natural setting. In the meeting room there was a table in the middle of the room with 5 chairs. While there was a computer in the room, it was not turned on. There were no whiteboards in the room.

Three video cameras were set up on tripods at the edges of the room. In an attempt to minimize participants' awareness of the cameras, these cameras were always turned on before any participants arrived. Several participants remarked on the fact that they quickly forgot they were being observed and recorded.

The problem statements handed out during the workshops can be found in Appendix C. 
EXPERT GROUP SKETCHING

\subsection{Design}

Four design workshops were conducted. The workshop protocol was identical for all four workshops. Participants were asked to design solutions to two problems, one concrete and one abstract problem, during the workshops. The first problem, which will be referred to as the "concrete-kitchen" problem, asked the group to design a kitchen for a young family with two children that would fit in a 60 square foot area. The second problem, known as the "abstract-ebook" problem, asked them to design a strategy for a small book publisher that addressed the introduction of e-book readers into their marketplace.

For each workshop, four identical sets of 4 coloured fine tip markers (Sharpies ${ }^{\mathbb{C}}$ ) were set out at each place setting on the table. In the center of the table several sheets of plain newsprint paper (18" x 42 ") were laid out. A roll of newsprint in a dispenser was left in the room off to one side in case they needed more paper. Large sheets of newsprint were chosen specifically to ensure that a permanent record was obtained for the researcher as well as to limit any one participant's ability to control access to the media.

The order of the problems was reversed for half of the workshops to counterbalance. After each problem, the group presented their results to the researcher.

All workshops were video recorded and all paper products were collected after each design problem session. Note that there was no researcher or facilitator in the room during the actual design sessions. 


\subsection{Procedure}

Before the participants arrived, the room was prepared by laying out the large newsprint sheets and markers on the table, setting up refreshments and turning on the video cameras.

Once all the participants were collected in the room, the researcher described the purpose of the workshop (Script 1 in Appendix D) and had participants read and fill in the informed consent forms. No mention was made about sketching or drawing in any of the instructions to the group.

The researcher then explained that the workshop was structured into 2 parts (see Script 2 in Appendix D) with 2 problems being worked on, one at a time. The group would have 50 minutes to work on each problem and then would present their results to the researcher. They would be notified when there was 5 minutes left in the design session. Following the first design session, there would be a 10 minute break before the second problem session began. After both sessions, there would be a brief discussion at the end of the workshop. The group was also informed that if the researcher detected any issues or problems that appeared to be irresolvable, that she would enter the room and mediate the situation as quickly as possible. No such events occurred. Note that no suggestions about group process or structure were made.

The researcher then mentioned that the markers and paper were set out for their use but did not emphasize their relevancy to the study. Any questions participants had about the study topic or purpose were deferred until the end of the workshop.

The first problem was read aloud to the group and a printout of the problem (see Appendix C) was provided. At the end of reading the problem statement any questions 
about the problem were answered and the researcher left the room. During the workshop the researcher sat in the adjacent control room observing and taking notes. When there was 5 minutes left in the session, the researcher stepped into the room to give them a 5 minute warning. If a group felt they were finished and the researcher was satisfied then the workshop moved to the next step. Once the group was finished, the researcher had them present their solution (script 4 in Appendix D). Following the presentation there was a 10 minute break. At the end of each design problem session (half workshop), all paper that was used was collected by the researcher and fresh sheets of paper laid out for the next problem session.

After the break, the second problem was read to the group and identical procedures were followed as for the first problem. Once the group had finished with presenting their second solution, there was a semi-structured group interview that inquired about their perception of their solutions and about the workshop effectiveness (Script 5 in Appendix D). This concluded the workshop. Following this, debriefing forms were handed out and any questions that participants had about the study were answered.

\subsection{Data Analysis}

The analysis approach was open and as such could not be completely defined before the analysis process was started. This was intentional because the study was exploratory in nature and as results emerged it served to guide the researcher's line of inquiry.

An Interaction Analysis approach was used for the analysis. The initial step was to view the video recordings a number of times taking note of possible types of activities 
and events to code. The codes were not identified a priori for this step but general categories of interest were identified. These included activities involving sketching, writing, sharing as well as any verbal activity. Once the activities of interest were identified, a set of codes was defined for specific types of events within that category.

With the event codes identified, the next planned step was to analyze the video to identify video sequences that contained these selected types of events and assign keywords to them. All video analysis data was collected using Transana ${ }^{\mathrm{TM}}$ (see www.transana.org) which provides the ability to create and manage video clips of events of interest. Once the clips were identified in Transana, keywords could be assigned to each clip. For each video clip, the specific participant or participants involved was also identified as part of the coding.

It was anticipated that transcripts of each video would be created but it was not known a priori whether a complete transcript would be needed or simply small excerpts. An open-coding approach was also used to analyze the paper artifacts that resulted from the workshops. Each large sheet was parsed to identify individual artifacts such as a single diagram, and these were classified as either sketching or writing. The original creator of the paper artifact was identified through a review of the video. More detailed coding of the artifacts was done only after the workshops had been run.

The video recordings were also used to collect up qualitative observation data. Individual events that were relevant to the study were examined and documented by the researcher. As well, the post-workshop interviews were qualitatively assessed and summarized with the observational data. 
4 Results

The first section of the results presents the overall activities during the workshop in terms of how paper was used by the groups (both writing and sketching). The next part shows what individual participants did and how this varied between participants. Looking at individuals' contribution to the design through paper led to the next subsection's topic which provides the results on how much individuals contributed verbally in the group and how that was related to their use of paper. This led to the next topic that investigated whether there was any relationship between professional background and a participant's use of paper. The role of story-telling in the workshops is discussed next. After that, the analysis explored the possibility of measuring the level of interactivity in a design session during different activities by measuring the rate of turntaking (speaker turns). The next section presents the results of the analysis of paper artifacts. The final section discusses observations made from the video recordings and how they relate to the other results that had emerged during the analysis.

\subsection{Activity levels in the Groups}

The first step in the analysis was to try to understand what was going on overall in each of the workshop sessions. This was done by identifying the main activities in the workshops through repeated viewings of the video recordings and coding them.

Each video was analyzed and all activities of interest were identified and their start and stop times logged to create an event video clip. The video clips varied in duration as time stamps were inserted between speakers to avoid breaking clips apart mid-sentence. The process of identifying the start and stop of an activity was not always easy. Participants would pick up a pen, start to write and then stop for a while with the 
pen in hand, often to discuss some details. These short interruptions in the flow of an activity were not tracked; these events were coded as though they were continuous. In some cases there were multiple activities at the same time. For example, one participant might be drawing on their own (solo) while the rest of the group was discussing something written. These were coded as two separate events even if they overlapped in time.

Three main types of activities were identified: drawing, writing and story-telling. Drawing and writing involved using paper, while story-telling was a verbal only activity where a participant described a personal story around the problem topic. The researcher added story-telling as an event after watching the video recordings because there seemed to be some special treatment accorded this activity. The intention was to investigate whether there were any relationships between stories being told in the workshops and the generation of paper artifacts. The stories told included personal experience stories, $3^{\text {Td }}$ party stories about someone else's experiences, and stories that were purely speculative for illustrating a point. For this study, only stories that were somehow related to the workshop problems were coded.

For writing and drawing activities, the codings were further expanded to indicate whether it was a solo activity to create an artifact or a group activity to create or a group activity to share an artifact. Modifying an existing artifact was considered to be the same as creating an artifact for the purposes of the activity coding. The list of activity categories used for coding is shown in Table 5. Each event was also coded to indicate the participant involved using the letters $\mathrm{A}, \mathrm{B}, \mathrm{C}$, or D that correspond to their assigned occupation category. Activities involving all individuals were assigned the code "All". 
EXPERT GROUP SKETCHING

Table 5 Operatıonal Definttions for Workshop Activities

\begin{tabular}{|l|l|}
\hline Activity & Operational Definition \\
\hline Writing solo & $\begin{array}{l}\text { A solo activity where a participant creates a written artifact on } \\
\text { paper }\end{array}$ \\
\hline Writing group & $\begin{array}{l}\text { Activity where one person writes and other participants } \\
\text { contribute to the writing. Involves 2 or more participants. }\end{array}$ \\
\hline Writing Sharing & $\begin{array}{l}\text { Occurs when a participant reads back written material to the } \\
\text { group or points to the written material to reference something. } \\
\text { Involves 2 or more participants. }\end{array}$ \\
\hline Drawing solo & $\begin{array}{l}\text { A solo activity where a participant creates some type of } \\
\text { drawing }\end{array}$ \\
\hline Drawing group & $\begin{array}{l}\text { A group activity where one or more people create some type } \\
\text { of drawing Involves 2 or more participants }\end{array}$ \\
\hline Drawing sharing & $\begin{array}{l}\text { An activity where people are pointing and referencing a } \\
\text { drawing. Involves 2 or more participants. }\end{array}$ \\
\hline Story-telling & $\begin{array}{l}\text { Occurs when one person tells a story to the group related to } \\
\text { the workshop problem. }\end{array}$ \\
\hline
\end{tabular}

Figure 5 Total Group Drawing Actrvity Time by Problem

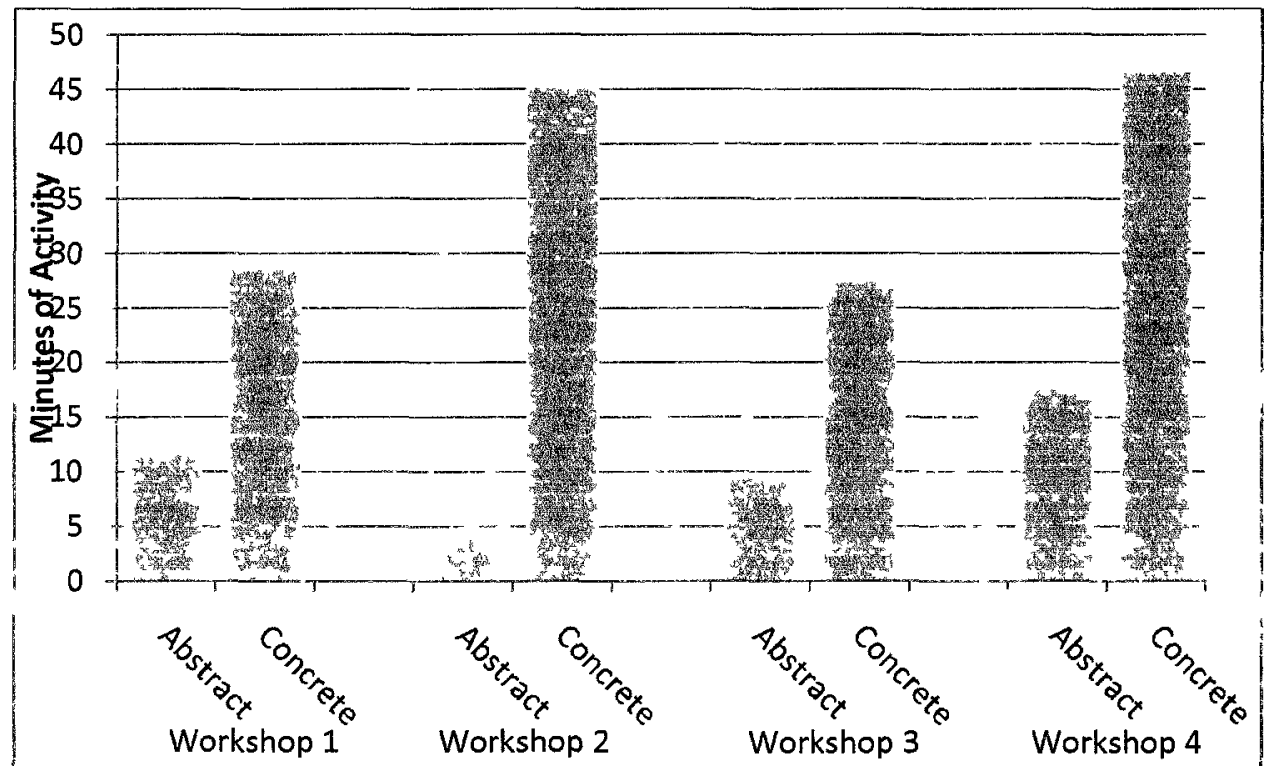

Once the activities were coded, the total durations of activities by type were

tallied for each problem to provide an overview of the time spent on each type of activity.

Figure 5 shows the total time each group spent drawing for each problem. Clearly, more 
time was spent drawing for the concrete-kitchen problem than for the abstract-ebook problem. This provides evidence that the type of problem will influence a group's tendency to choose to sketch

For writing activities, the results were somewhat less consistent. In 3 of the 4 groups, more time was spent on writing activities for the abstract-ebook problem as shown in Figure 6. The fourth group (workshop 1) only spent slightly more time writing for the concrete-kitchen problem (difference $=30 \%$ ). The amount of writing activity for the concrete-kitchen problem varied quite substantially between groups Some groups wrote notes and did calculations on paper while other groups focused solely on creating diagrams.

Figure 6 Total Group Writing Activlty Time by Group and by Problem

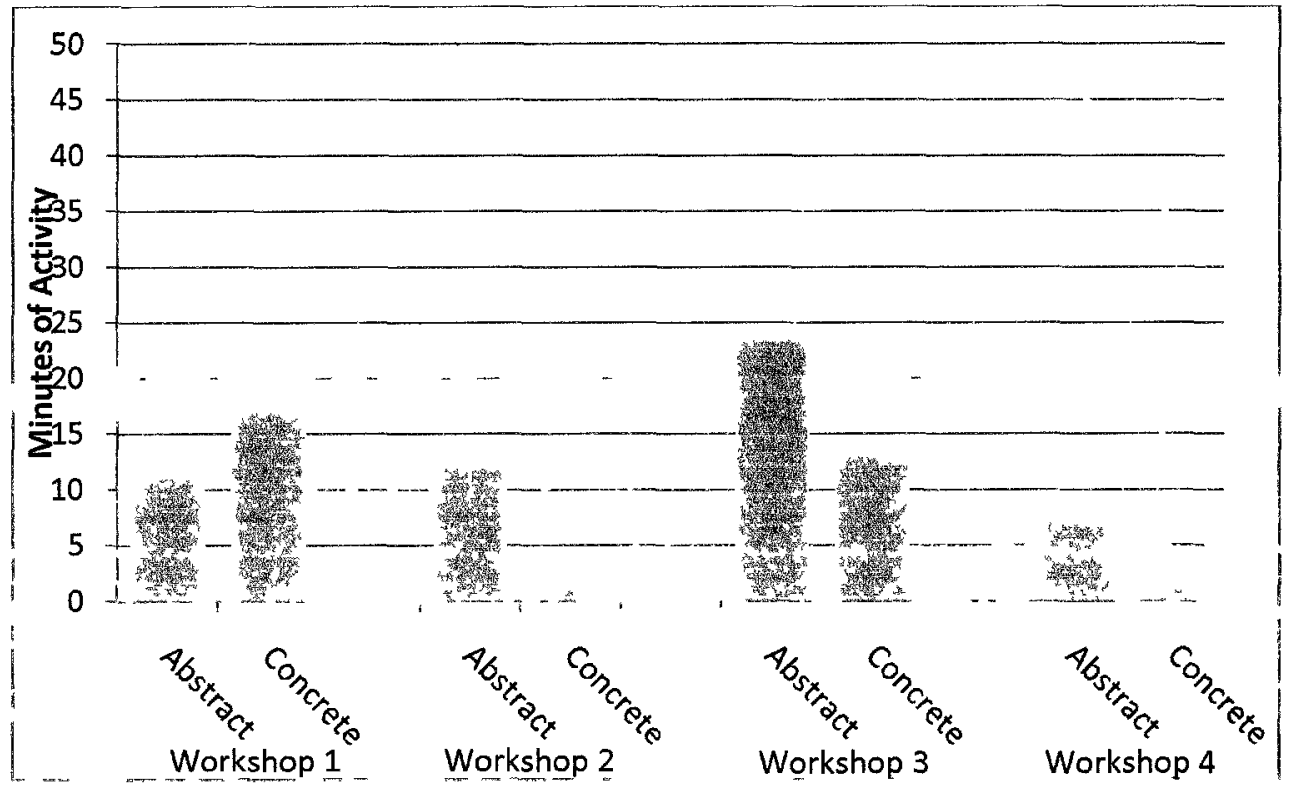

For the abstract-ebook problem, the ratio of time spent on writing compared to drawing varied between the groups. Some groups worked through the abstract problem design using more writing while others used more drawing. Workshop 2 and Workshop 
3 spent more time writing while Workshop 1 and 4 spent more time drawing. Overall, when comparing writing to drawing activities, when faced with an abstract problem, experts in these workshops tended to write instead of sketching.

Figure 7 shows the combined total for both writıng and drawing time in each group for each problem It shows that in all four workshops the groups spent more time working with paper overall for the concrete-kitchen problem than for the abstract-ebook problem.

Figure 7 Total Paper Activity by Group and by Problem

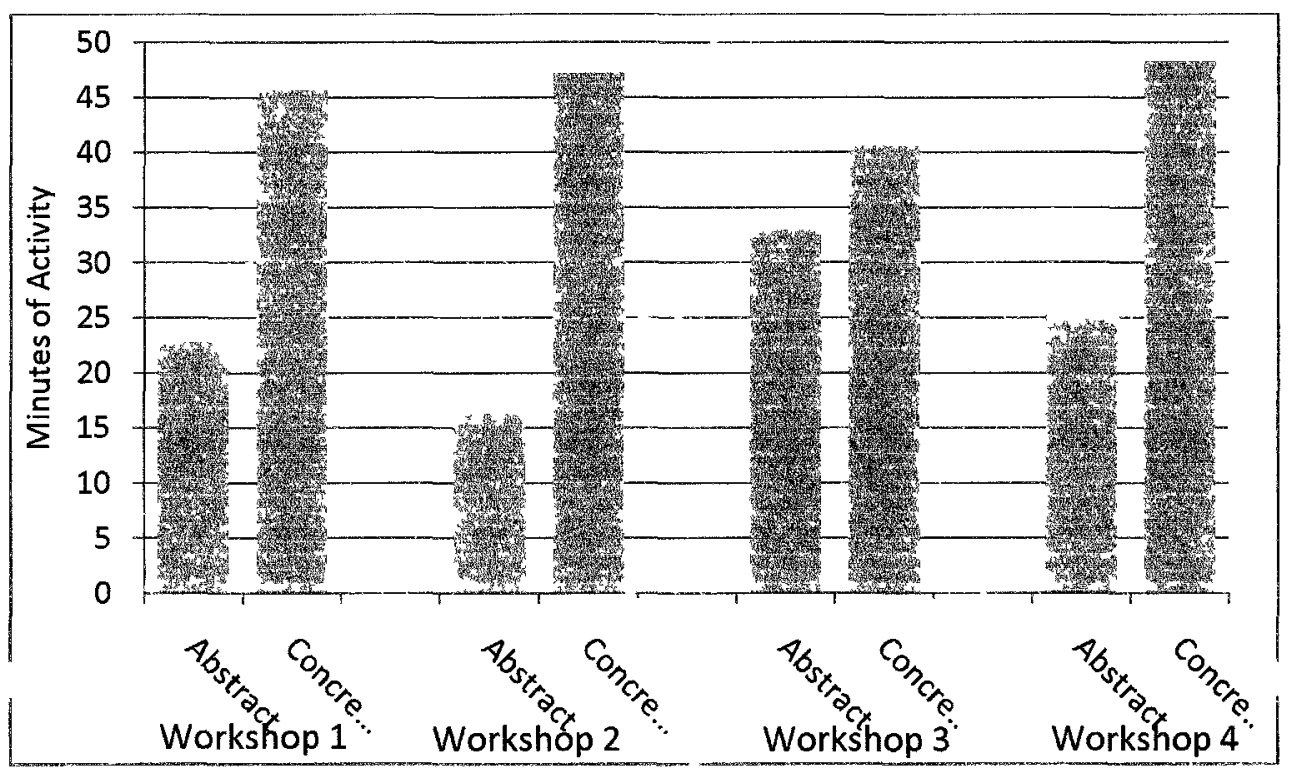

While the tallies for total time per activity provided an overall idea of the duration of paper activities in the group, the researcher was also interested in when the various activities occurred in time and whether there were any relationships around the sequencing of activities. The intention was to look for patterns of activities within each workshop. To accomplish this, the activities were plotted on a timeline to show the overall flow in each group over time. The event diagram for workshop 1 is shown in 
Figure 8 for both problems. The top half of the diagram shows the event diagram for the abstract-ebook problem. The lower half of the diagram is the concrete-kitchen problem event diagram. The workshop session timeline is shown at the top. On the left hand side, there are 7 activities listed, grouped into 3 categories: drawing, writing and story-telling. The bars to the right of each activity are shaded to indicate when these activities occurred relative to elapsed time. For example, in Figure 8, the first event in the concrete-kitchen problem is "Drawing as a group" at around 29:00.0 minutes on the timeline and lasted for about 1 minute. These diagrams provide an indication of the sequencing of activities during each session and how the group shifted between different activities. The full set of event diagrams can be found in Appendix G.

These event diagrams make it possible to easily see the differences between the two problem types. For example, for the abstract-ebook problem, no drawing occurred until 30 minutes into the session (shown on the diagram as elapsed time of 1:57:39). However for the concrete-kitchen problem, this same group started to draw within the first 5 minutes of the session. An examination of all of the event diagrams revealed that all groups except one started to draw very late in the abstract-ebook problem session (35 to 40 minutes into that session). For the concrete-kitchen problem, however, all groups had started to draw as a group within the first 10 minutes of the session. In comparison, writing began in all groups for both problems within the first 15 minutes of each session. 


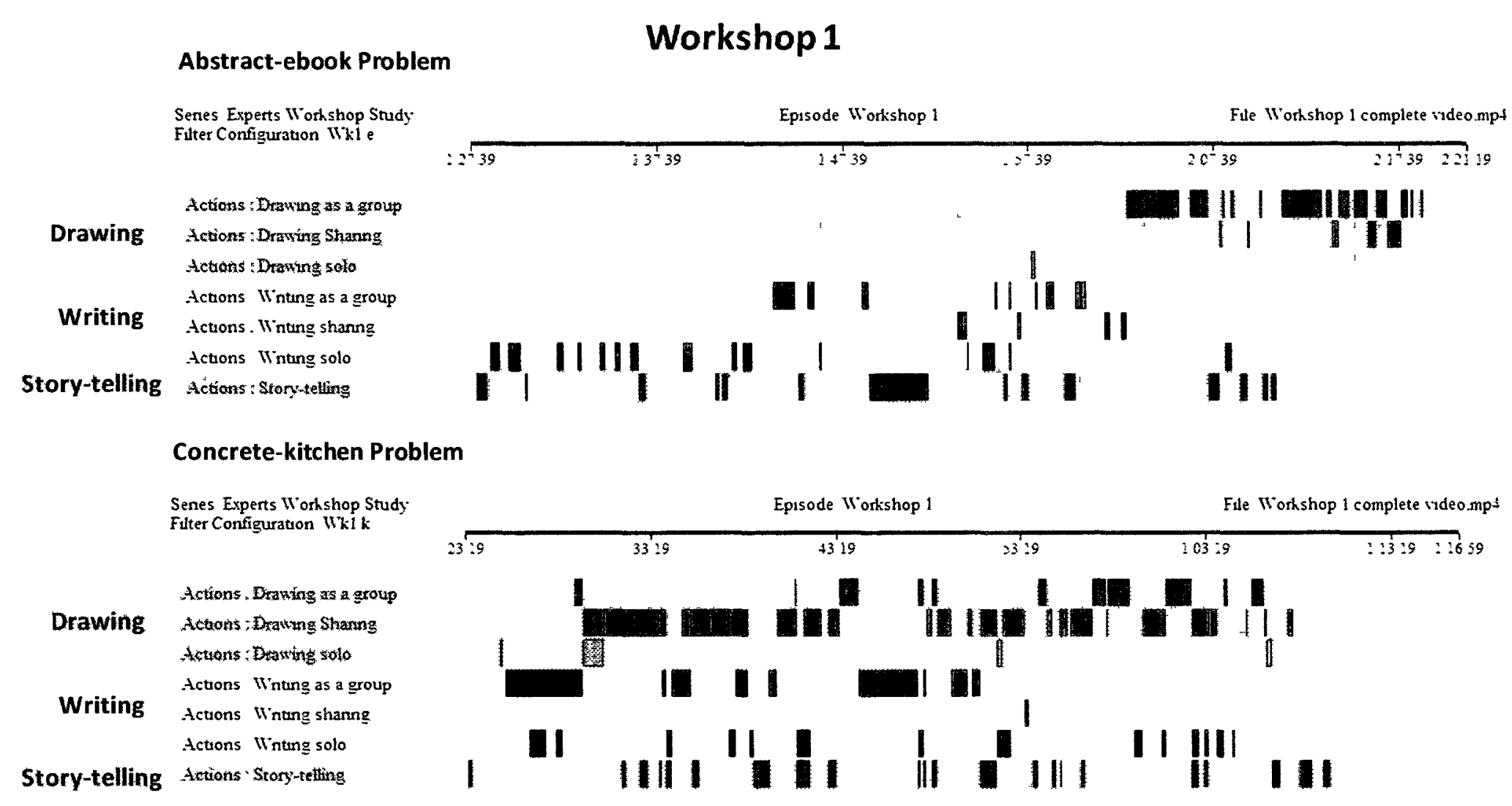

enes Experts Worh shop Stud

Actions . Draxing as a group

Actoons ; Drawng Sharng

tetrons Wintung shanne

Aetions' Story-tetting 


\subsection{Level of Participation within each Group}

After examining the total time spent by the groups on activities by each group, the researcher examined the individual participants' use of paper for each of the problem types During the workshops, individual participation levels for each activity varied between participants and between problem types. Some participants tended to draw more, some wrote more and others did a lot of both or did none. The total time spent on drawing activities by each participant for the 2 problem types varied considerably both within and between groups as shown in Figure 9 and Figure 10. (Note that for consistency, all figures use the same ordinate scale in this section.)

For the abstract-ebook problem, each group had one participant that did most of the drawing as shown in Figure 9. For the concrete-kitchen problem, there were several participants consistently engaged in drawing in all groups as shown in Figure 11.

Figure 9 Total Drawing Time by Participant for Abstract-ebook Problem

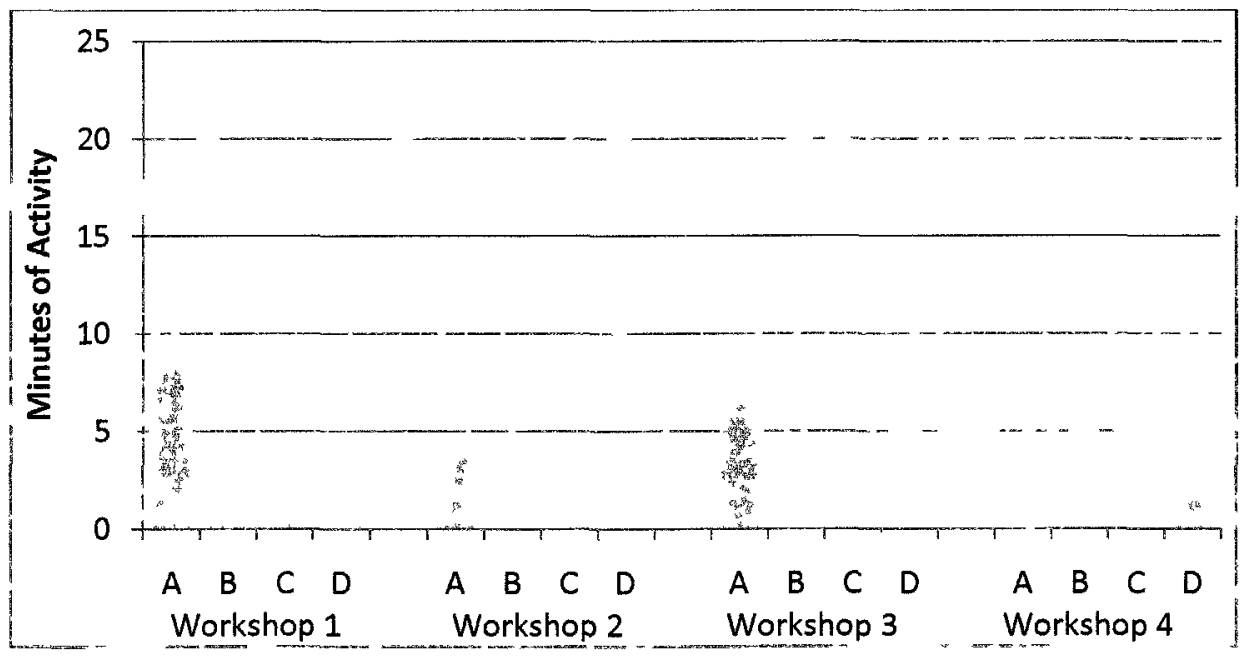


Figure 10 Total Drawing Time by Partıcipant for Concrete-kitchen Problem

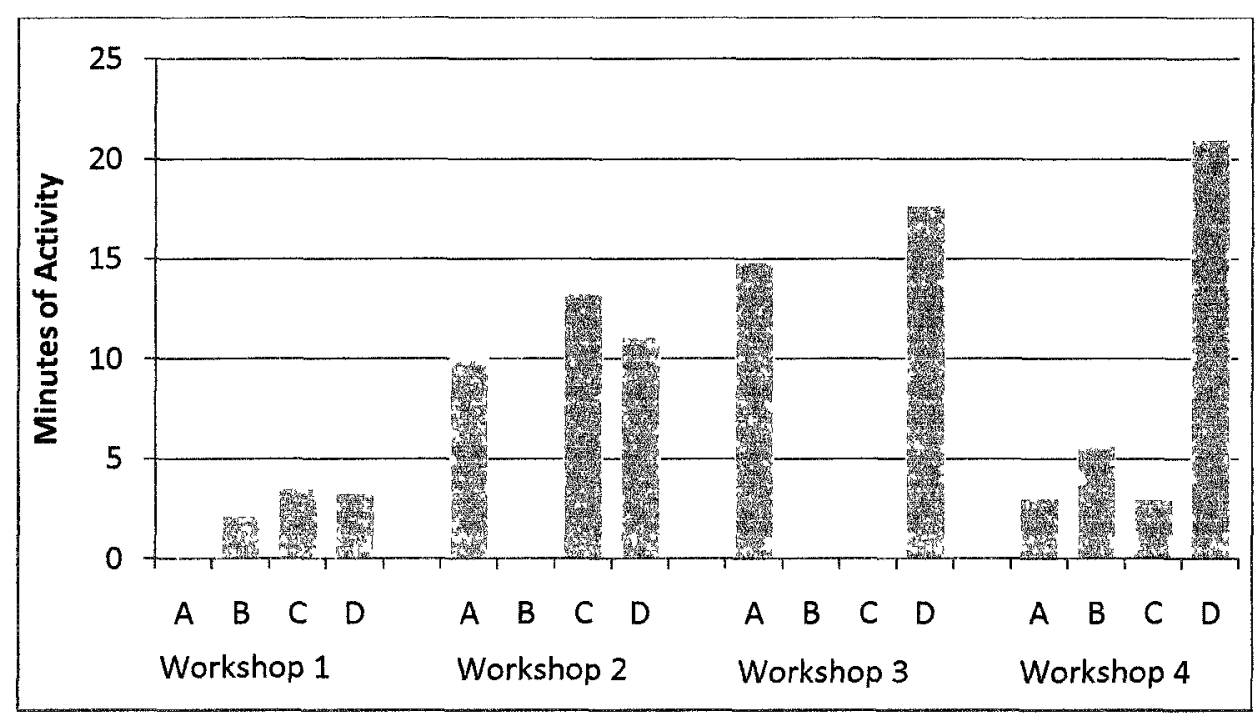

In comparison, for writing, there did not appear to be much consistency when looking across individual participants' level of activity as revealed in Figure 11 and Figure 12. For the abstract-ebook problem, Workshop 1 had two people who were active writers and Workshop 2 and 4 had three people who wrote. Workshop 3 only had one person who did almost all of the writing and spent more than three times as much time writing as any other participant in any of the groups. For the concrete-kitchen problem, Workshop 1 had one person who wrote a lot, Workshops 3 had three people who wrote some, while workshops 2 and 4 only had one person that wrote and did very little of it at that in comparison to the other groups. As well, the set of participants that chose to write were different from one problem to the next. These variations suggest that participants' inclination to express and share ideas in writing was less dependent on the type of problem being addressed. 
Figure 11 Total Writıng Time by Participant for Abstract-ebook Problem

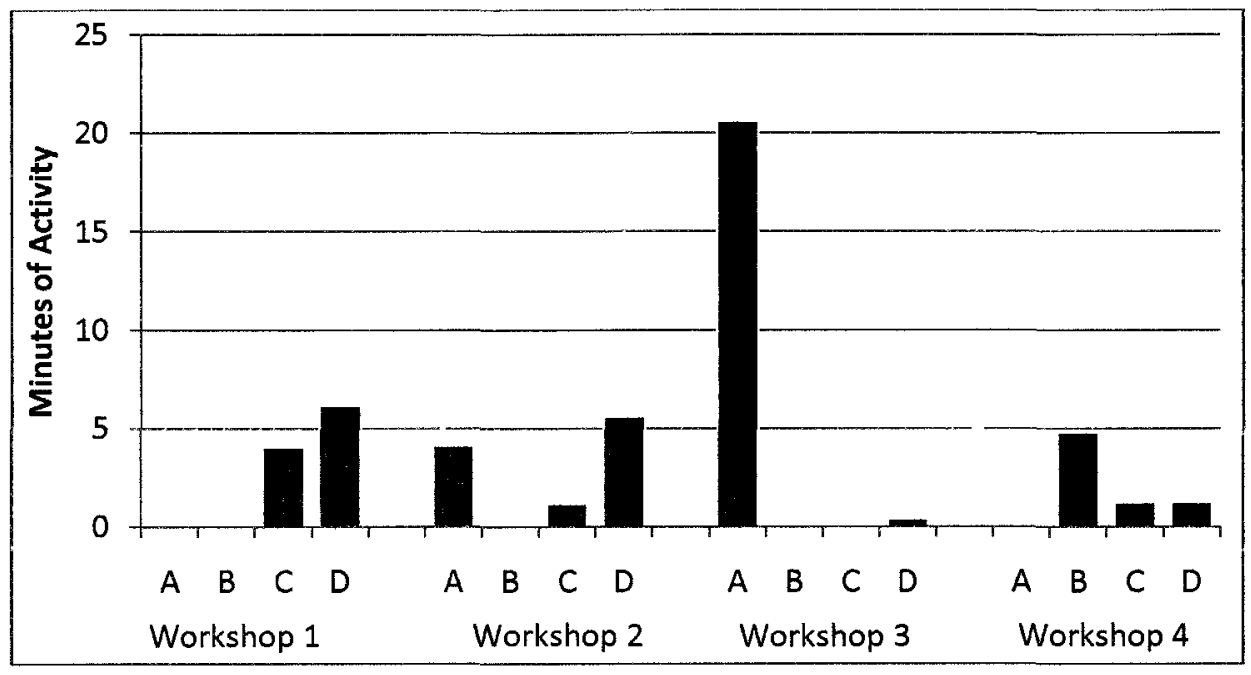

Figure 12 Total Writıng Time by Participant for Concrete-kitchen Problem

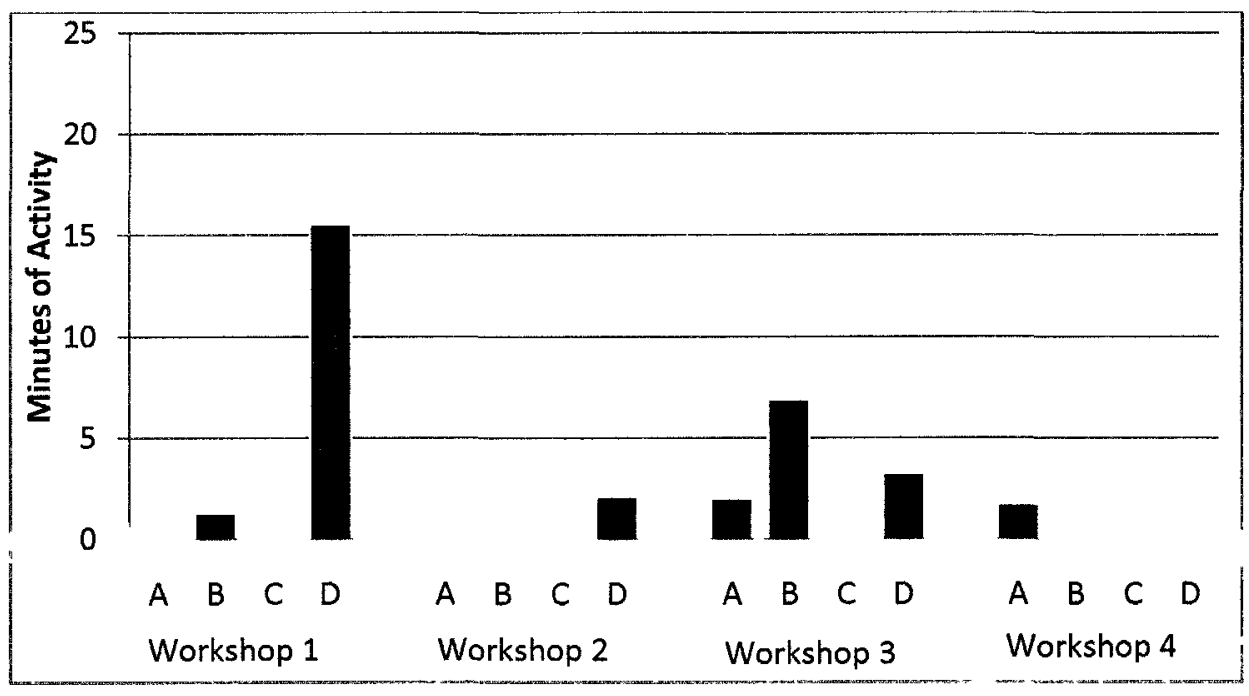

To further examine individual participants' use of paper during the workshops, the total combined time spent writing and drawing is shown in Figure 13. From the graph, it is apparent that some individuals either did not draw or write at all or very little compared to the other participants. In fact, two groups had one participant who chose not to draw or write at all during the whole workshop. This is an important consideration for a group facilitator in a design workshop. There will be people in many groups whose 
EXPERT GROUP SKETCHING

natural tendencies are not to express on paper.

Figure 13 Total Paper Creation Time by Participant

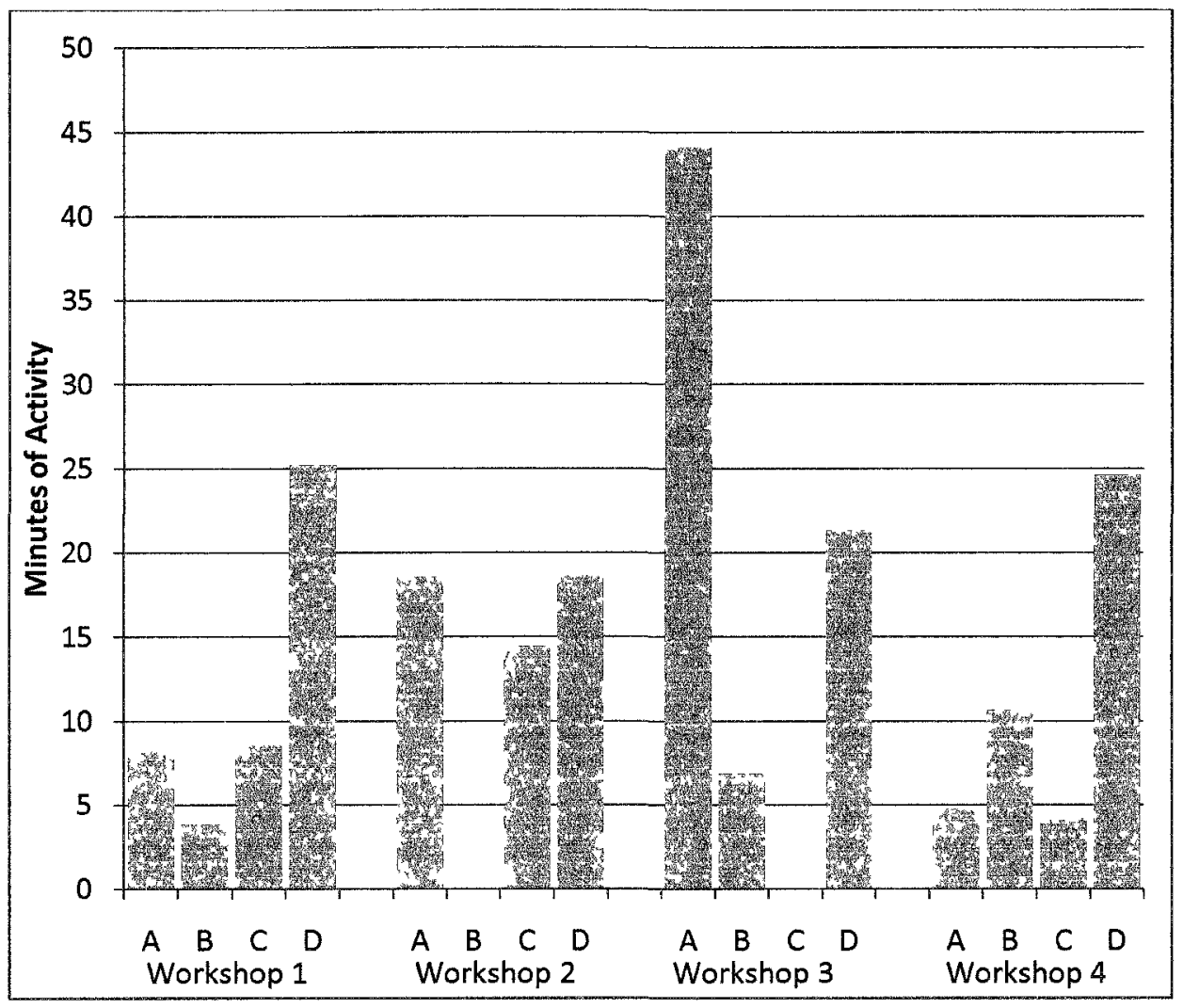

\subsection{Results of Verbal Activity Analysis}

The amount of time spent drawing and writing thus far has only revealed the paper-based participation level of each group member. After examining the time spent on paper activities, it became apparent that some individuals spent little time using paper but appeared from the video recordings to still be participating in the conversations. To assess this, a complete transcript was created for each workshop and used to tally how many words were spoken by each partıcipant. While words spoken did include extraneous personal discussions and small talk that was off-topic, these were not frequent or long-lasting based on a review of the video recordings. The word count was thus 
assessed by the researcher as a reasonable measure of verbal contribution within each group. This word counts allowed the researcher to examine how much individuals participated verbally to understand whether it was related in any way to the amount of tıme spent drawing and writing. The total words spoken by each partıcipant was tallied to discern their level of verbal activity relative to others in the group and is shown in Figure 14 for both problems. When looking at each group it became apparent that the total word counts between groups were different and that each participant's word count should only be compared to the word counts of other participants within the same group. Th1s would provide an indication of their relative verbal contribution. This difference between groups was attributed simply to differences in the speed of talking between groups.

Figure 14 Total Word Count by Participant

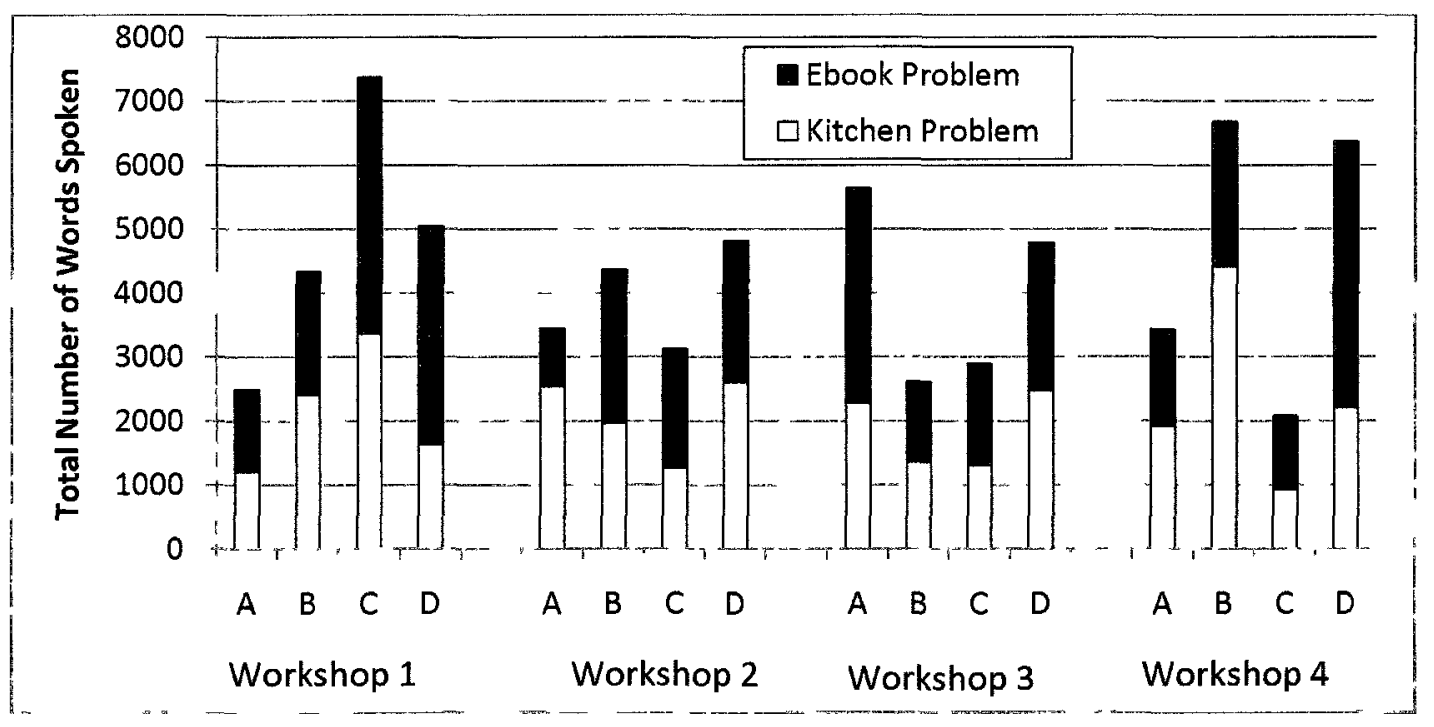

Upon reflection, it would have been useful to ask participants about their paper use (or lack thereof) at the end of the workshops and any reasons they had for not using paper to express themselves. This should be done for any future studies. 
For each problem type, Table 6 presents the number of words spoken with the amount of activity time using paper for each participant. The person with the highest amount of each of these (spoken words and paper activity minutes) has been highlighted in the table. In each group there was one person who talked more than the others. In only 2 of the 8 problem sessions did the most dominant speaker also spend the most time on paper activities. This suggests that individuals who are the most prolific speakers are not necessarily the ones that decide to express using paper.

Table 6 Total Word Count and Total Paper Activity Minutes by Participant

\begin{tabular}{|c|c|c|c|c|c|c|}
\hline \multirow[b]{3}{*}{ Workshop } & \multirow[b]{3}{*}{ Participant } & \multicolumn{2}{|c|}{ Concrete-Kitchen Problem } & \multicolumn{2}{|c|}{ Abstract-eBook Problem } & \\
\hline & & Total Words & Total Paper & Total Words & Activity & \\
\hline & & Spoken & Activity Minutes & Spoken & Minutes & \\
\hline 1 & A & 1203 & 0.00 & 1285 & 8.27 & \\
\hline 1 & B & 2408 & 3.43 & 1923 & 0.42 & \\
\hline 1 & c & 3360 & 3.50 & 4010 & 5.02 & \\
\hline 1 & D & 1626 & 18.82 & 3421 & 6.37 & \\
\hline 2 & A & 2533 & 10.08 & 908 & 8.47 & \\
\hline 2 & B & 1959 & 0.00 & 2404 & 0.00 & \\
\hline 2 & c & 1256 & 13.23 & 1869 & 1.20 & \\
\hline 2 & D & 2602 & 13.20 & 2214 & 5.60 & \\
\hline 3 & A & 2281 & 16.83 & 3356 & 2723 & Participants that \\
\hline 3 & B & 1359 & 6.88 & 1248 & 0.00 & spoke the most \\
\hline 3 & c & 1305 & 0.00 & 1586 & ممـم & and expressed \\
\hline 3 & D & 2476 & 20.92 & 2314 & 0.42 & $\begin{array}{l}\text { on paper the } \\
\text { most. }\end{array}$ \\
\hline 4 & A & 1919 & 4.73 & 1503 & 0.00 & \\
\hline 4 & B & 4409 & 5.83 & 2267 & 4.82 & \\
\hline 4 & c & 925 & 2.95 & 1150 & 1.25 & \\
\hline 4 & D & 2199 & 21.00 & 4171 & 3.62 & \\
\hline
\end{tabular}

From one problem to the next, the amount spoken by each participant would vary. For example, in Workshop 2 for the concrete-kitchen problem, participant A was the second most verbal participant in the group with almost the same number of words as their colleague who spoke the most (2533 words as compared to 2602 words), but then spoke the least amount for the second problem (908 words). This means that participant 
A was less inclined to contribute for the abstract-ebook problem verbally, suggesting that the topic and type of problem will affect a person's willingness to contribute.

Overall, it appears that there was little relationship between how verbally active someone was in the workshop and how much time they spent drawing or writing. It is important to note that participants who did not draw or write still contributed verbally in the groups. It did not seem to matter which problem type was involved. In fact in one session, the person who spoke the most spent absolutely no time on paper activities at all.

\subsection{Comparing Level of Activity and Occupation}

After examining the individual participants' contribution to the design sessions this researcher decided to investigate whether there was any relationship between their professional background and their choices on how they participated through time spent writing and drawing. While the sample of 16 participants was small and thus the results will require further research to validate, there were some very interesting findings. Both the Occupation types based on the Holland/Prediger model as used by this thesis and the raw Holland code occupation preference questionnaire results for the participants were compared against their time spent drawing and writing in the workshops.

After tallying the total paper activity for each occupation category (A, B, C, D), there appeared to be noticeably less writing and drawing activity for participants who had been classified as having a $\mathrm{B}$ or $\mathrm{C}$ occupation type (see Figure 15). Note that the "B" occupation category was defined as a "people-focused person who influences others" and a "C" category was defined as a "thing-focused person who is a big-picture, systems thinker". This shows that participants who had an occupation type of A or D spent more than twice the time drawing or writing than those in the other two categories of $\mathrm{B}$ or $\mathrm{C}$. 
EXPERT GROUP SKETCHING

This suggests that perhaps the attempt to create diversity by using occupation categories may have segregated those people that prefer not to express themselves on paper from those that do.

Figure 15 Total Paper Activity by Occupation Category

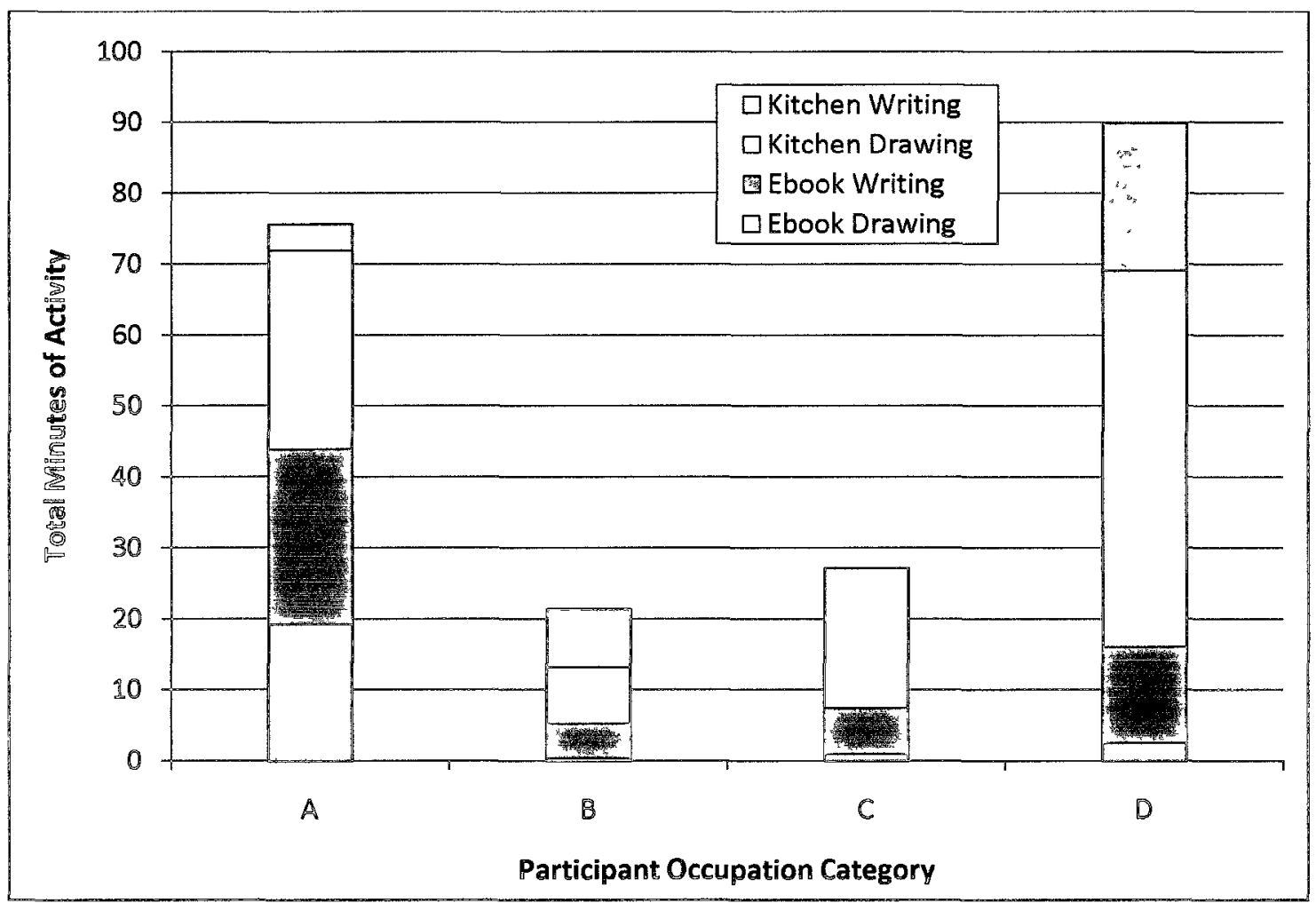

To investigate further, the actual scores from the Holland code questionnaire were analyzed against the activities of each participant. Each participant had 6 Holland scores corresponding to the 6 Holland codes (Realistic, Investigative, Artistic, Social, Enterprising, and Conventional). These were compared to each participant's total drawing and total writing activity time. The most significant correlation found was between the drawing time and the Enterprising dimension of the Holland codes ( $r(14)=$ $.59, \mathrm{p}<.017)$. Thus, individuals with a high score on the Enterprising dimension were less inclined to draw during the workshops. The characteristics attributed to the 
Enterprising dimension include: persuasive, energetic, sociable, adventurous, ambitious, and risk-taking. Strong "E" career preferences tend to strive towards leadership roles. The individuals with high Enterprising scores were assigned to the study's occupation category "B" (defined as people-focused influencing). For this study, the small sample size was only 16 , and thus cannot be considered conclusive. Further research to validate whether a relationship exists between people's professional background and their willingness to sketch and write in a group would be needed. Note that there was no relationship (between the scores for the Artistic Holland code dimension and participants" tendency to draw $(r(14)=.14, p<.597)$, which was the one factor that the researcher thought might demonstrate sone relationship.

The relationship between gender and the tendency to draw or write during the workshop was analyzed. For this set of workshops, the female participants drew and wrote more than their male counterparts as shown in Table 7. The sample sizes $(n=10$ males, $n=6$ fermales) are quite small and there may have been other factors such as the selection of female "experts" that may have influenced the results and so no conclusions are made. Further research would be required to investigate any relationship between males and females tendencies to draw and write in this context.

Table 7 Drawing/Writing Activity Time by Gender

\begin{tabular}{|c|c|c|}
\hline Gender & Average Drawing Time & Average Writing Time \\
\hline Male $(\mathrm{n}=10)$ & 7.10 minutes & 4.49 minutes \\
\hline Female $(\mathrm{n}=6)$ & 10.13 minutes & 6.24 minutes \\
\hline
\end{tabular}




\subsection{Personal Story-telling}

One activity that became apparent while viewing the video recordings was storytelling. These activities were coded as events using the video recordings in the same way as the writing and drawing activities. There were different dynamics observable in the group around story-telling events. As someone told a story, the others did not interrupt the story-teller and waited until the end of the story to return to a more interactive conversational approach.

Stories were also useful to guide the designs. For example, for the concretekitchen sessions, every group ended up modeling their design based on one participant's existing or previous kitchen. These kitchens served as templates in the design of the eventual solution. In all groups, the participant with the personal experiences was queried during the design session to understand their experiences with that layout.

Upon closer examination of the event diagrams discussed in section 4.1, there did not appear to be any discernable relationship between story-telling and the creation of paper artifacts. However, upon further review of the video recordings involving storytelling, the groups did appear to be more engaged verbally subsequent to story-telling. This is discussed in the section that follows.

Table 8 shows the number of story-telling events for each problem and group. There were more story-telling events for the concrete-kitchen problem in 3 of the 4 groups. Since all participants could be expected to have personal experiences with kitchens but not necessarily with ebooks or publishing, this was not all that surprising. 
EXPERT GROUP SKETCHING

Table 8 Number of Story-telling Events in each Workshop by Problem

\begin{tabular}{|c|c|c|}
\hline Workshop & Abstract-ebook & Concrete-kitchen \\
\hline 1 & 14 & 30 \\
\hline 2 & 8 & 26 \\
\hline 3 & 11 & 7 \\
\hline 4 & 3 & 11 \\
\hline
\end{tabular}

\subsection{Turn-taking}

After viewing the video recordings repeatedly, the researcher could see that there were periods during which each group seemed to be more active and animated in their discussion while other periods were much more passive. This prompted the researcher to look for some way to measure the "energy-level" in the groups. Several different approaches were considered including the rate of words spoken, the volume in decibels of the conversation and the rate of turn-taking. The rate of words spoken was not used because there was no way of differentiating between one person's monologue and more collaborative conversation. Measuring the decibels was not feasible for a number of technical reasons and it was not clear if other background noise would interfere. The third approach, measuring how frequently the conversation changed speakers (known as turn-taking), was selected. Based on the research into turn-taking in creative groups, in highly engaged creative discussions participants interject their ideas and often interrupt or finish someone else's half spoken ideas which could manifest itself as a high rate of turntaking. The researcher was interested in finding out if high rates of turn-taking could potentially indicate a very active and engaged group and whether it related to any of the activities of interest. 
To calculate the rate of turn taking from the workshops, the number of times any participant spoke was tallied between each pair of timestamps contained in the transcript. This was then divided by the number of minutes for that time slot to calculate the rate of speaker turns or turn-taking rate. A more detailed example calculation can be found in Appendix E.

The overall average rate of turn-taking for each of the problem sessions is shown in Table 9. In 3 out of 4 workshops, the average rate was higher during the concretekitchen problem than the abstract-ebook problem, which means that generally, the groups were more interactive while working on the concrete-kitchen problem.

Table 9 Average Turns per Minute by Workshop and Problem

\begin{tabular}{|c|c|c|}
\cline { 2 - 3 } \multicolumn{1}{c|}{} & \multicolumn{2}{c|}{$\begin{array}{c}\text { Tallies of turn taking by problem } \\
\text { session }\end{array}$} \\
\cline { 2 - 3 } & Ebook & Kitchen \\
\hline Workshop 1 & 21.52 & 16.87 \\
\hline Workshop 2 & 9.35 & 15.02 \\
\hline Workshop 3 & 14.19 & 19.59 \\
\hline Workshop 4 & 13.78 & 15.96 \\
\hline
\end{tabular}

The researcher then plotted the rate of turn-taking over time as shown in Figure 16 for Workshop 3. The heavy black line in the graph is the moving average line (plotting the average calculated from two sequential values to alleviate some of the calculation abnormalities due to measurement and rounding errors). From the graph it is possible to see changes in the level of interactivity among participants through fluctuations in the rate of speaker turns. 
Figure 16 Rate of Turn-taking for Workshop 3 for Abstract-ebook Problem

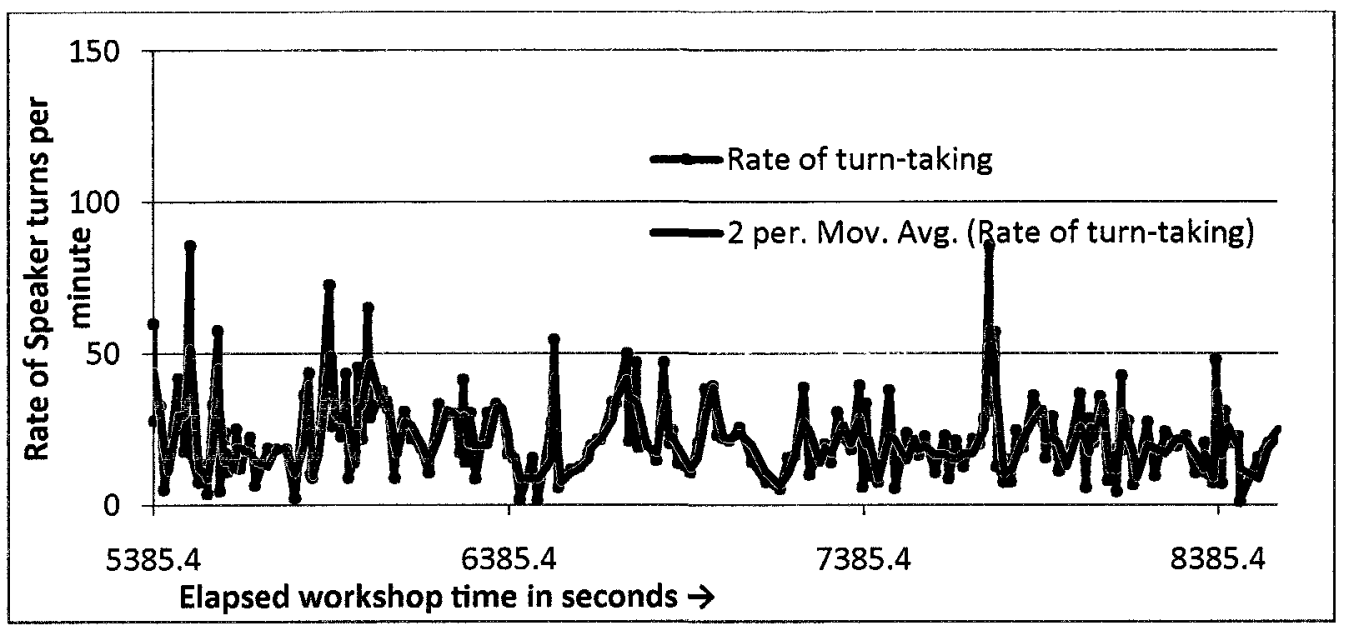

There are many possible reasons for low or high turn-taking rates on this graph.

For this study, consistently high levels of turn-taking represented high levels of interactivity in the group, and suggested a high level of collaborative discourse was ongoing. Note that a low rate of turn-taking can mean two things: either no one is speaking or a single speaker is talking with no one else interjecting or interacting. These results are not definitive but were used to identify periods of time that had a consistent high rate and then look at what was going on in the workshop during those periods of a high rate of turn-taking.

To understand what was going on in each workshop, a graph of the turn-taking rate was overlaid above event diagram produced in Section 4.1. One of the resulting diagrams is shown in Figure 17 for Workshop 3 abstract-ebook problem. The figures for the other workshops can be found in Appendix $\mathrm{H}$. This combined diagram provides a view of which activities preceded, occurred during and which activities followed a high rate of turns. 


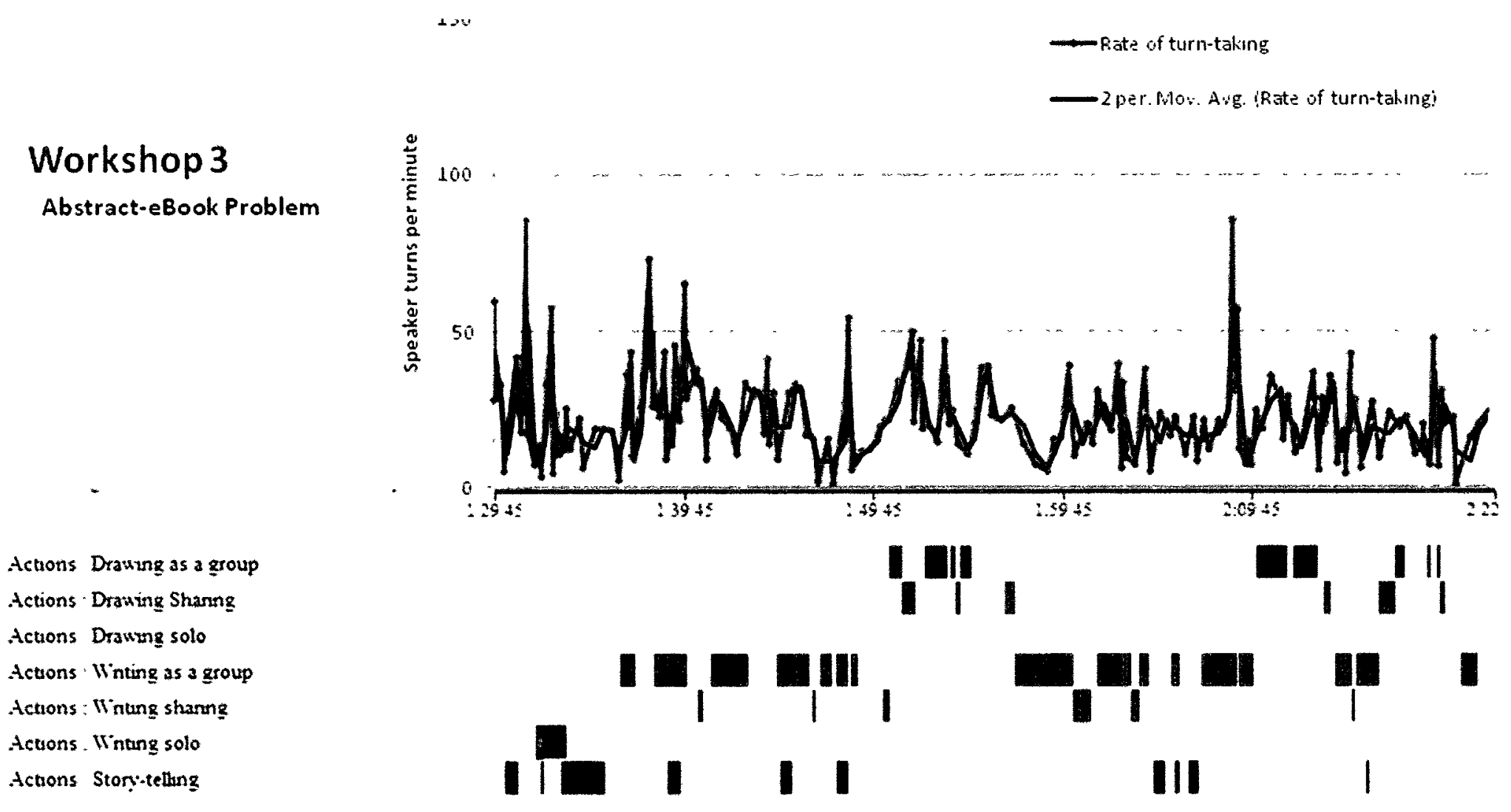


EXPERT GROUP SKETCHING

By examining the diagrams, it appeared that as participants engaged in group activities for drawing or writing, the level of turn-taking would rise but not consistently for all events. The researcher then examined the video recordings and found that sometimes the discussion around a sketch was very intense. However, in other cases, the conversation actually slowed down as participants were either busy creating an artifact or reflecting on the artifact. This lack of consistency meant that for drawing and writing activities, the rate of turn-taking was not definitive enough to identify any relationships. Where there were solo activities for writing or drawing, the rate of discourse and turntaking did go down as some participants worked on their own and withdrew from the group. This was not that surprising since fewer people would be involved in the discussions. One of the most prominent patterns that emerged from this visual inspection was an increase in the rate of turn-taking and thus interactivity subsequent to someone telling a story. Following a story-telling event, the rate of turn-taking and thus interactivity generally increased for a while. This suggests that story-telling might be providing some form of stimulus or raw material for generating discussion, leading to a subsequent increased level of interactivity and hopefully leading to further ideas. To examine this in more detail, the rate of turn-taking during and for several minutes following the story-telling events was calculated and is presented in Table 10. These rates show that generally, there was an increase in the rate of turn-taking subsequent to a story being told in the group. Note that the researcher chose to use a four minute long window for the post-story-telling measurement because it demonstrated the highest average rate. 
EXPERT GROUP SKETCHING

Table 10 Average Turn-taking Rate During and Following Story-Telling

\begin{tabular}{|l|c|c|}
\hline & $\begin{array}{c}\text { Average Turn-taking Rate } \\
\text { during Story telling }\end{array}$ & $\begin{array}{c}\text { Average Turn-taking rate following } \\
\text { Story-telling (4 minutes long) }\end{array}$ \\
\hline Workshop 1 & 17.6 & 20.0 \\
\hline Workshop 2 & 12.1 & 16.3 \\
\hline Workshop 3 & 12.8 & 21.1 \\
\hline Workshop 4 & 11.1 & 15.6 \\
\hline
\end{tabular}

\subsection{Paper Artifact Analysis}

Upon examining the paper artifacts produced in the workshop and reviewing the video in terms of how the artifacts were used, all of the artifacts were analyzed and coded using a set of categories created during the analysis process. To analyze the paper, each large sheet of newsprint from the workshops was parsed into parts by identifying distinguishable separate components. For example, for the kitchen layout problem, it was easy to distinguish between different kitchen floor plans that were adjacent. Each of these parts was considered a separate artifact. In the case of lists and notes, it was less obvious where the boundaries were because oftentimes the person creating it had added to it at different times.

Initially the paper artifacts produced in the workshops were analyzed and coded based on the type of artifact as defined in Table 11 and who drew it using the participants' occupation category codes of A, B, C, or D. In some cases, there was more than one creator of an artifact and these were coded as such.

Three types of sketching artifacts were identified: Drawing, diagram and prototype. For this study, the term prototype is used loosely to identify paper artifacts that were made by cutting out shapes for the kitchen appliances and cupboards so they could modify their kitchen layouts by moving the cutouts around. Drawings were 
identified as sketches that were a physically representative of an object. Diagrams were sketches that did not represent a physical object such as a shape with words in it.

Diagrams were more difficult to differentiate from writing because sometimes the ordering and positioning of words on the paper implied relationships between concepts to the person who created it. They were classified as diagrams if the position of the words on paper contained meaning to the creator as determined by viewing the video recording to understand how the participant used the diagram.

Table 11 Operational Definitions for Paper Artifacts

\begin{tabular}{|l|l|}
\hline $\begin{array}{l}\text { Coding for paper } \\
\text { artifact }\end{array}$ & Operational definition \\
\hline Writing & $\begin{array}{l}\text { Sentences and lists of items where the sequencing and } \\
\text { position on the paper does not hold additional information to } \\
\text { the writer. }\end{array}$ \\
\hline Diagram & $\begin{array}{l}\text { A sketch involving words and shapes that are used to indicate } \\
\text { relationships between ideas and concepts but do not represent } \\
\text { physical objects. e.g. a box with the word "strategy" inside of } \\
\text { it, or a list of words or sentences that denote important } \\
\text { sequencing of the items to the writer e.g. a series of steps. }\end{array}$ \\
\hline Drawing & \begin{tabular}{l} 
A sketch representing a physical object. \\
\hline Prototype
\end{tabular} \\
$\begin{array}{l}\text { Shaping the paper (e.g. cutting out) as a physical medium to } \\
\text { create a representation of a logical or physical item. For this } \\
\text { study, that meant creating cut-outs of objects. }\end{array}$ \\
\hline
\end{tabular}

Artifacts identified as a diagram, drawing or prototype as per Table 11 were classified as "drawing" activities in the activity coding as described in activity analysis section (Section 4.1). The artifacts that were identified and coded as writing artifacts were considered "writing" activities.

After further reviewing of the video recordings, the researcher noticed that the handling of the different artifacts in the groups varied. Some artifacts were used repeatedly by a group while other artifacts were barely created before they were ignored. 
It appeared that the more centrally located and accessible an artifact was, the more a group used and reused an artifact for exploring ideas for their solution. To investigate this, another set of categories was defined relating to the physical characteristics of each artifact which allowed the artifacts to be classified by their location relative to the center of the sheet of newsprint, the artifact's physical size as measured by surface area on the sheet, and the level of usage. These classifications are defined in Table 12, Table 14 and Table 13.

Table 12 Operatıonal Definttıons for Artifact Locatıon on Paper Sheet

\begin{tabular}{|l|l|}
\hline Coding of Position & Operational Definition \\
\hline Center & Up to 6" from the center of the paper sheet \\
\hline Middle & From 6" to 12" from the center of the paper sheet \\
\hline Periphery & Outside of 12" from the center of the paper sheet. \\
\hline
\end{tabular}

Table 13 Operatıonal Definttion for Artifact Size

\begin{tabular}{|l|l|}
\hline Size & Operational Definition \\
\hline Small & $\begin{array}{l}\text { Artifact covers less than 4 sq. inches of area on } \\
\text { the paper }\end{array}$ \\
\hline Medium & $\begin{array}{l}\text { Artifact covers between } 4 \text { and } 25 \text { sq. inches on } \\
\text { the paper }\end{array}$ \\
\hline Large & Artifact is larger than 25 sq. inches on the paper \\
\hline
\end{tabular}

Table 14 Operational Definttons for Artifact Level of Usage

\begin{tabular}{|l|l|}
\hline Coding for Level of Usage & Operational Definition \\
\hline Major & $\begin{array}{l}\text { Artifact was revisited numerous times by participants } \\
\text { and shared and modified by the group. } \\
\text { Regular }\end{array}$ \\
$\begin{array}{l}\text { Artifact was created and shared with the group. It may } \\
\text { be visited once or twice but was abandoned at some } \\
\text { point by its creator. }\end{array}$ \\
\hline Partial & $\begin{array}{l}\text { Artifact was only partially completed and was never } \\
\text { revisited by its creator. }\end{array}$ \\
\hline
\end{tabular}

The total number of writing and drawing artifacts produced for each problem type is shown in Table 15. Overall, there were noticeably more artifacts created for the 
concrete-kitchen sessions than for the abstract-ebook ones. This is consistent with the finding that more time was spent using paper in the concrete-kitchen problem sessions. As well, drawing artifacts were more common than writing artifacts for the concretekitchen problem while for the abstract-ebook problem sessions had roughly the same number for both writing and drawing artifacts.

Table 15 Paper Artifact Counts by Workshop and Problem

\begin{tabular}{|c|c|c|c|c|c|c|}
\hline & Workshop & $\begin{array}{c}\text { Total } \\
\text { Sketching } \\
\text { Artifacts }\end{array}$ & & $\begin{array}{c}\text { Total } \\
\text { Writing } \\
\text { Artifacts }\end{array}$ & & $\begin{array}{c}\text { Total } \\
\text { Artifacts }\end{array}$ \\
\hline \multirow{5}{*}{ 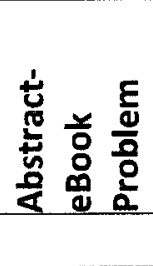 } & 1 & 2 & & 2 & & \\
\hline & 2 & 2 & & 5 & & \\
\hline & 3 & 3 & & 4 & & \\
\hline & 4 & 4 & & 3 & & \\
\hline & \multicolumn{2}{|c|}{ Total Abstract-ebook } & 11 & & 14 & 25 \\
\hline \multirow{5}{*}{ 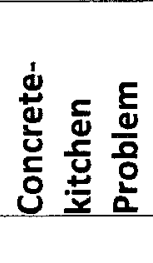 } & 1 & 10 & & 5 & & \\
\hline & 2 & 13 & & 1 & & \\
\hline & 3 & 3 & & 7 & & \\
\hline & 4 & 12 & & 3 & & \\
\hline & \multicolumn{2}{|c|}{ Total Concrete-kitchen } & 38 & & 16 & 54 \\
\hline
\end{tabular}

Specifically, there were over three times as many sketching artifacts created for the concrete-kitchen problem compared to the abstract-ebook problem except for Workshop 3. This group's low drawing artifact count was the result of them creating a prototype (classified as a sketch for the purposes of this study) with cutouts and thus they were able to modify their kitchen layout without creating multiple artifacts. So while this group may appear to have had fewer sketching artifacts for the concrete-kitchen problem than the abstract problem, they used one large artifact to represent many different options during the session. 
Table 16 presents the results of the artifact counts comparing size to the usage of artifacts. Generally, the larger the artifact was, the more likely the artifact was used over and over again by a group. There was only one small artifact that was classified as a "major" artifact while there were 8 large and 6 medium sized artifacts that were "major". Thus, artifacts that were small were less likely to be reused. When comparing the location of the artifact on the large newsprint sheets to the usage of the artifacts as shown in Table 17, a similar trend is visible. The major usage artifacts tended to be more centrally located and the artifacts that were created and discarded tended to be on the periphery of the sheets. This suggests that the larger artifacts were either created large specifically to aid in sharing or were shared more because they were larger. In either case, the larger artifacts were used more.

Table 16 Artifact Counts for Usage and Size

\begin{tabular}{|c|c|c|c|c|}
\hline & & \multicolumn{3}{|c|}{ Artifact Size } \\
\hline & & Large & Medium & Small \\
\hline \multirow{3}{*}{ 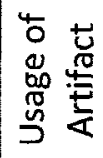 } & Major & 8 & 6 & 1 \\
\hline & Regular & 8 & 12 & 14 \\
\hline & Partial & 0 & 7 & 23 \\
\hline
\end{tabular}

Table 17 Artifact Counts for Usage and Location

\begin{tabular}{|c|c|c|c|c|}
\hline & & \multicolumn{3}{|c|}{ Artifact Location } \\
\hline & & Centre & Middle & Periphery \\
\hline \multirow{3}{*}{ 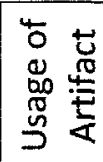 } & Major & 10 & 4 & 1 \\
\hline & Regular & 6 & 11 & 17 \\
\hline & Partial & 4 & 4 & 22 \\
\hline
\end{tabular}

Generally, it would appear that those artifacts that played the most important role in the design workshops were either medium or large in size and were more centrally located on the large sheet of newsprint. 
At the end of each workshop, each group chose, without prompting, artifacts (in 3 of the 4 groups it was a single artifact) to present their results to the researcher. The artifacts that each group chose were identified and reexamined to determine what characteristics they had in common. All of these artifacts were classified as medium or large in size and all except one were created within the middle area of the newsprint sheets. This one that was not in the middle of the newsprint sheet consisted of a set of notes written hurriedly after the session had ended by a lone participant to capture the ideas of the group. This group had been late in committing to their solution for that one problem session. Overall, the groups inherently understood the importance of the size of the artifact and that a larger size provided a better way to share their results.

\subsection{Observations from the Workshops}

When each of the groups started to draw for the concrete-kitchen problem, they all chose the same bird's eye view of a floor plan to layout to represent the kitchen. This is a commonly used convention for kitchen design. For the abstract-ebook problem, representations on paper, whether drawing or writing, were all considerably different between the groups. These are shown in Figure 18 and Figure 19. Workshop 1 chose to categorize their ideas to organize their thoughts. Workshop 2 created a small word diagram with arrows to highlight the relative importance of items and sequenced the steps for their strategy. Workshop 3 chose to create a decision tree for the steps the publisher would have to follow and Workshop 4 created a diagram with four boxes to represent the four technology options described in the problem statement. All four approaches represented a different perspective on the same problem. It was clear that there was no "standard" way of communicating the content of the abstract-ebook problem space and 
this meant that each group had to create their own way to represent it on paper.

Figure 18 Abstract-ebook Representations from Workshops 1 and 2
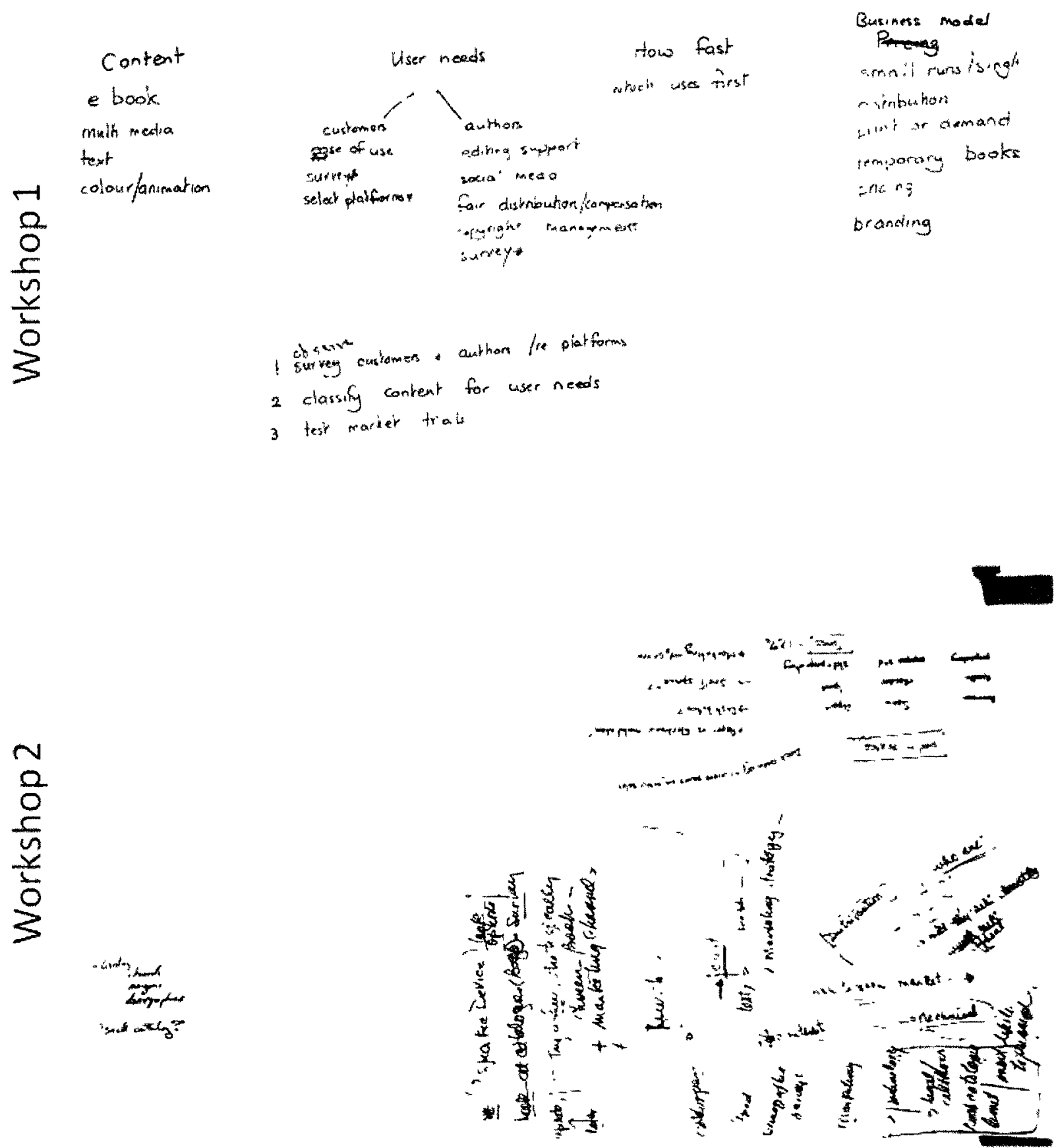
Figure 19 Abstract-ebook Representations from Workshops 3 and 4
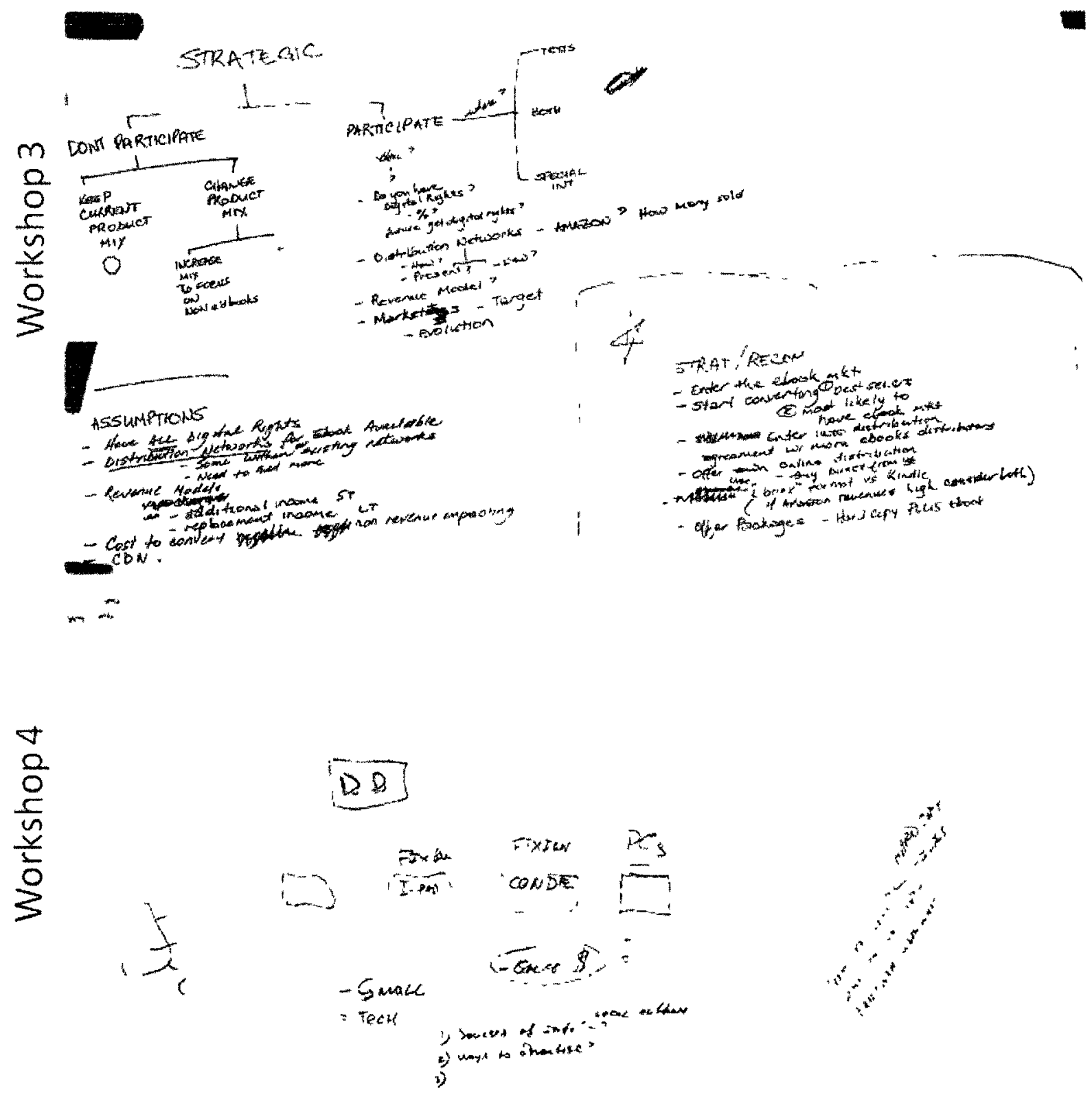

Reflective design practice as discussed previously is about creating a sketch and then using it to trigger more ideas. In some groups, it was almost like the opposite happened. In one group in particular, one participant drew four boxes to represent the 
EXPERT GROUP SKETCHING

four different ebook options at the very beginning of the problem discussion. This diagram became a focal point for the discussion in that group. Members referred to it by gesturing, pointing to it, describing aspects of it and spending a lot of time glancing at it. These four box diagrams became central to all that that group talked about. This meant they spent less time on other facets of the problem such as marketing or strategy rollout or tactics. The problem with this became even more apparent at the end of the session when one participant had to hurriedly write up some notes for the strategy presentation and even continued to write for several minutes after the researcher had ended the design session. There was no evidence to suggest that this group was in any way less capable than the other groups at addressing the topic. The early diagram appears to have distracted the group from investigating other lines of inquiry or may simply have been a reflection of their lack of ideas about the problem space.

Through observations of the video, it became apparent that participants did not modify by marking on another participant's drawing or writing. This was somewhat surprising, given that there were common shared newsprint sheets shared by all in the group. Individuals would sketch in their corner of the sheet. They might then introduce their artifact to the group to share it, but the other participants would not mark on top of that artifact. During the discussions, the other participant might point directly to that item and talk about it but would never mark it. If there were changes to be made, they were done by the original creator of the artifact. The only exception to this was when a drawing or writing was very large and centrally located on the newsprint sheet. The size and position of the artifact in these cases seemed to imply it was a communal creation and this somehow gave others permission to modify the artifact. Thus there was a 
territorial element to the positioning of an artifact that influenced how participants interacted with the artifact.

Where artifacts were located at the periphery of the newsprint sheet, participants who were not close to that artifact treated it deferentially. In some cases, a participant would be positioned away from the artifact being discussed, would then lean in, point to the artifact and provide an idea and then return to their more distant position. This is demonstrated in the sketch sequence shown in Figure 20 where a participant leans in to suggest a change and then withdraws to allow the artifact's creator to reflect and then make any necessary changes.

Figure 20 Sketch Sequence of Participant Pointing and then Leaning Back
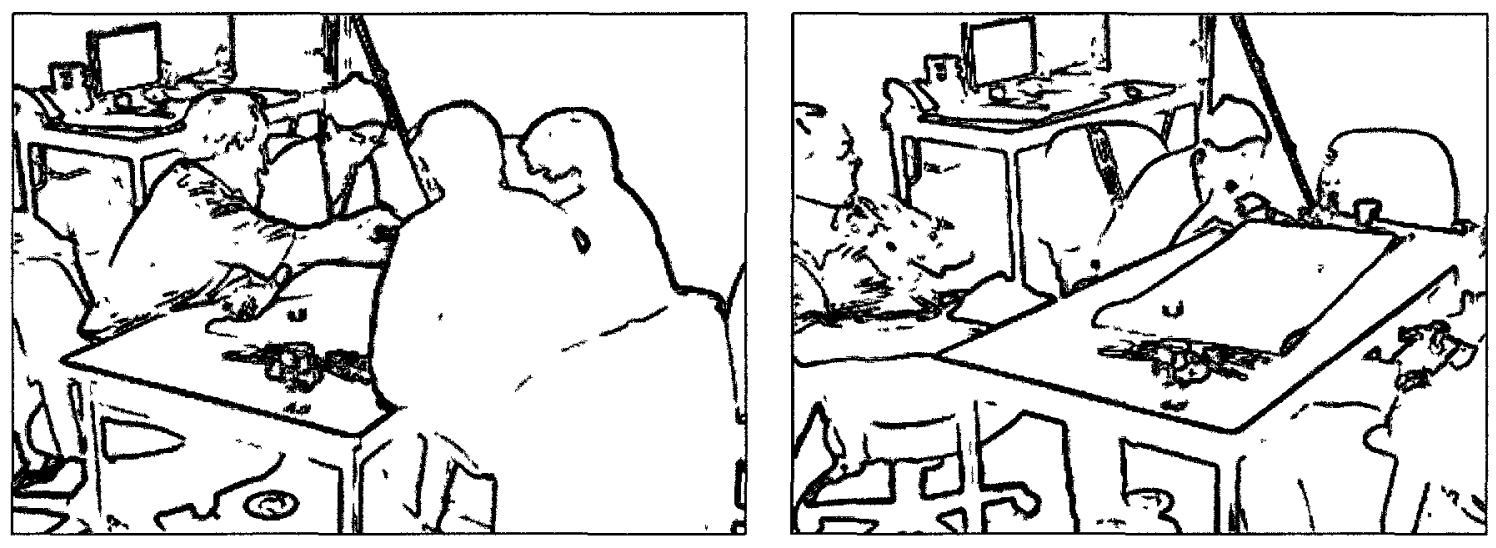

For the concrete-kitchen problem, two groups created prototype cutouts of the appliances so they could move them around on an outline of the kitchen floor to explore options. Workshop 3 created a prototype floor layout that was quite large and covered most of a full sheet of the newsprint provided. They also created cutouts of the appliances. This group's discussion and activities were then centered almost solely on this prototype. There was very little solo drawing compared to the other groups. These 
participants appeared to be content concentrating their efforts on the large artifact. The ability to see and modify and test ideas immediately with the group without redrawing the layout did speed up this group's process. But the key difference compared to another group that had made a similar type of prototype, was that this group's artifact was very large and thus all participants could easily see it. The centrally-located large size also meant that the artifact became a communal artifact and thus all of the participants actively moved the parts of the kitchen around in the space. This group was the fastest of all the groups to come to a final choice for the kitchen layout and finished early and then continued to refine the details of their design even further. Once they had finished overall placement of the major items in the kitchen, they moved to discuss under counter lighting and other accessories for the kitchen.

In contrast, another group that created a much smaller prototype with cutouts were not quite as successful and had trouble near the end of the session agreeing on a solution. Their prototype was only about 4 square inches in area (classified as a "small" artifact). The group members had to move to be quite close physically so they could all see what was going on and move the cutouts around. However because it was very crowded with four people trying to gain access to such a small artifact not all members of this group chose to move items around in the prototype. This suggests that perhaps some participants did not feel that the prototype was communal enough for them to adjust and change things or that they did not feel physically comfortable vying for the cutouts. Thus, it appears that the less accessible the main drawing was, the higher the chance that someone in the group may withdraw, disagree, or as happened in this case, bring up alternative proposals near the final stages of the workshop. For the group with the small 
prototype, as they approached the end of the design session and were trying to agree on the final layout, one of the individuals who had not attempted to move the cutouts around started to express their opinion about the need to explore other options and approaches. This suggests that even though the group worked together using the prototype, not all members of the group were fully committed to the proposed solution. This same participant then went on to offer other suggestions and sketched up several of these on the paper in an attempt to initiate discussions in other directions.

Figure 21 Sketch of Workshop Group Crowding around Prototype

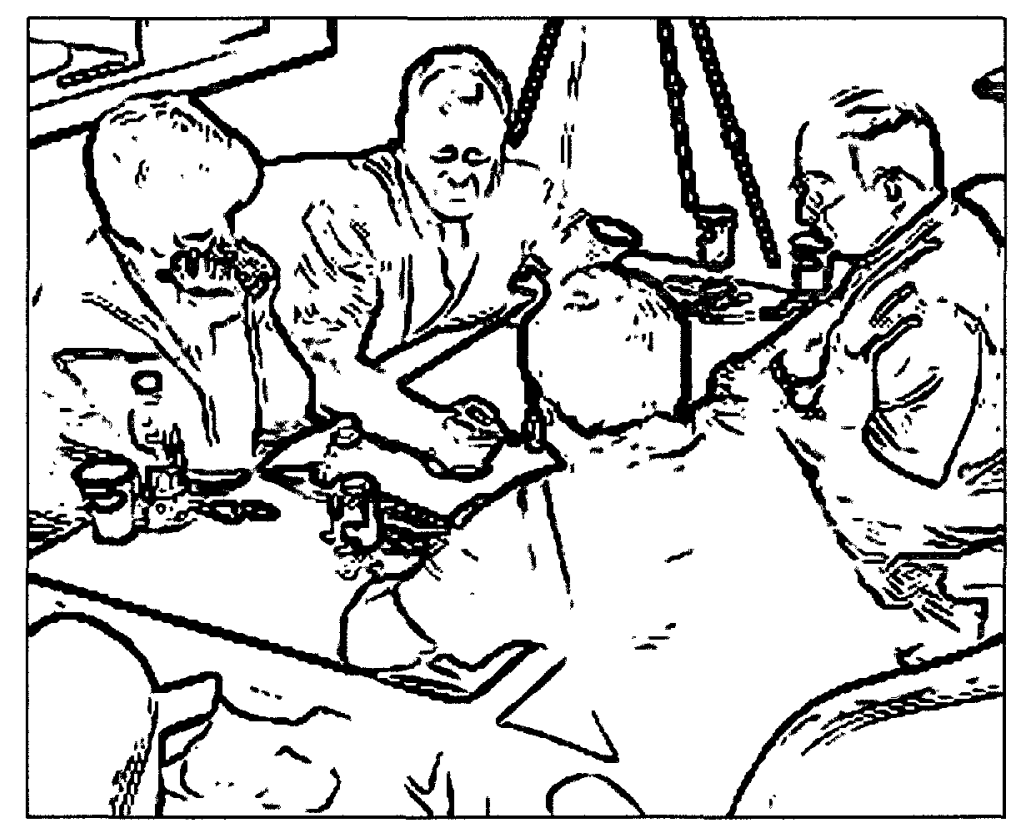

So the size and location of an artifact appeared to influence the engagement by participants with a particular artifact. In many groups, participants would lean back and withdraw to contemplate things. Without being able to clearly see the smaller artifact from a distance, it was not possible for all members of the group to do this and reflect on the design from a distance. The more visible and accessible an artifact was, the more the artifact was used for discussion. 
In all of the groups, no single leader was designated or emerged. While in some groups a single participant played a central role in mediating the discussion, these did not appear as leaders because there was no indication that the other participants were deferring to them. In the post-workshop discussion, all the groups mentioned the collaborative nature of the exercise. They all mentioned the equal status in the groups and that everyone had played an active and significant part in developing the solutions.

As the groups approached the end of each design session, their final solution was always transferred to paper. By expressing it on paper, the groups negotiated the final details of the design and were thus able to commit as a group to a single solution. For all the groups, the final paper representation appeared helped to coalesce the group on a single solution. While each group agreed on their final solution using an artifact, these final solution representations were extremely rough and crude in style. Without the verbal explanation provided by the participants during the post-session presentation, it would have been difficult for the researcher to discern the actual details of any of the designed solutions. Given the limited time for the workshop sessions, this may not be surprising but because the level of professional experience was high, a failure to document the results effectively was not anticipated. 


\section{Discussion}

This study investigated how experienced professionals might choose to sketch and use paper while they are designing solutions to concrete and abstract problems. The purpose was to better understand experts' natural tendencies and inclinations to sketch and use paper to represent problem spaces. The study specifically targeted experts whose disciplines do not formally teach sketching as part of their training. Setting up the workshops so that many of the variables were controlled allowed for comparisons between many factors in the data analysis. The most useful one was the comparison between the two problem types. The other key factor was controlling the diversity within each group so that comparisons could be made between groups. The study used career preferences based on the Holland-Prediger model coupled with professional background information to create an equivalent diversity in each group.

The results suggest that some very simple aspects in a workshop logistics can influence their success. The physical size and location of an artifact appears to influence the dynamics of a group around that item. The larger and more centrally located an artifact was, the more repeatedly it was used within a group. The large sheets of newsprint used in the workshop were unofficially divided into territories by the participants where the edges of the sheets were personal and the more central part was communal. Participants knew implicitly when an artifact was personal and when it was communal. Communal artifacts tended to be larger and were centrally located on the table. The experts in these workshops were very respectful of other participants' writing and drawing. They consistently avoided marking on others' work except when the artifact was considered communal. 
There was a consistent approach across all workshops in the drawings produced for the concrete-kitchen problem. Every group drew a floor layout to represent the kitchen. For the abstract problem however, there was no consistency in the choice for representing the problem spaces on paper. When a problem is abstract and ill-defined with no "standard" model, the process of discovering a problem's facets and idiosyncrasies can take a group in many directions. This was reflected in the wide variability of artifact content for the abstract-ebook problems in the workshops.

When exploring the problem space, the things that are put on paper tended to guide the discussion. For the abstract-ebook problem, one group became fixated on only one aspect of the problem because of an early drawing produced that showed the four technology options. The sketch in front of their eyes appeared to direct their discussion. Alternatively, it could be that it simply represented the sole familiar aspect of the problem space that they knew and understood. In either case, the limited view of the problem they embraced resulted in the group being rushed at the end of the session to finish their solution.

Near the end of each session, every group used paper (either drawing or writing) to negotiate and commit to their final solution. The act of tangibly expressing on paper appeared to solidify the decisions for the groups. This consistent approach to use paper as a permanent representation of decisions highlights another usage of paper: to mediate and reach agreement for the final result.

After examining the individual levels of participation, there were some interesting observations. Some people choose not to write or draw in a group activity. It did not matter which problem was involved for these people; these participants simply had no 
inclination to draw or write. Choosing not to express themselves on paper, however, did not seem to impact their participation in the group. Individuals who did not use the paper still participated verbally and all groups reported in the post-workshop interviews that their groups worked very collaboratively with all participants.

Further detailed analysis of the participants' activity levels identified that those participants who scored higher on the Enterprising dimension of the Holland Codes were less likely to draw or write on paper. It would be interesting to follow up on to learn if it generalizes to other groups, other participants, and to other problems as well.

Another factor that emerged from the workshop analysis was the importance of story-telling. Whenever a story was told, the rate of interactivity increased. These stories acted as valuable raw material and subsequently triggered more discussions. As such, the groups seemed to recognize this and automatically deferred to the story-teller and did not interrupt them. After the story-telling events, the level of interactivity measured through rate of turn-taking generally increased. This suggests that story-telling somehow stimulates the group and may in fact provide a valuable vehicle to transfer knowledge in the groups.

While this study was specifically targeting experts to gather insights on how they express and share ideas during the early stages of designing solutions to problems, many of the insights derived from the results, such as the importance of artifact size and location, may be transferrable to other types of collaborative groups. The one key aspect of the study that was different from most other studies into group sketching was the use of experts from outside of design disciplines (e.g. industrial design or architecture). Experts have significant experience at designing solutions to problems in their fields. For 
EXPERT GROUP SKETCHING

these workshops, the experts appeared to be fully engaged with the design process.

However, it is impossible to know the extent to which the results would generalize to other groups and to other problems. The choice of problems for the workshops did not actually match any specific expertise in the groups. In that sense, it might not be considered representative of an interdisciplinary team because the process did not recruit experts by profession to suit a specific problem. The original reason for using experts was to explore how their different approaches to problems solving and design would be transferred to sketching. The problems were chosen specifically to appeal to the demographic of the study. While the participants were not specifically familiar with the topic, their pre-conditioning from their professional experience is believed to have influenced each participant's approach to designing a solution. During one workshop, a participant remarked:

"That's what I do. Part of my job is just to listen."

She was referring to the difference in approach that she had compared to the other participants in her group. This suggests that while the problems were not specific to their particular professions, the goal of the study to tap into different professionals' methodologies was accomplished.

In summary, while concrete problems appear to naturally lend themselves to being sketched as part of a design process, abstract problems are more likely to lead to writing things out than to sketching. Sketching can be extremely powerful in focusing the efforts of a group onto a subject. As people contemplate ideas, they look at whatever is in front of them and this can end up influencing their thoughts. Thus the ability to easily see the materials about the problem during the design sessions impacts the acceptance of a 
group's solution by all members. Where mediating artifacts were large and centrally located, this appeared to increase collaboration.

Some of the benefits of sketching may be attributable simply to their size on paper and thus their visibility. Writing in the groups tended to be a normal handwriting size similar to that used for taking notes and as such was less visible from a distance to other participants. When participants leaned back to contemplate, the text was simply not as easy to see.

\subsection{Study Limitations}

The range of professions in the workshops was broad but was still influenced by a number of factors that may have contributed some bias to the study. All of the participants were recruited from the Ottawa area and as a result there were many participants with technology backgrounds. As well, the researcher knew all of the participants and this may have resulted in some bias in the selection of the participants because they may have similar personal values and tendencies. While some people had met prior to the workshop, an attempt was made to avoid placing people in the same workshop who knew each other well. There were some noticeable trends in the selection of professionals that the researcher was able to recruit. Most of the participants were either industry-based or from helping roles; none were from academics or government or with purely artistic backgrounds (e.g. artist or musician).

There were many things in the study that could have been analyzed beyond what the researcher chose to examine. These included such things as the flow of ideas as they emerged, gestures and body language, and individual evolution of the drawings and 
writing as they were created and modified. The workshops were rich with information and the researcher had to limit the scope of the items examined.

The solutions produced in the workshops were not evaluated. In retrospect, it would have been prudent to include some way to evaluate the final results to determine if there was any relationship between the use of paper and the success of each group's collaboration. To compensate for this, the solutions were assessed in terms of completeness, and how many topics were discussed and agreed upon but not presented by the group.

In retrospect it would have also been useful if there had been a post-workshop questionnaire to find out more about why people did or did not use paper to draw or write and this should be done in any further studies.

For the workshops, three video cameras were placed around the room and aimed at the participants. It would be very useful to have another camera directly over top of the work table aimed at the surface to record the individual actions of each participant. To compensate for this, the researcher had to distinguish activities based on the location of the participants' pen relative to the paper and then compare that to the newsprint sheets.

\subsection{Opportunities for Future Research}

This study specifically investigated interdisciplinary teams and sketching. One finding related career preferences to a person's tendency to express themselves on paper during group activities. This was an unexpected result from the study. Additional research exploring this further could provide some useful insights for all collaborative design methodologies. 
The study revealed where groups created larger and more centrally located artifacts, they collaborated better and were more successful. While this study was small, further research into the topic of size and location of artifacts and its effect on collaboration could yield some useful results.

Paper artifacts were characterized for this study by type, size, location and usage. Potentially, further research could be done evaluating other sketch characteristics such as line weight, orientation and pen colour, to explore their effect.

This study used large newsprint sheets in the center of the meeting table around which the participants sat. This resulted in equal status to all participants which may explain why there appeared to be no hierarchy in the workshops. One possible avenue of research would be to look at other media such as the use of whiteboards for a similar type of workshop where usually only one person can be marking on the whiteboard at any given time.

The study identified that story-telling appears to lead to more interactivity in a group and subsequently the generation of ideas. Further research would be needed to understand and validate the role of story-telling as a means to increase the level of interactivity and the potential to generate more ideas in a brainstorming session.

The analysis of the rate of turn-taking or speaker turns provided a means to gauge interactivity in a group. This approach might be a useful tool for other researchers as a way to measure the energy-level of a group activity especially in a brainstorming session where people are continuously interjecting ideas and where half spoken sentences are left hanging as ideas emerge in the group. Further research into the details surrounding turn- 
EXPERT GROUP SKETCHING

taking as a way of measuring the interactivity level of a collaborative process could prove useful in a variety of applications.

\subsection{Conclusions}

This research tried to identify generalizations about how these experts use sketching and other paper artifacts to design solutions to problems as part of an interdisciplinary group. Some of the findings from the study may prove useful to any collaborative design method. Specifically, that size, orientations and accessibility of artifacts will impact people's tendencies towards using the artifacts. As well, participants inherently distinguished between communal and personal artifacts. Communal artifacts could be modified by all and usually sat in the center of the common paper sheet while the more personal artifacts tended to sit at the edges and could only be modified by the owner-creator.

Overall, each group spent more time sketching while working on the visual concrete problem than on the abstract problem. As well, the sketches for the concretekitchen problem were all quite similar in style and structure. For the abstract-ebook problem, all the diagrams were quite different in content between groups. For this reason alone, it may be more of a challenge to gain consensus in a group for abstract problems. One surprising finding was a correlation between participants' career preferences as measured using the Holland Codes and their tendencies to express ideas on paper.

In the end, only a subset of the potential areas of inquiry could be investigated in this study and there is still more possible research using this study's data. It is hoped that the results of this research prove useful to others trying to investigate similar topics. 
EXPERT GROUP SKETCHING

5.4 Suggestions for Designers Facilitating Highly Diverse Expert Teams

While this was an exploratory study, a number of findings hold potential for helping designers facilitate collaborative design sessions with an interdisciplinary team. Some of these findings were sketching-related while others were general facilitation considerations.

Sketching-related suggestions:

1. Encouraging the creation of large artifacts. If the artifacts are too small then participants cannot sit back and reflect on them. As well, if an artifact is small, the participants may not feel that it is communal and may hesitate to modify it.

2. Paying attention to the layout and logistics of the work area for the session. Make sure all materials and media produced by the group remain accessible and can be seen easily. Wherever possible, keep the working material central in the workspace. This will allow the participants to reflect on the alternatives.

3. Not expecting everyone to express themselves through external media such as prototypes or through paper. Some people are more verbally oriented. These people still make useful observations based on viewing the work of other participants in the group.

General facilitation suggestions:

4. Pushing the group to express a wide variety of facets of the problem space. Refresh any paper frequently. Prompt the group with questions to move in other directions.

5. Encouraging story-telling related to the subject matter. Stories are raw material to trigger further ideas in the group. 
References

Akın, O. (1990). Necessary conditions for design expertise and creativity. Desıgn Studıes, $11(2), 107-113$.

Amabile, T. M. (1996). Creatıvty in context. Boulder, CO: Westview Press.

Bly, S. A. (1988). A use of drawing surfaces in different collaborative settings. Proceedings of the 1988 ACM conference on Computer-supported cooperative work (p. 250-256). ACM.

Brown, T., \& Katz, B. (2009). Change by design: how design thinking transforms organizatıons and inspires innovation New York: Harper Business.

Buxton, W. (2007). Sketching user experiences : gettıng the design right and the right design. Boston MA: Morgan Kaufmann.

Cagan, J., \& Vogel, C. (2002). Creatıng breakthrough products. Upper Saddle River· FT Press.

Campbell, D. T. (1969). Ethnocentrism of disciplines and the fish-scale model of omniscience. In M. Sherif \& C. Sherif (Eds.), Interdisciplinary relationships in the social sciences (pp. 3-21). Chicago: Aldine.

Carlile, P R (2004). Transferring, Translating, and Transforming: An Integrative Framework for Managing Knowledge Across Boundaries. Organizatıon Sctence, $15(5), 555-568$.

Casakin, H (2004). Visual analogy as a cognitive strategy in the design process: expert versus novice performance. Journal of Design Research, 4(2).

Casakin, H., \& Goldschmidt, G. (1999). Expertise and the use of visual analogy. implications for design education. Destgn Studies, 20(2), 153-175.

Casakin, H, \& Goldschmidt, G. (2000). Reasoning by visual analogy in design problemsolving the role of guidance. Environment and Planning $B, 27(1), 105-120$.

Clark, J., Dodd, D., \& Coll, R. (2008). Border crossing and enculturation into higher education science and engineering learning communities. Research in Scrence \& Technological Educatıon, 26(3), 323-334.

Crookes, G. (1990). The Utterance, and Other Basic Units for Second Language Discourse Analysis. Applied linguistics, 1l(2), 183-199. 
Cross, N. (2006). Designerly ways of knowing. London: Springer.

Csikszentmihalyi, M. (1997). Creattvity: Flow and the psychology of discovery and invention. 1996. New York. New York: Harper Perennial.

Diehl, M., \& Stroebe, W. (1987). Productivity loss in brainstorming groups: Toward the solution of a riddle. Journal of Personality and Social Psychology, 53(3), 497-509.

Diehl, M., \& Stroebe, W. (1991). Productivity loss in idea-generating groups: Tracking down the blocking effect. Journal of Personality and Social Psychology, 61(3), 392403.

Dunbar, K. (1997). How scientists think: On-line creativity and conceptual change in science. Creattve thought: An investigation of conceptual structures and processes, 461-493.

Erickson, T. (1995). Notes on design practice: Stories and prototypes as catalysts for communication. Scenarlo-based design: envisloning work and technology in system development (p. 58). New York: John Wiley \& Sons, Inc.

Ericsson, K. A. (1998). The Scientific Study of Expert Levels of Performance: general implications for optimal learning and creativity. High Abllity Studies, 9(1), 75-100.

Ericsson, K. A., \& Smith, J. (1991). Toward a general theory of expertise: Prospects and limits. Cambridge, UK: Cambridge University Press.

Esslinger, H. (2009). A fine line: how design strategies are shaping the future of business. San Francisco, CA: Jossey-Bass.

Finke, R., Ward, T., \& Smith, S. (1996). Creative cognition. Handbook of creativity. Boston: MIT Press.

Fischer, G. (1999). Symmetry of ignorance, social creativity, and meta-design. Proceedings of the $3 r d$ conference on Creativity $\& \&$ cognition (p. 116-123). New York: ACM.

Fischer, G. (2005). Creativity and Distributed Intelligence. Workshop on Creativity Support Tools. Washington: National Science Foundation. Retrieved September 4, 2009, from http://www.cs.umd.edu/hcil/CST/Papers/distributed.pdf.

Fischer, G., \& Giaccardi, E. (2004). Meta-design: A framework for the future of end user development. End User Development: Empowering People to Flexibly Employ Advanced Information and Communication Technology (p. 427-457). Dordrecht, The Netherlands: Kluwer Academic Publishers. 
EXPERT GROUP SKETCHING

Fish, J. (2004). Cognitive catalysis: Sketches for a time-lagged brain. Design Representation, 2, 151-184.

Free Merriam-Webster Dictionary. (2011). . Retrieved May 6, 2011, from http://www.merriam-webster.com/dictionary/visualization.

Gardner, H. (1983). Frames of Mind: The Theory of Multiple Intelligences. New York: Basic Books.

Gick, M L., \& Holyoak, K. J. (1980). Analogical problem solving Cognittve psychology, $12(3), 306-355$.

Gick, M. L., \& Holyoak, K. J (1983). Schema induction and analogical transfer. Cognutive psychology, 15(1), 1-38.

Gladwell, M. (2005). Blink: The Power of Thinking Without Thinkıng. London UK: Little Brown.

Glaser, B. G., \& Strauss, A. L. (1967). The Discovery of Grounded Theory: Strategies for Qualitative Research. Chicago: Aldine.

Goel, V. (1995). Sketches of thought. Cambridge MA: The MIT Press.

Goldschmidt, G. (1991). The dialectics of sketching. Creatıvty Research Journal, 4(2), 123-143.

Goldschmidt, G. (1994). On visual design thinking: the vis kids of architecture. Design Studies, 15(2), 158-174.

Guffey, M. E., \& Loewy, D. (2009). Essentials of business communication (8th ed.). Nashville: South Western Educational Publishing

Holland Code Quiz. (2010). . Retrieved December 13, 2010, from http://www.roguecc.edu/Counseling/HollandCodes/test.asp.

Holland, J. L. (1985). Making vocational chotces: A theory of vocational personalities and work environments. Englewood Cliffs, NJ: Prentice-Hall.

Holyoak, K. J., \& Thagard, P. (1996). Mental leaps: Analogy in creatve thought. Cambridge, MA: The MIT Press.

Janis, I. L. (1982). Groupthınk. Boston MA: Houghton Mifflin. 
Johansson, F. (2004). The Medicl Effect: Breakthrough Insights at the Intersection of Ideas, Concepts, and Cultures. Boston MA: Harvard Business School Press.

Jordan, B., \& Henderson, A. (1995). Interaction Analysis: Foundations and Practice. Journal of the Learning Sciences, 4(1), 39-103.

Kaufmann, A., \& Tödtling, F (2001). Science-industry interaction in the process of innovation. the importance of boundary-crossing between systems. Research Policy, 30(5), 791-804.

Kavakli, M., \& Gero, J. S. (2001). Sketching as mental imagery processing. Destgn Studies, 22(4), 347-364.

Kavakli, M., Suwa, M., Gero, J. S., \& Purcell, A. T. (1999). Sketching interpretation in novice and expert designers. In J. S. Gero \& B. Tversky (Eds.), Visual and Spatzal Reasoning in Design (p 209-219). Sydney Australia: Key Centre of Design Computing and Cognition, University of Sydney.

Kilker, J. (1999). Conflict on collaborative design teams' understanding the role of social identities. IEEE Technology and Society Magazine, 18(3), 12-21.

Klein, J. T. (2004). Prospects for transdisciplinarity. Futures, 36(4), 515-526.

Larkin, J., \& Simon, H. A. (1987). Why a Diagram is (Sometimes) Worth Ten Thousand Words. Cognitive Science, 11(1), 65-100.

Lawson, B. (2005). How designers think (4th ed.). London UK: Architectural Press.

Leonard, D. A., \& Swap, W. C. (2005). When sparks fly: harnessing the power of group creativity. Boston MA: Harvard Business School Press.

Lélé, S., \& Norgaard, R. B. (2005). Practicing interdisciplinarity. BıoScıence, 55(11), 967-975.

Martin, R. L. (2009). The design of Business. Boston MA: Harvard Business Press.

Mathewson, J. H. (1999). Visual-spatial thinking: An aspect of science overlooked by educators. Science Education, 83(1), 33-54.

Matthews, B. (2009). Intersections of brainstorming rules and social order. CoDesign, $5(1), 65-76$.

Myers, I. B, \& McCaulley, M. H. (1985). Manual: A gulde to the development and use of the Myers-Briggs Type Indicator. Palo Alto, CA: Consulting Psychologists Press. 
EXPERT GROUP SKETCHING

Newell, A., \& Simon, H. A. (1972). Human problem solving. Englewood Cliffs, NJ: Prentice-Hall.

Osborn, A. F. (1957). Applied imagination: Principles and procedures of creative problem-solving (Revised ed.). New York: Charles Scribner's Sons.

Oxford Advanced Learner's Dictionary. (2010). . Retrieved December 29, 2010, from http://www.oxfordadvancedlearnersdictionary.com/dictionary/abstract_1.

Oxford Dictionaries Online. (2011). . Retrieved January 11, 2011, from http://www.oxforddictionaries.com/view/entry/m_en_gb0170400\#m_en_gb0170400

Paulus, P. B. (2000). Groups, teams, and creativity: The creative potential of ideagenerating groups. Applied psychology, 49(2), 237-262.

Paulus, P. B., \& Dzindolet, M. T. (1993). Social influence processes in group brainstorming. Journal of Personality and Social Psychology, 64(4), 575-586.

Prediger, D. J. (1976). A World of Work Map for Career Exploration. Vocatıonal Guldance Quarterly, 24(3), 198-208.

Prediger, D. J., \& Vansickle, T. R. (1992). Locating occupations on Holland's hexagon: Beyond RIASEC. Journal of Vocatıonal Behavior, 40(2), 111-128.

ProMentor - Brainstorming Rules. (2010). . Retrieved March 30, 2011, from http://www.promentor.co.za/articles/brainstorming_rules.html.

Rhoten, D. (2004). Interdisciplinary research: Trend or transition. Items and Issues, 5, 611 .

Rittel, H. W. J., \& Webber, M. M. (1973). Dilemmas in a general theory of planning. Policy sciences, 4(2), 155-169.

Sacks, H., Schegloff, E. A., \& Jefferson, G. (1974). A simplest systematics for the organization of turn-taking for conversation. Language, 50(4), 696-735.

Sanders, E., \& Stappers, P. J. (2008). Co-creation and the new landscapes of design. CoDesign, 4(1), 5-18.

Sawyer, R. K. (2007). Group genius: The creative power of collaboratıon. New York: Perseus. 
Schrage, M. (2000). Serious play: How the world's best companies simulate to innovate. Journal of Curriculum Studies. Boston MA' Harvard Business Press.

Schwartz, D. L. (1995). The emergence of abstract representations in dyad problem solving. Journal of the Learning Sciences, 4(3), 321-354.

Schwartz, D. L., \& Heiser, J. (2006) Spatial representations and imagery in learning. In K. Sawyer (Ed.), Handbook of the Learning Sciences (p. 283-298). Cambridge, UK. Cambridge University Press.

Schön, D. A. (1983). The reflective practitıoner: how professionals think in actıon. New York : Basic Books.

Schon, D. A. (1990). Educatıng the Reflective Practttioner: Toward a New Design for Teaching and Learning in the Professions. San Francisco: Jossey-Bass.

Schütze, M., Sachse, P., \& Römer, A. (2003). Support value of sketching in the design process. Research in Engineering Design, 14(2), 89-97.

Simon, H. A. (1959). Theories of decision-making in economics and behavioral science. The American Economic Review, 49(3), 253-283.

Simon, H. A. (1973). The structure of ill structured problems. Artifictal intelligence, 4(34), 181-201.

Snow, C. P. (1959). The two cultures. The Two Cultures (pp. 1-21). Cambridge University Press.

Stebbins, R. A. (2001). Exploratory Research in the Social Sciences. Thousand Oaks, CA: Sage Publications, Inc.

Suwa, M., Purcell, A. T., \& Gero, J. S. (1998). Macroscopic analysis of design processes based on a scheme for coding designers' cognitive actions. Design Studies, 19(4), 455-483.

Suwa, M., \& Tversky, B. (1997). What do architects and students perceive in their design sketches? A protocol analysis. Design Studies, 18(4), 385-403.

Tang, J. C. (1989). Toward an understanding of the use of shared workspaces by design teams. Ph.D. Thesis, Stanford University.

The Random House Dictionary of the English Language (1987). New York: Author. New York: Random House. 
Tohıdi, M., Buxton, W., Baecker, R., \& Sellen, A. (2006). User sketches: a quick, inexpensive, and effective way to elicit more reflective user feedback. Proceedings of the 4th Nordic conference on Human-computer interaction: changing roles ( $\mathrm{p}$. 105-114). New York: ACM.

Tversky, B. (2005). Visuospatial reasoning. The Cambridge handbook of thınkıng and reasoning (p. 209-240). Cambridge, UK: Cambridge University Press.

Vanderlugt, R. (2002). Functions of sketching in design idea generation meetıngs. Proceedings of the 4th conference on Creativity \& cognition (p. 72-79). New York: ACM.

Vanderlugt, R. (2005). How sketching can affect the idea generation process in design group meetings Design Studies, 26(2), 101-122.

VanLehn, K. (1996). Cognitive skill acquisition. Annual revıew of psychology, 47, 51339.

Verstijnen, I., Vanleeuwen, C., Goldschmidt, G., Hamel, R., \& Hennessey, J. (1998). Sketching and creative discovery. Design Studies, 19(4), 519-546.

Vyas, D., Heylen, D., Nijholt, A., \& Der Veer, G van. (2009). Experiential role of artefacts in cooperative design. Proceedings of the fourth international conference on Communttes and technologies - C\&T 09 (pp. 105-114). New York: ACM Press.

West, M. A. (2002). Sparkling Fountains or Stagnant Ponds: An Integrative Model of Creativity and Innovation Implementation in Work Groups. Applled Psychology, $5 l(3), 355-387$. 
Appendix A Recruitment Emails

Email to use for contacts that the researcher knows personally

Email Subject: Looking for Experts!

Hi <insert name>,

I'm hoping you can help me out.

As you may know, I am currently working on my master's thesis at Carleton University in the School of Industrial design.

As part of my thesis, I am doing a study looking at problem-solving strategies of professionals in groups where there is a mix of backgrounds.

For the study, I need to recruit professionals. What I need to find are experts (any professional with 10 or more years of experience) from a wide variety of disciplines who would be willing to participate in the study.

As part of this study, I am also fund raising for The Hospice at Maycourt which provided my dad with the most gentle of care during his illness. For each workshop participant, a donation of $\mathbf{\$ 5 0}$ will be made to The Hospice at Maycourt or to a charity of the participant's choice.

I am hoping that you could participate. Please send me an email or call me , if you would be willing to be part of the study.

If this is not feasible, then perhaps you know of someone who might be willing. If so, please let me know.

I've appended the notice for the study at the end of this email with some of the details for the study participation.

Thanks in advance,

Diana Wilhelm

dwilhelm@connect.carleton.ca

\section{Teams}

Research Study: Expert Problem-solving strategies in Interdisciplinary 
For each workshop participant, a donation of $\$ \mathbf{5 0}$ will be made to The Hospice at Maycourt or a charity of your choice.

Your participation would be appreciated for an experiment that is being conducted by a Master's student from the School of Industrial Design at Carleton University. We are interested in how experts problem-solve in a group. Participants recruited for this study will be asked to develop solutions for 2 problems as part of a four-person team. The sessions will be video- and audio recorded, and will also be observed by the researcher through a one-way mirror. The design session will last four hours.

\section{Eligibility Requirements:}

Participants are sought who are professionals with 10 years or more experience in their field of work. Examples would be doctors, engineers, marketers, researchers, professional sales, teachers, lawyers etc.

Study Duration: 10 minutes to fill in a background questionnaire available online. 4 hours for the workshop which will be scheduled for your convenience.

If you are interested in participating in this study and would like more information please email Diana Wilhelm at dwilhelm@connect.carleton.ca or call

This study has received clearance by the Carleton University Psychology Research Ethics Board (ethics file number to be inserted).

\section{Recruitment Email for secondary contacts}

\section{Email Subject: Looking for Experts!}

Hi <insert name>,

I'm hoping you can help me out.

$<$ insert name of person who suggested contact> suggested that you might be interested in being involved with my research project.

My name is Diana Wilhelm. I am currently working on my master's thesis at Carleton University in the School of Industrial design. It's been an exciting project for me to undertake.

As part of my thesis, I am doing a study looking at problem-solving strategies of professionals in groups where there is a mix of disciplines. 
For the study, I need to recruit professionals. What I need to find are experts (any professional with 10 or more years of experience) from a wide variety of disciplines who would be willing to participate in the study.

I would like to ask you to participate, or if you could suggest someone who might be willing to participate please send me an email or call me,

As part of this study, I am also fund raising for The Hospice at Maycourt which provided my dad with the most gentle of care during his illness. For each workshop participant, a donation of $\$ 50$ will be made to The Hospice at Maycourt or to a charity of the participant's choice.

I've appended the notice for the study at the end of this email.

Thanks in advance for any help on this,

Diana Wilhelm

dwilhelm@connect.carleton.ca

Attention: All Professionals with 10 years or more experience.

For each workshop participant, a donation of $\$ 50$ will be made to The Hospice at Maycourt or a charity of your choice.

Your participation would be appreciated for an experiment that is being conducted by a Master's student from the School of Industrial Design at Carleton University. We are interested in how experts problem-solve in a group. Participants recruited for this study will be asked to develop solutions for 2 problems as part of a four-person team. The sessions will be video- and audio recorded, and will also be observed by the researcher through a one-way mirror. The design session will last four hours.

\section{Eligibility Requirements:}

Participants are sought who are professionals with 10 years or more experience in their field of work. Examples would be doctors, engineers, marketers, researchers, professional sales, teachers, lawyers etc.

Study Duration: 10 minutes to fill in a background questionnaire available online. 4 hours for the workshop which will be scheduled for your convenience.

If you are interested in participating in this study and would like more information please email me Diana Wilhelm at dwilhelm@connect.carleton.ca or call

This study has received clearance by the Carleton University Psychology Research Ethics Board (ethics file number to be inserted). 
Email for participants not selected for workshop.

Subject: Study into expert strategies in problem-solving

Thank you so much for completing the questionnaire for the study.

I have had significant responses for my study and have already filled up my workshops. As a result, at this time you are not required to attend a workshop.

Thanks again for your time. I do appreciate your interest.

If you have any questions or comments, feel free to contact me.

Diana Wilhelm 


\title{
Appendix B Online Questionnaire
}

\author{
Prepared using SurveyMonkey.com
}

\section{INFORMED CONSENT}

\section{Introduction}

The purpose of an informed consent is to ensure that you understand the purpose and your involvement in the study. After reading the informed consent, you should be able to determine whether or not you wish to participate in this study.

Study

This study is looking at problem-solving strategies that experts use in an interdisciplinary group.

Research Personnel

The following personnel are involved in this research project and may be contacted at any time:

Diana Wilhelm (principal researcher) dwilhelm@connect.carleton.ca

Dr. Gitte Lindgaard

(Psychology Faculty advisor) gitte_lindgaard@carleton.ca 613-520-20uv exc. _255, Dr. Won Joon Chung

(Industrial Design Faculty advisor) wonjoon_chung@carleton.ca 613 520-6606.

Purpose

The study aims to examine the process of problem-solving in group situations where there are experts from different backgrounds in the group.

Task Requirements

The first step of your participation is to fill in this online questionnaire. It should only take about 10 minutes of your time.

Subsequent to that, at a later date, you will be participating in a group workshop consisting of 4 professionals where you will work together on solutions for two different problems.

Duration and Locale

The questionnaire should take about 10 minutes of your time.

The workshop session will take about 4 hours and will be conducted at the Carleton University campus. These workshops will be scheduled at a convenient time for the participants.

Potential Risk or Discomfort

There are no potential risks or discomforts in this study.

\section{Confidentiallty}

The data collected in this study will be treated with the utmost care and confidentiality. All data are coded such that your name will not be assoclated with the data. The coded raw data will only be available to the researchers involved in this study.

Right to Withdraw

You have the right to withdraw from the study at any time without penalty.

If any ethlcal concerns about this study should arise, please contact Dr. Monlque Sénéchal, 613-5202600 ext. 1155, monique_senechal@carleton.ca). Should you have any other concerns about this study, please contact Dr. Janet Mantler (Chair, Dept. of Psychology, 520-2600 ext. 2648,

psychchair@carleton.ca or Dr. Thomas Garvey (Director, School of Industrial Design) , 613-520-5674, thomas_garvey@carleton.ca.

This study has received clearance by the Carleton University Psychology Research Ethics Board (ethics file number to be inserted). 
* 1. I have read the above description of the study and understand the conditions of my participation. I agree to participate in this research project. OrES Ono 


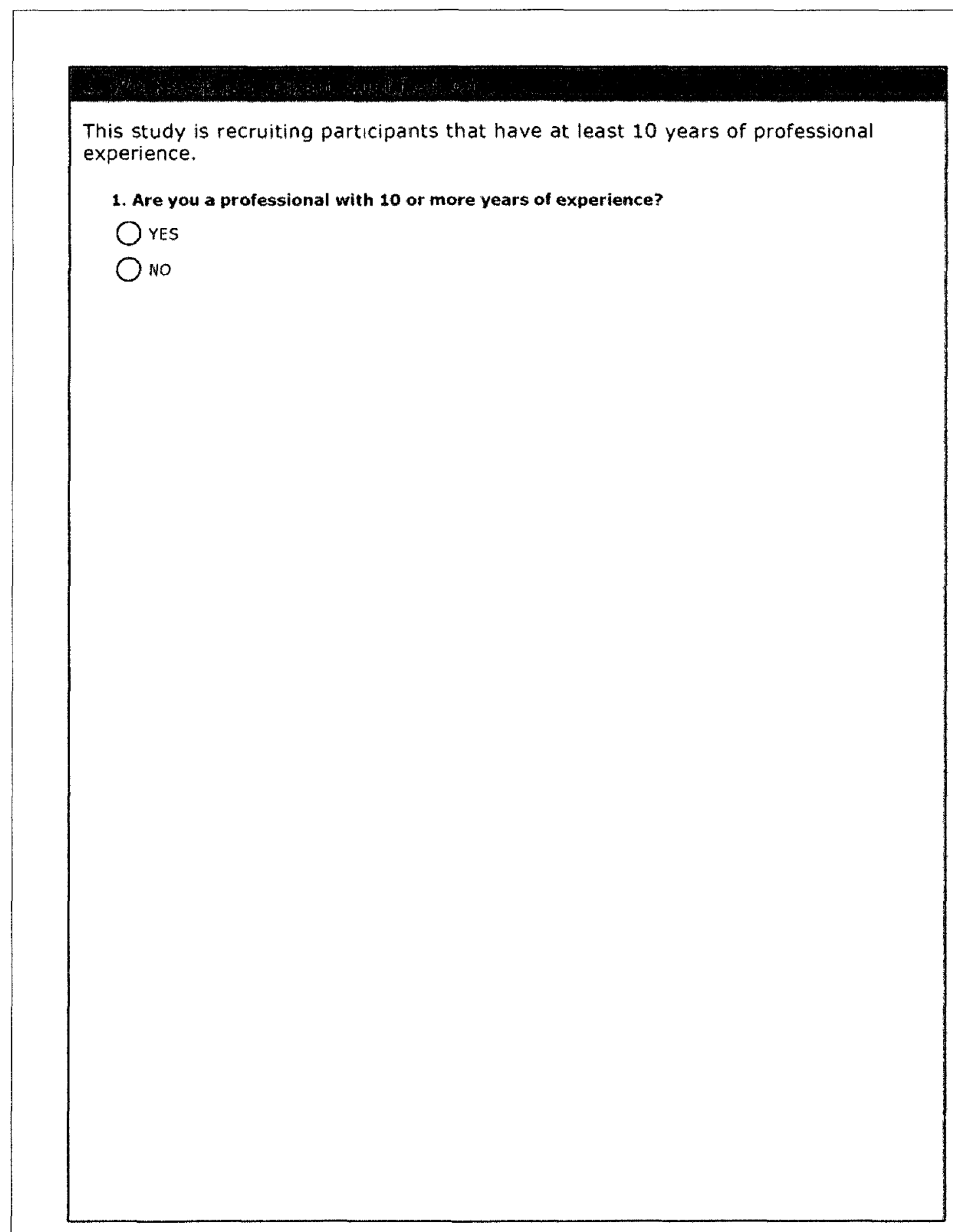




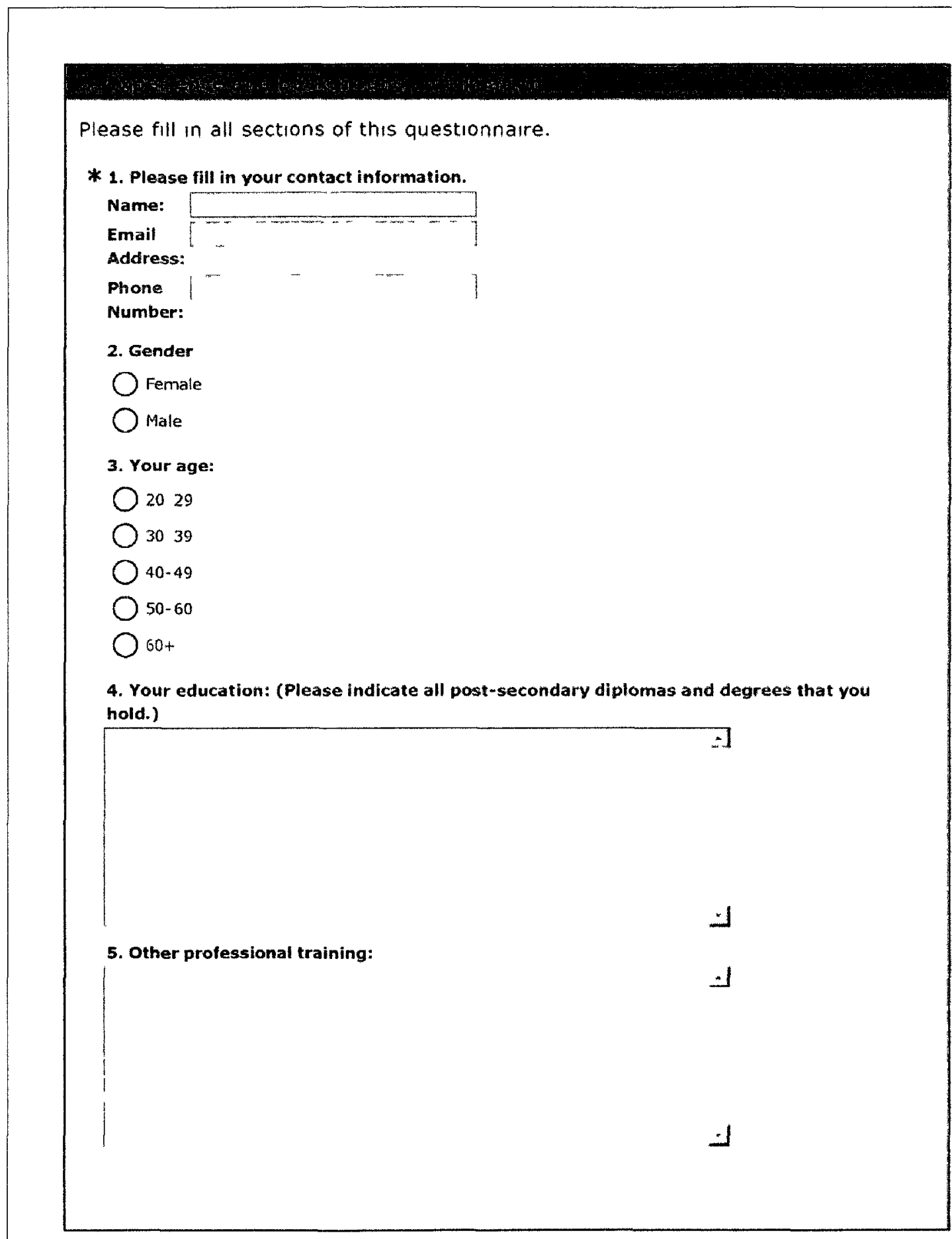




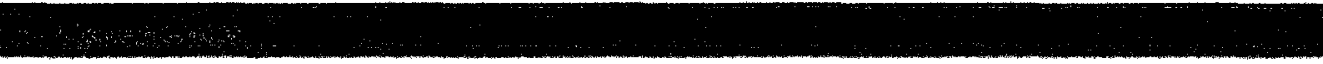

1. Current Profession:

1 .

* 2. Years of experience in current profession?

3. What industry are you currently employed in?

4. If you were asked at a social gathering, how would you describe your current job to someone?

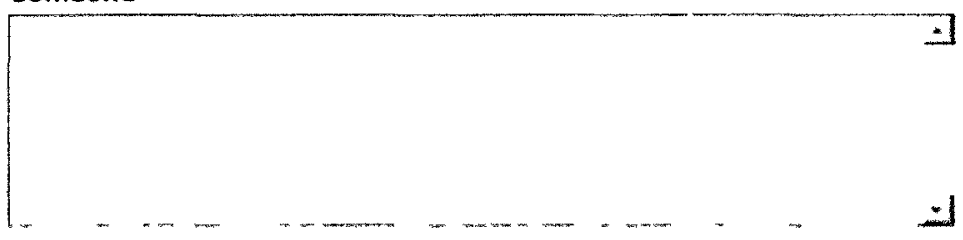

5. If you have had other professions, please list them here and provide the number of years experience in each role.

Profession

Profession

Profession

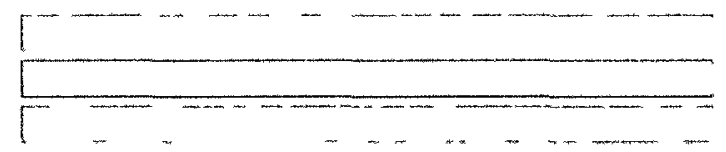

6. Briefly describe your most recent activities and/or projects in your current position: $\pm$ 


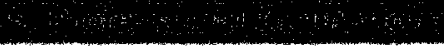 \\ Check all the boxes that apply to you.}

1. Are You ...

$\square$ Assertive?

$\square$ observant?

$\square$ Precise?

$\square$ Curious?

$\square$ Mechanical?

$\square$ Understanding?

$\square$ Enthusiastic?

$\square$ Well groomed?

$\square$ Inventive, original?

$\square$ Friendly?

$\square$ self-confident?

$\square$ Intuitive?

$\square$ Free spirit or a rebel?

$\square$ Idealistic?

$\square$ Creative?

$\square$ Persuasive?

$\square$ Analytical (like to figure things out)?

$\square$ stuaight forward?

$\square$ A nature lover?

Dechanically inclined?

$\square$ Efficient?

$\square$ Practical?

$\square$ Helpful?

$\square$ Imaginative?

$\square$ Scientific-use information to solve new problems?

7 Able to operate tools and machinery?

$\square$ Responsible?

$\square$ Methodical?

$\square$ Energetic?

$\square$ Able to do your own thing?

$\square$ sociable?

$\square$ Outgonn?

$\square$ Athletic?

Insightful? 


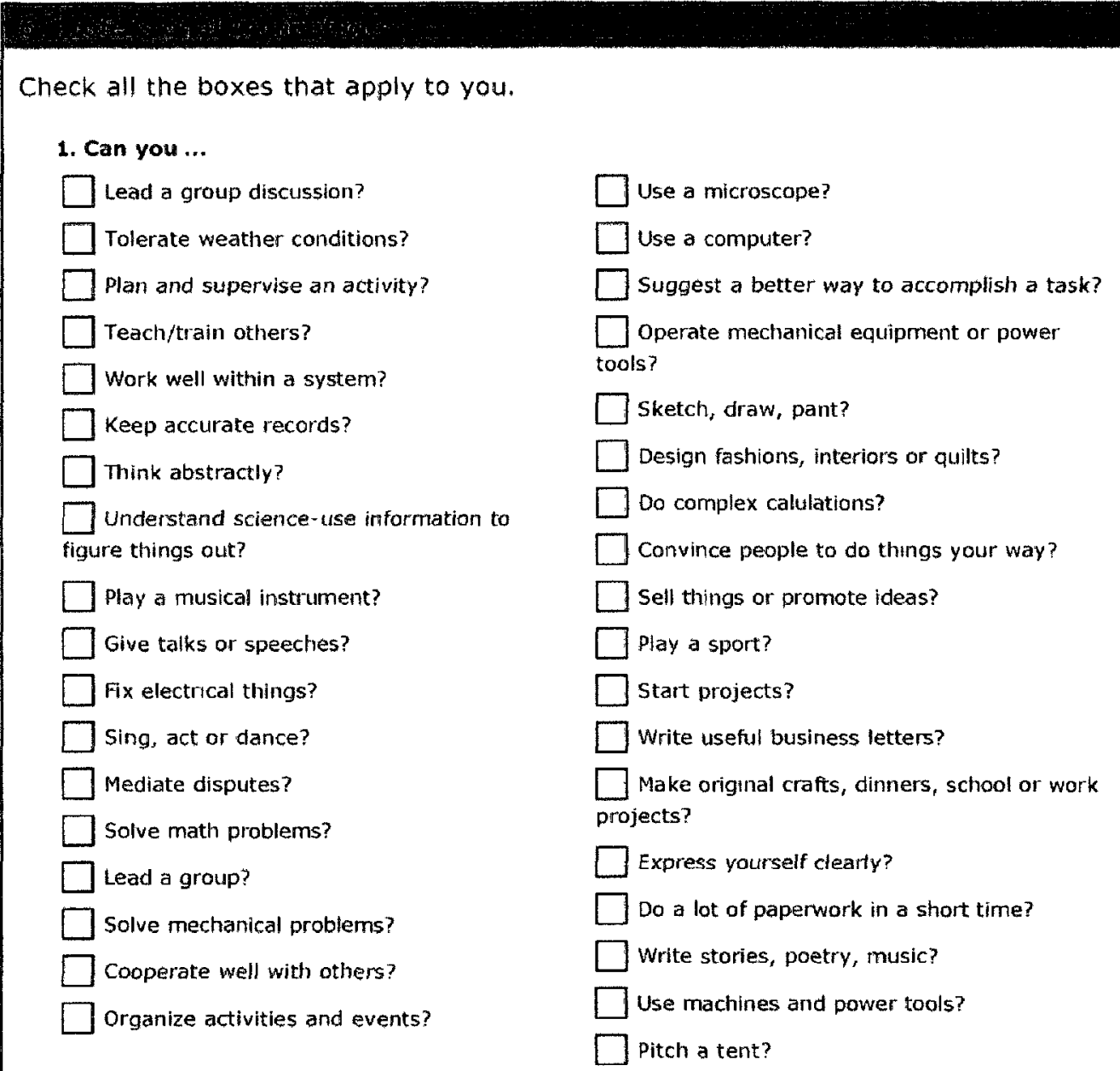


Check all the boxes that apply to you.

\section{Do you like to ...}

$\square$ Do volunteer service?

$\square$ Work with numbers?

$\square$ Take photographs?

Meet important people?

$\square$ Use computers?

Work on crafts, make gifts for friends and relatives?

$\square$ Start your own political campaign?

Be physically active?

$\square$ Work on cars, lawnmowers or sewing machines; repair kids' toys?

Tollow clearly defined procedures?

$\square$ Work outdoors?

Read scientific or technical magazines?

$\square$ Read fiction, plays, poetry?

$\square$ Be responsible for details?

$\square$ work in groups?

$\square$ Perform experiments?

$\square$ work with young people?

$\square$ Attend concerts, theaters, art exhibits?
Win a leadership or sales award?

$\square$ Be in the center of activity?

Type, file, use a 10-key pad?

cook?

$\square$ Work independently (by yourself with little direction)?

Make decisions affecting others?

$\square$ Cook without a recipe to guide you?

Explore ideas?

$\square$ Tinker or work with your hands?

$\square$ Express your own style?

$\square$ Push through to task completion?

$\square$ Play team sports?

$\square$ Be elected to office or make your opinions heard?

$\square$ Keep detailed records?

$\square$ Help people with problems?

$\square$ Make sure things get done?

$\square$ Be outdoors?

$\square$ Participate in meetings? 


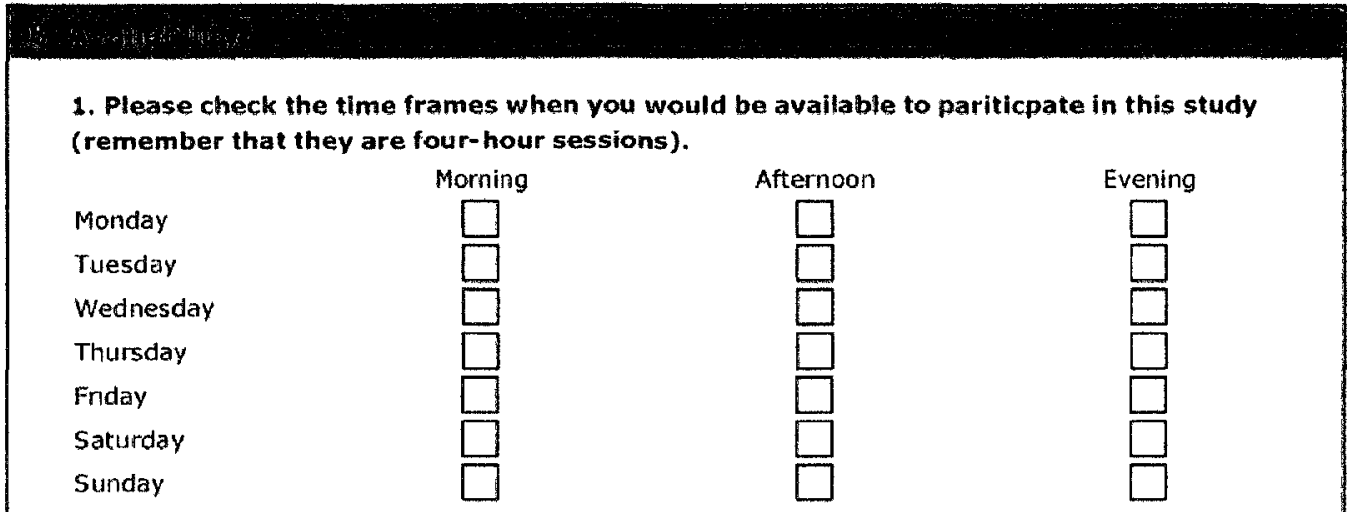

2. In recognition of your time and effort for participating in the workshop, a donation of $\$ 50$ will be made to charity. Please select your preference:

Donation to Hospice Maycourt

Other (please specify)

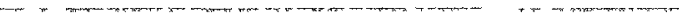




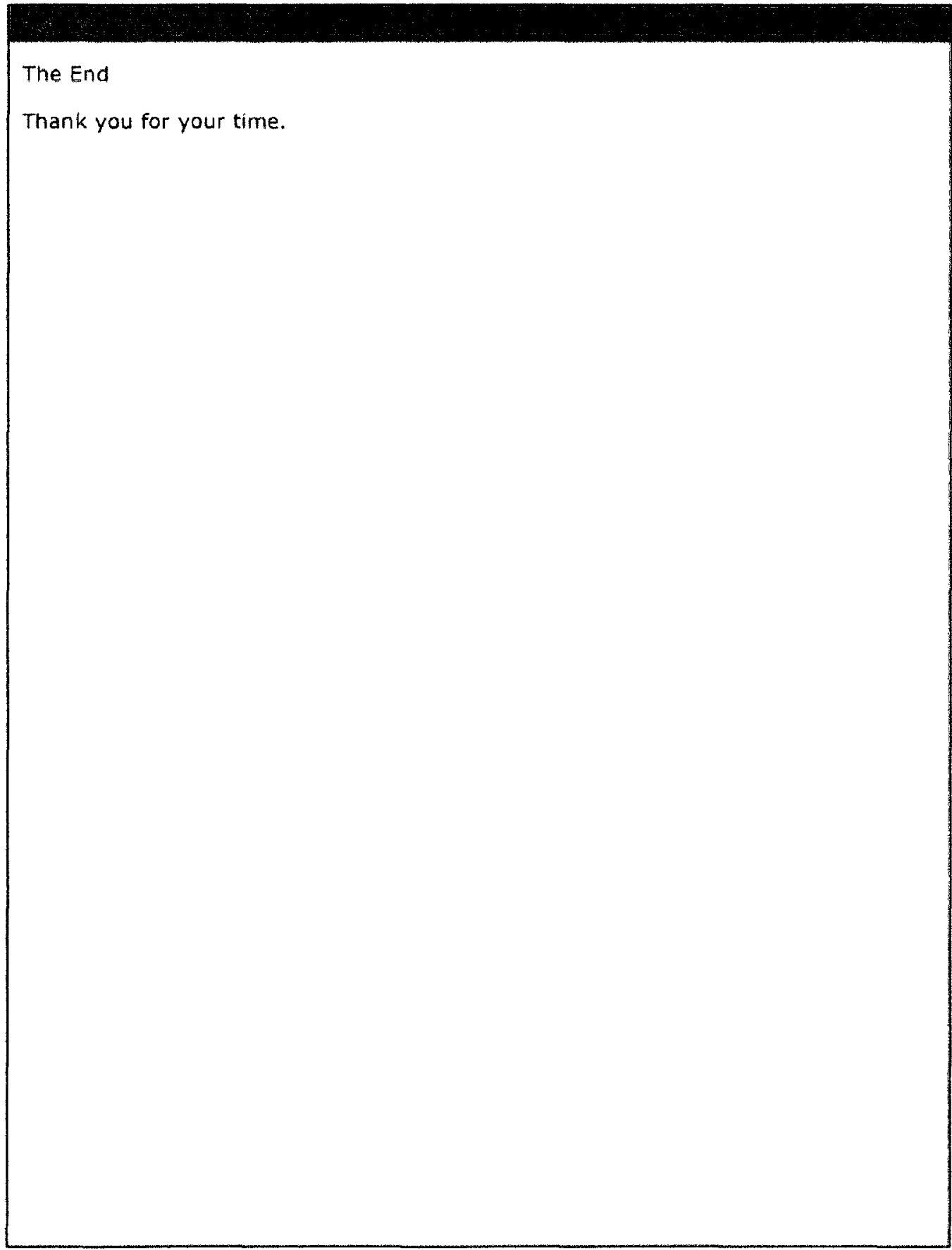


Thank you for completing the questionnaire. You will be contacted to arrange a time for the workshop. Your time and effort is appreciated.

If you have any complaints, concerns, or questions about this research, please feel free to contact

Dr. Gitte Lindgaard (Faculty sponsor), 613-520-2600 ext. 2255, gitte_lindgaard@carleton.ca.

If any ethical concerns about this study should arise please contact Dr. Monique Sénéchal on 613-520-2600 ext. 1155 (Chair, ethics committee, Department of Psychology) monique senechal@carleton.ca.

Should you have any other concerns about this study, please contact Dr. Janet Mantler (Chair, Dept. of Psychology,) 520-2600 ext. 2648, psychchair@carleton.ca or Dr. Thomas Garvey (Director, School of Industrial Design) , 613-520-5674, thomas_garvey@carleton.ca. 
Appendix C Workshop Problem Statement Handouts

Handout \#1

Problem 1

For the first problem your task is to design a preliminary strategy for a small publishing company in Ottawa that publishes special interest books and text books. With the introduction of e-book readers, the company recognizes that its marketplace is changing. Currently, the company's business is roughly $40 \%$ from special interest books that have relatively small runs and $60 \%$ from specialized high tech textbooks. E-book readers provide a way for users to download books to a small reading device over the internet instead of them buying a hard copy of the book. These e-readers are much more convenient for consumers, are easy to use and use a special display that appears more like paper than a computer screen. The company is concerned that its business may be threatened if they do nothing, but they are unsure of what they need to do. There are currently 3 major e-book readers available. Amazon sells its exclusive Kindle e-reader which uses a proprietary format. Sony has an e-reader that uses a standardized e-book file format. Apple has recently released its IPAD that is a multi-function tablet that can function as a book reader as well. Apple's IPAD also uses the standardized e-book format and Amazon's proprietary format. In addition, customers can also read all of these softcopy e-books on their existing computers using a special application although it is seen as somewhat less convenient for the consumer. Your task is to come up with a strategy proposal for the publisher about how to address the introduction of e-book readers.

\section{Handout \#2}

\section{Problem 2}

The Morelli family has recently purchased their first home. The house is an 800 sq. $\mathrm{ft}$. bungalow with a kitchen area of only $60 \mathrm{sq}$. $\mathrm{ft}$. The family has two children:

Tommy who is 6 and Jessica who is 9 . The kitchen needs to be completely renovated and Frank Morelli, the father, is planning on doing it himself. Like any typical young family, the Morelli's are on a budget and so they plan on purchasing standard-sized appliances

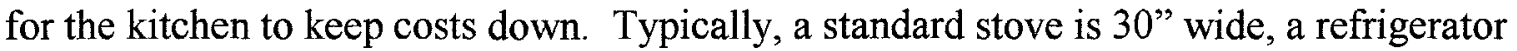
is 30 " to 36 " and a dishwasher is 24 ". Your task is to design a kitchen for the Morelli family that will suit the family and will fit in a 60 sq. $\mathrm{ft}$. space. 
Appendix D Workshop Scripts

\section{Script 1: Introduction}

Thank you all for coming. For those of you that don't know me, my name is Diana Wilhelm. I am the researcher for this study. This study is looking at the strategies experienced professionals use when problem-solving. Feel free to help yourself to the coffee and food that is available just outside. The washrooms are just down the hall. You may have to knock to get back into this area.

Before we start, I need you to read and sign the informed consent form that is sitting in front of you.

\section{Script 2 Outline of workshop schedule and process.} themselves.

So to get started, I would like to go around the table and have every one introduce

(introductions by participants)

Okay, so for today's workshop you will be working through 2 problems as part of a group. The first 50 minutes will be spent working on problem \#1. During the session I will be in the room next door observing through the one-way mirror. If there are any issues or problems during the session that appear irresolvable, I will come in to sort it out. Once the time is up, I will come back in and ask you to present the group solution and the details of your process. After that, we will have a 10 minute break. Then I will describe the second problem to you and leave you for another 50 minutes to work through that problem, followed again by a brief presentation of your group solution and process. Feel free to make any assumptions about each problem that you feel is appropriate; there is no "right" answer for this workshop. Near the end of each session I will let you know when there is 5 minutes left. And then after both sessions, there will be a brief discussion about the overall workshop. As you can see, there are markers and paper set out for you. I think that's it.

Do you have any questions before we begin?

\section{Script 3a Problem statement \#1}

For the first problem your task is to design a preliminary strategy for a small publishing company in Ottawa that publishes special interest books and text books. With the introduction of e-book readers, the company recognizes that its marketplace is changing. Currently, the company's business is roughly $40 \%$ from special interest books that have relatively small runs and $60 \%$ from specialized high tech textbooks. E-book readers provide a way for users to download books to a small reading device over the internet instead of them buying a hard copy of the book. These e-readers are much more convenient for consumers, are easy to use and use a special display that appears more like paper than a computer screen. The company is concerned that its business may be 
threatened if they do nothing, but they are unsure of what they need to do. There are currently 3 major e-book readers available. Amazon sells its exclusive Kindle e-reader which uses a proprietary format. Sony has an e-reader that uses a standardized e-book file format. Apple has recently released its IPAD that is a multi-function tablet that can function as a book reader as well. Apple's IPAD also uses the standardized e-book format and Amazon's proprietary format. In addition, customers can also read all of these softcopy e-books on their existing computers using a special application although it is seen as somewhat less convenient for the consumer. Your task is to come up with a strategy proposal for the publisher about how to address the introduction of e-book readers.

Do you have any questions?

\section{Script 3b Problem Statement \# 2}

The Morelli family has recently purchased their first home. The house is an 800 sq. $\mathrm{ft}$. bungalow with a kitchen area of only $60 \mathrm{sq}$. $\mathrm{ft}$. The family has two children:

Tommy who is 6 and Jessica who is 9 . The kitchen needs to be completely renovated and Frank Morelli, the father, is planning on doing it himself. Like any typical young family, the Morelli's are on a budget and so they plan on purchasing standard-sized appliances for the kitchen to keep costs down. Typically, a standard stove is 30 " wide, a refrigerator is 30 " to 36 " and a dishwasher is 24 ". Your task is to design a kitchen for the Morelli family that will suit the family and will fit in a 60 sq. $\mathrm{ft}$. space.

Do you have any questions?

\section{Script 4 After each problem session}

Okay, now I'd like you to describe how you approached the problem and walk me through your solution. interview):

Script 5 Post workshop group discussion/interview questions (semi-structured

I just have a few more questions about the workshop itself.

1. On a scale of 1 to 10 , how would you rate your group's solution?

2. On a scale of 1 to 10 , how satisfied were you with how much you accomplished in the workshop?

3. How effective was the group at working together?

4. Were there any things that struck you as an issue when working in this type of workshop?

5. Could you suggest 3 improvements that might have helped the sessions? 
Appendix E Example of Rate of Turn-taking Calculation Method

The calculation for the rate of turns taken involves counting the number of turns taken for a period of time and dividing it by the number of seconds for the period.

As an example, a conversation in the transcript contained the following:

Timestamp $=1: 43: 58.5$

A: A lot of authors now: Here's my first chapter, it doesn't cost you anything.

B: Yes

C: I would suggest like the free trial and try it out.

B: Yeah.

D: OK. So we-

B: Try it out?

Timestamp $=1: 44: 16.3$

This sample would calculate out to be 6 speaker turns in a period of 17.8 seconds or .2967 minutes and the rate of turn-taking for this sample would be 6 turns /.2967 minutes $=20.2$ speaker turns per minute. The rates can then be graphed on the workshop timeline to show how the rate of turns fluctuates during each workshop. To compensate for rounding errors and measurement errors with short duration timeslots, a moving average line needs to be included in the graph. The moving average line takes 2 consecutive values and averages them out so that fluctuations due to the calculation method are dampened. 
Appendix F Holland Code Quiz Results

Percentage of participants responses by Holland code

Participant

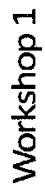

N
응
$\frac{1}{\sqrt{v}}$
$\frac{1}{5}$
3

$m$
$\frac{0}{0}$
$\frac{2}{y}$
$\frac{1}{0}$
3

+
응
$\frac{5}{y}$
$\frac{1}{0}$
3
A

B

C

D

A

B

C

D

A

B

C

D

A

B

C

D<smiles>O=c1c#ccccc1</smiles>

A $26.00 \%$ $11.36 \%$ $14.55 \%$ $15.00 \%$

$15.96 \%$

$11.67 \%$

$17.74 \%$

$8.70 \%$

C $10.00 \%$ $13.64 \%$

$5.45 \%$

$13.75 \%$<smiles>c1c#cccc#1</smiles>

E

$12.00 \%$ $20.45 \%$

$18.18 \%$

$15.00 \%$

$15.96 \%$

$13.33 \%$

$14.52 \%$

$34.78 \%$

$20.90 \%$

$12.50 \%$

$19.40 \%$

$12.50 \%$

$7.35 \%$

$19.12 \%$

$8.47 \%$

$18.64 \%$

$18.09 \%$

$15.00 \%$

16. $13 \%$

$8.70 \%$

$14.93 \%$

$16.25 \%$

$11.76 \%$

$6.78 \%$

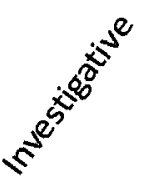

I

$8.00 \%$

$18.18 \%$

$18.18 \%$

$18.75 \%$

$15.96 \%$

$20.00 \%$

$14.52 \%$

$13.04 \%$

$16.42 \%$

$18.75 \%$

$22.06 \%$

$27.12 \%$

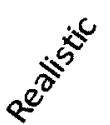

$R$

$18.00 \%$ $15.91 \%$ $25.45 \%$

$18.75 \%$

$14.89 \%$ $25.00 \%$ $20.97 \%$

$13.04 \%$

$10.45 \%$

$21.25 \%$

$22.06 \%$

$25.42 \%$

$16.92 \%$

$14.29 \%$

$22.06 \%$
$31.03 \%$
$18.46 \%$

$16.07 \%$

$16.18 \%$

$0.00 \%$
$10.77 \% \quad 21.54 \%$

$28.57 \% \quad 14.29 \%$

$23.53 \% \quad 19.12 \%$

$17.24 \% \quad 24.14 \%$ 
Appendix G Workshop Activity Event Diagrams

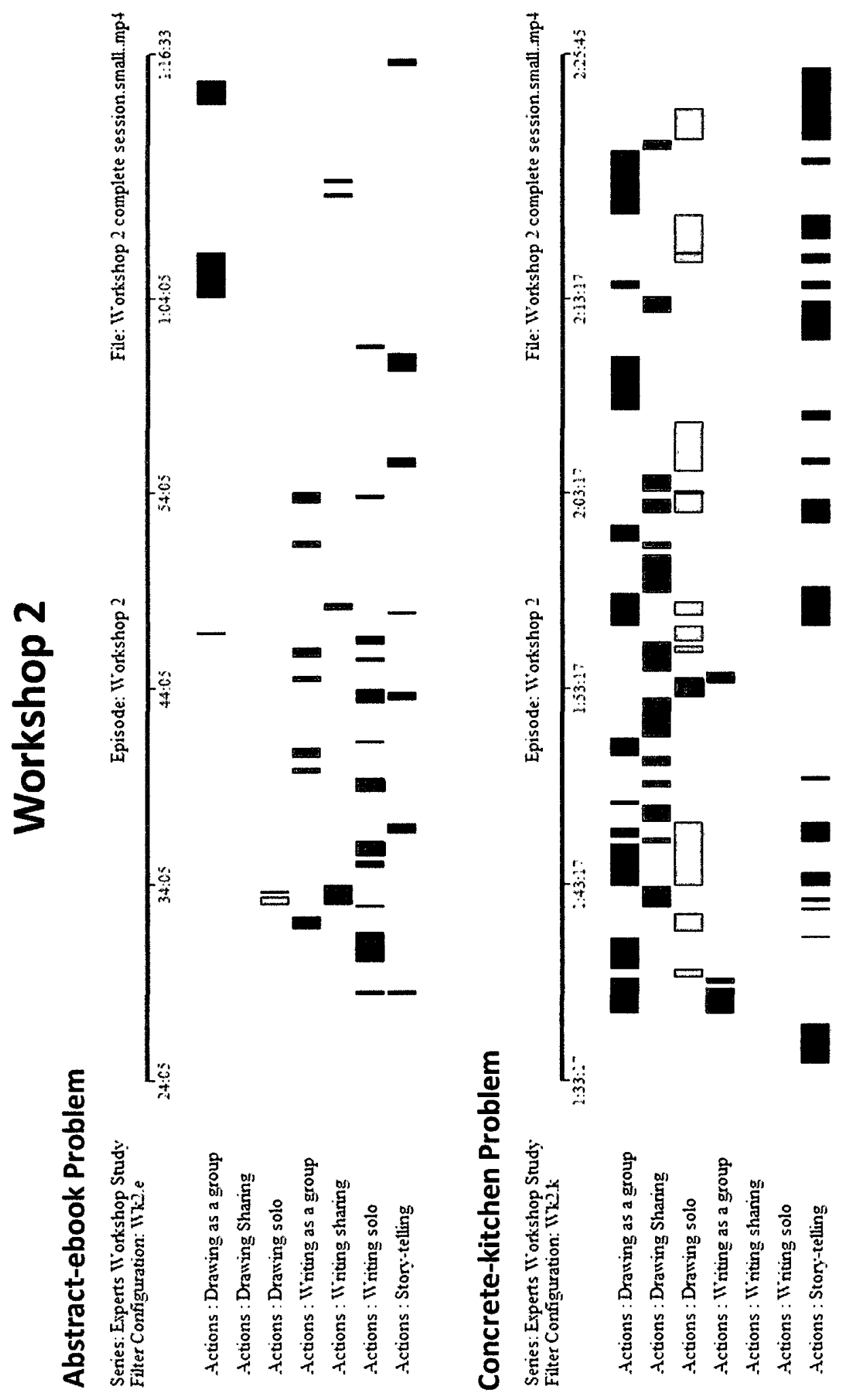




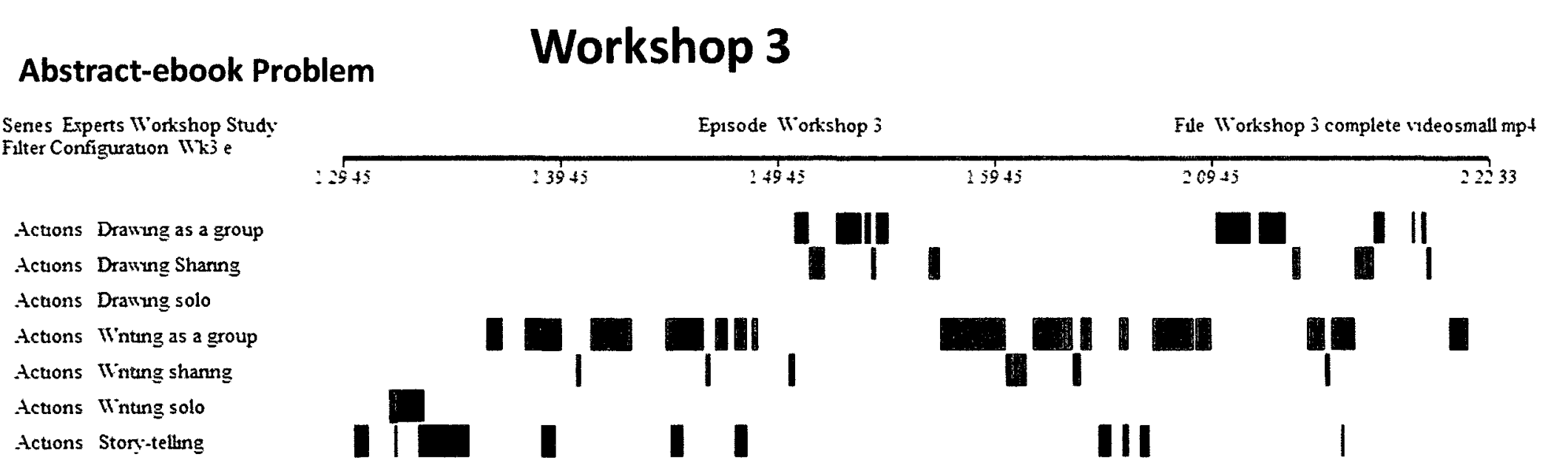

\section{Concrete-kitchen Problem}

Senes Experts Workshop Study Filter Configuration $\mathrm{Wk} 3 \mathrm{k}$

Actrons Drawing as a group

Actsons Drawing Shanng

Actrons Drawing solo

Actions Writung as a group

Actuons Winung shanng

Actons Winting solo

Actions Story-telling
Ep1sode Workshop 3

Fle Workshop 3 complete videosmall mpt

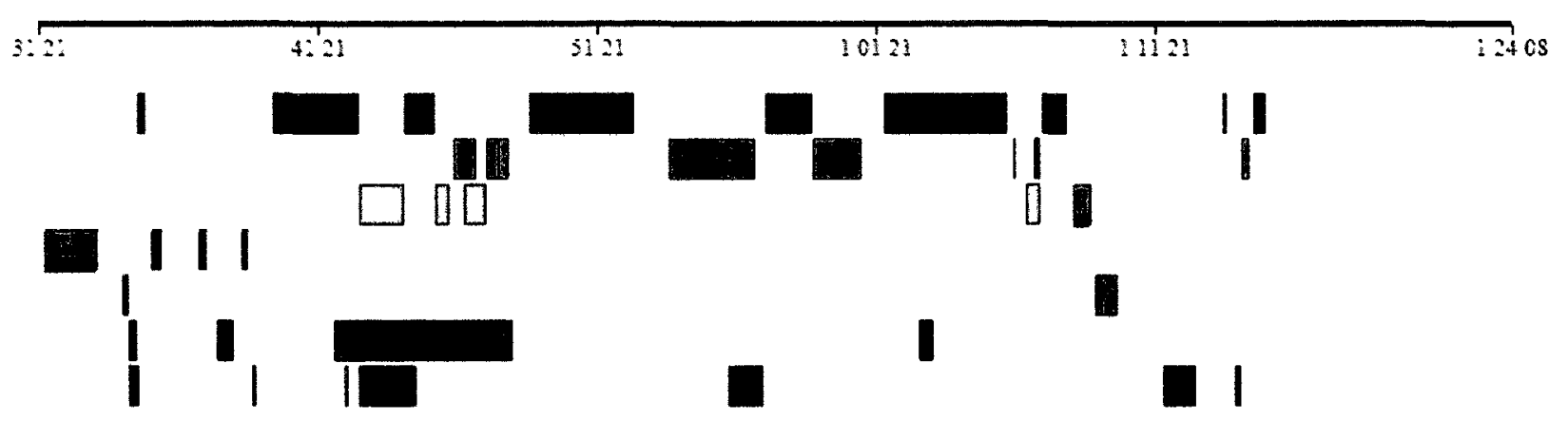




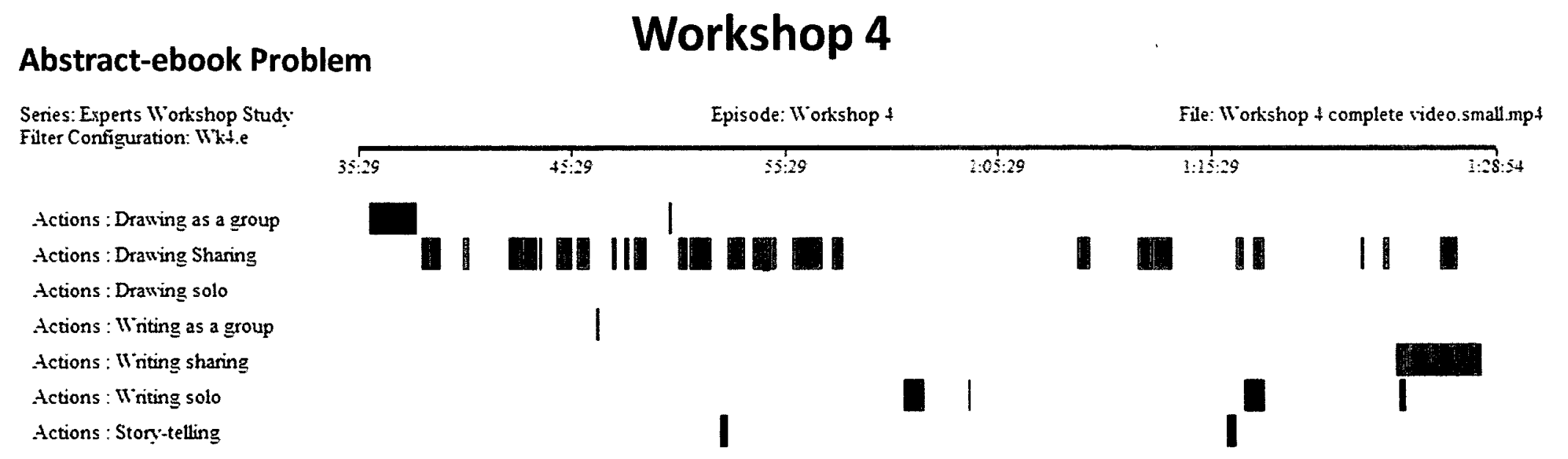

\section{Concrete-kitchen Problem}

Series: Experts Workshop Study Filter Configuration: $W \mathrm{k}+\mathrm{k}$

IVriting as a group

Actions: Writing sharing

Actions: Writing solo

Actions: Story-telling

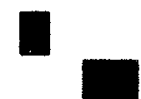

II

| || || | 
Appendix H Rate of Turn-taking with Event Diagrams

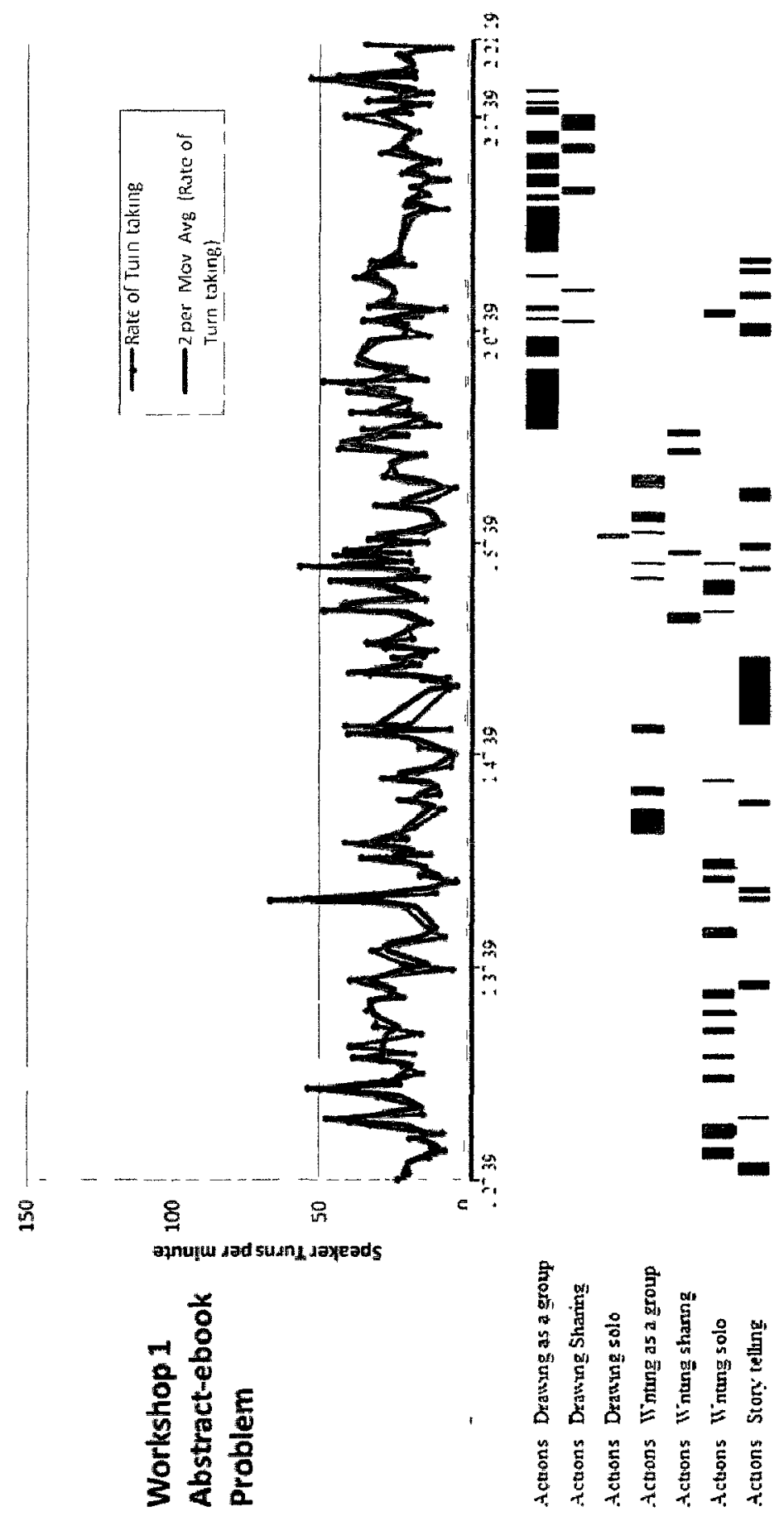




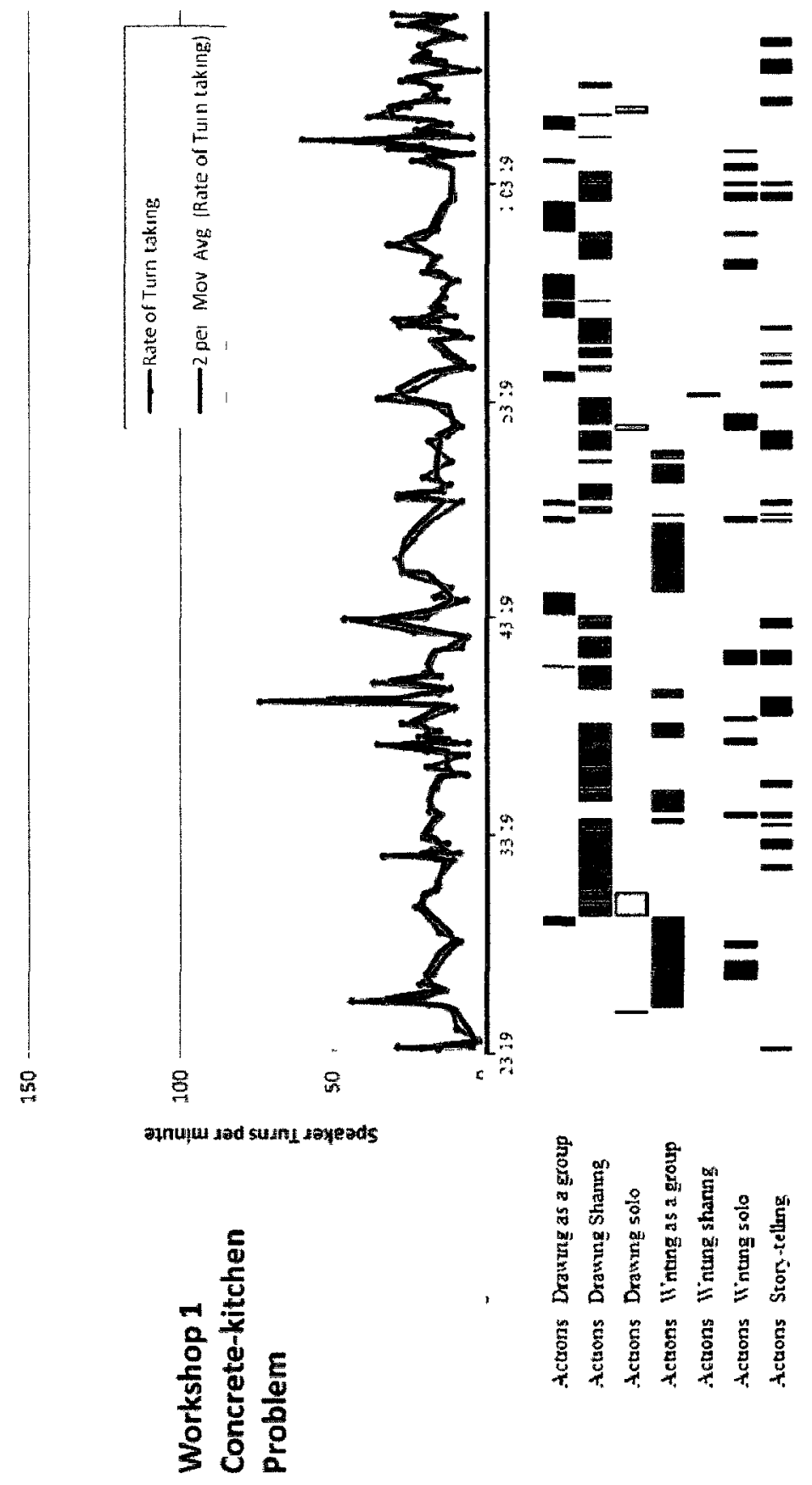




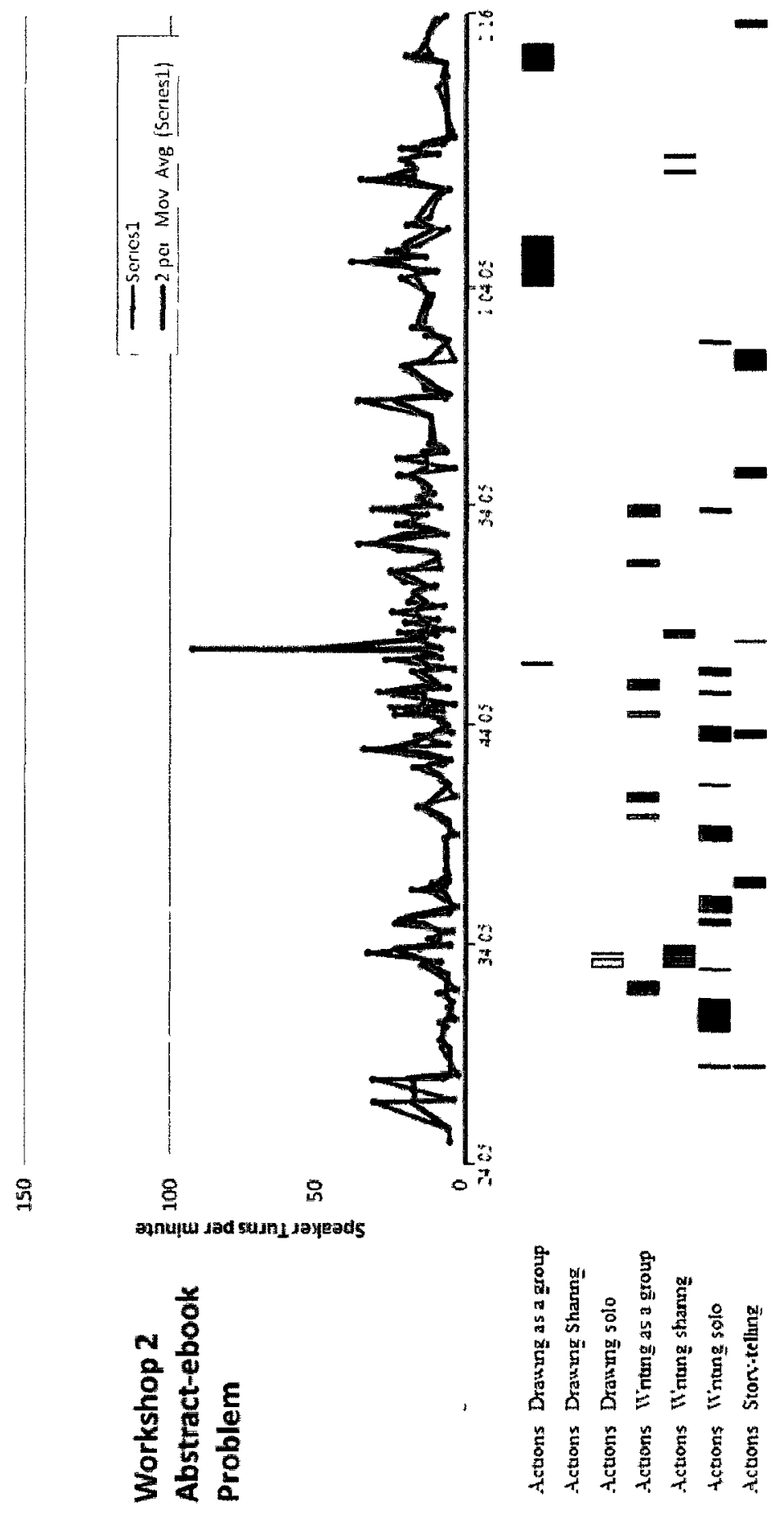




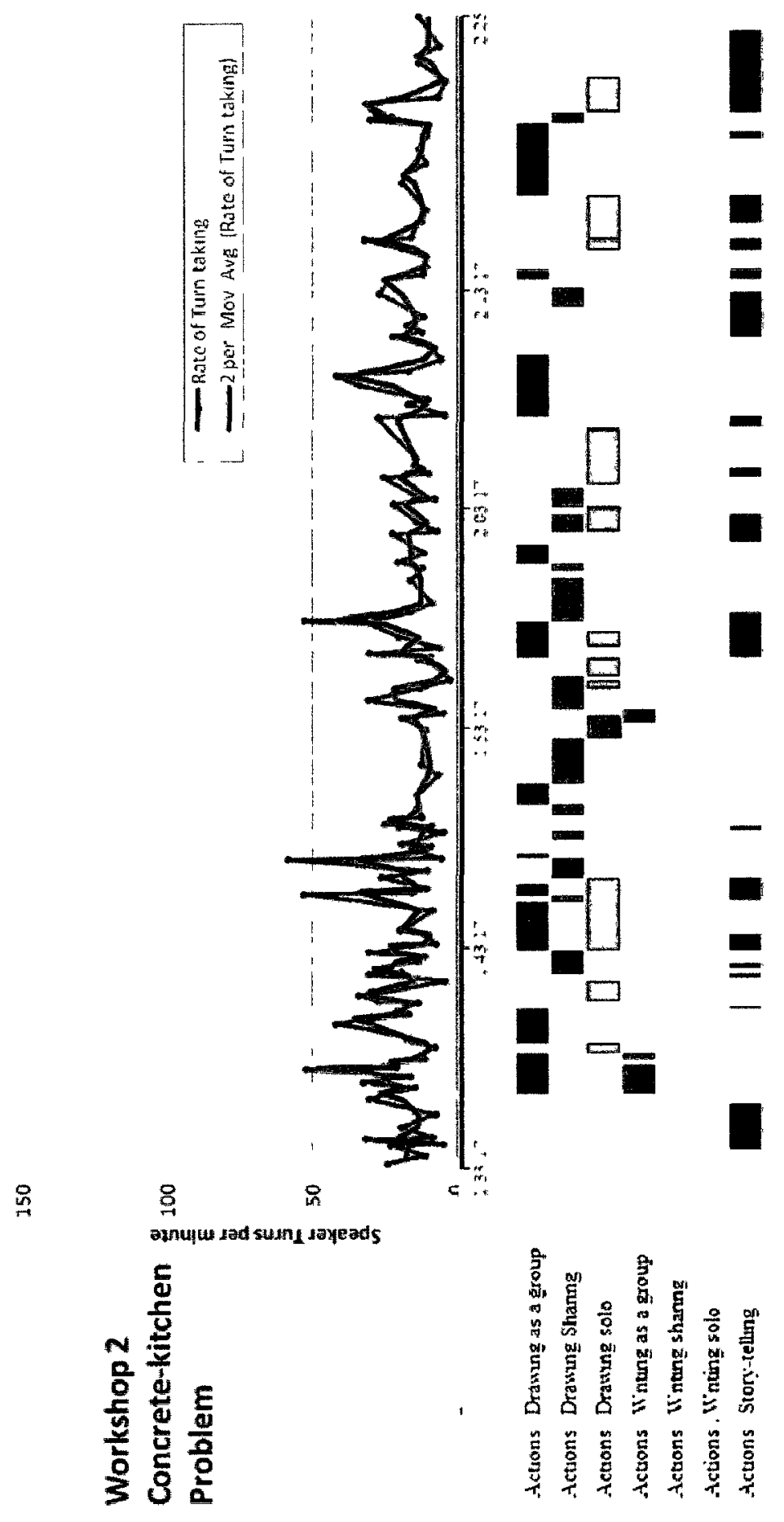




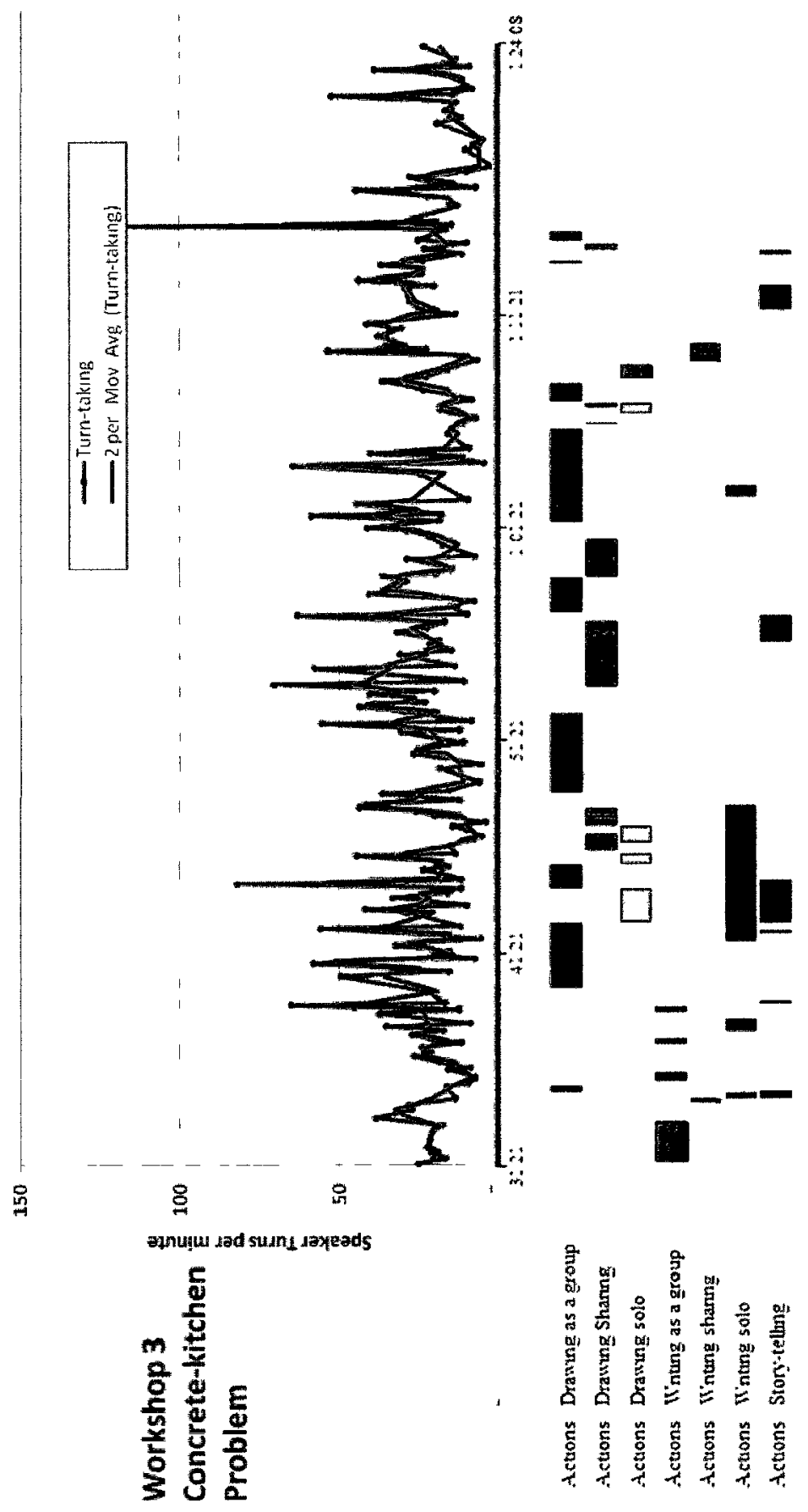




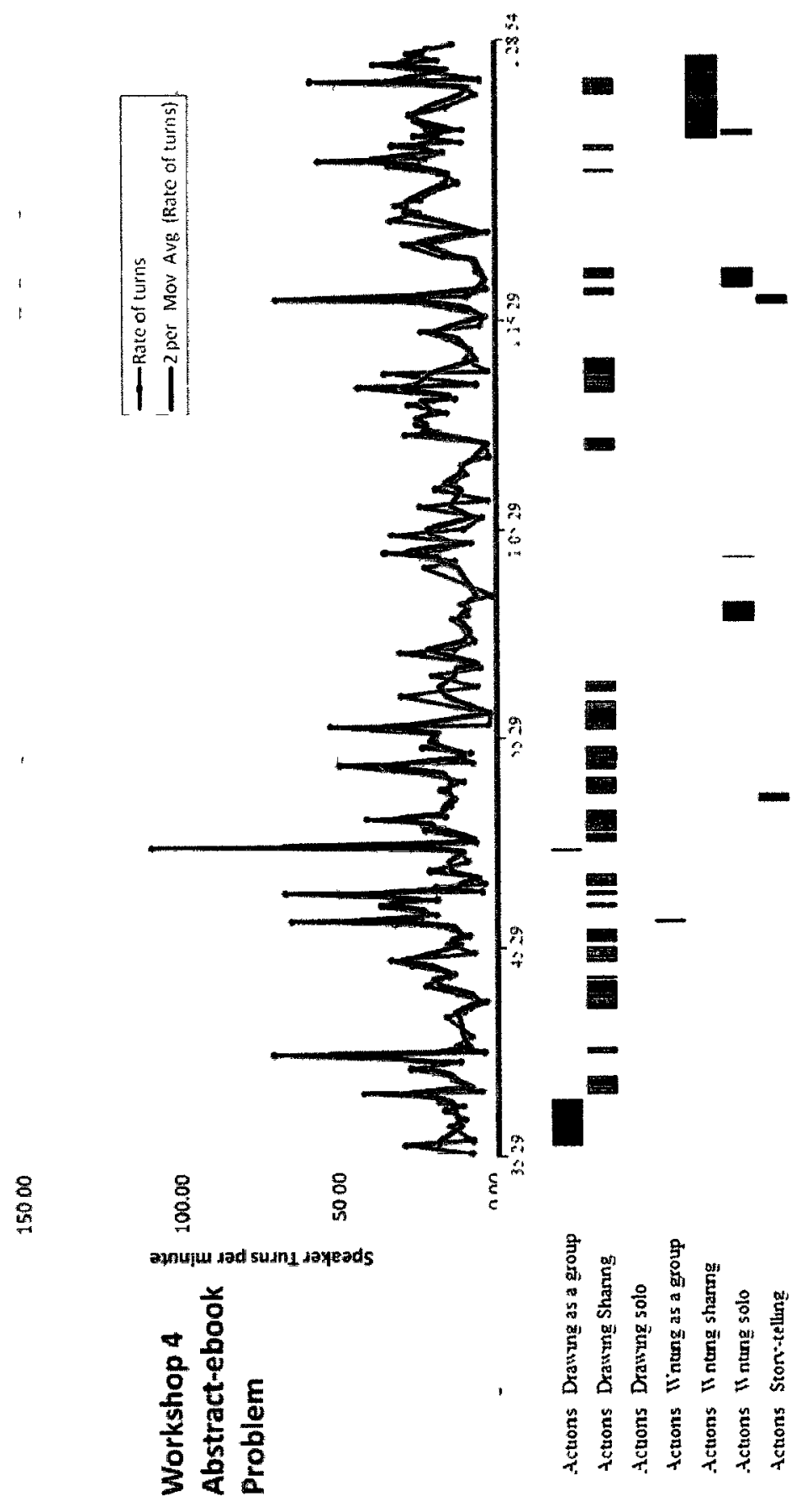




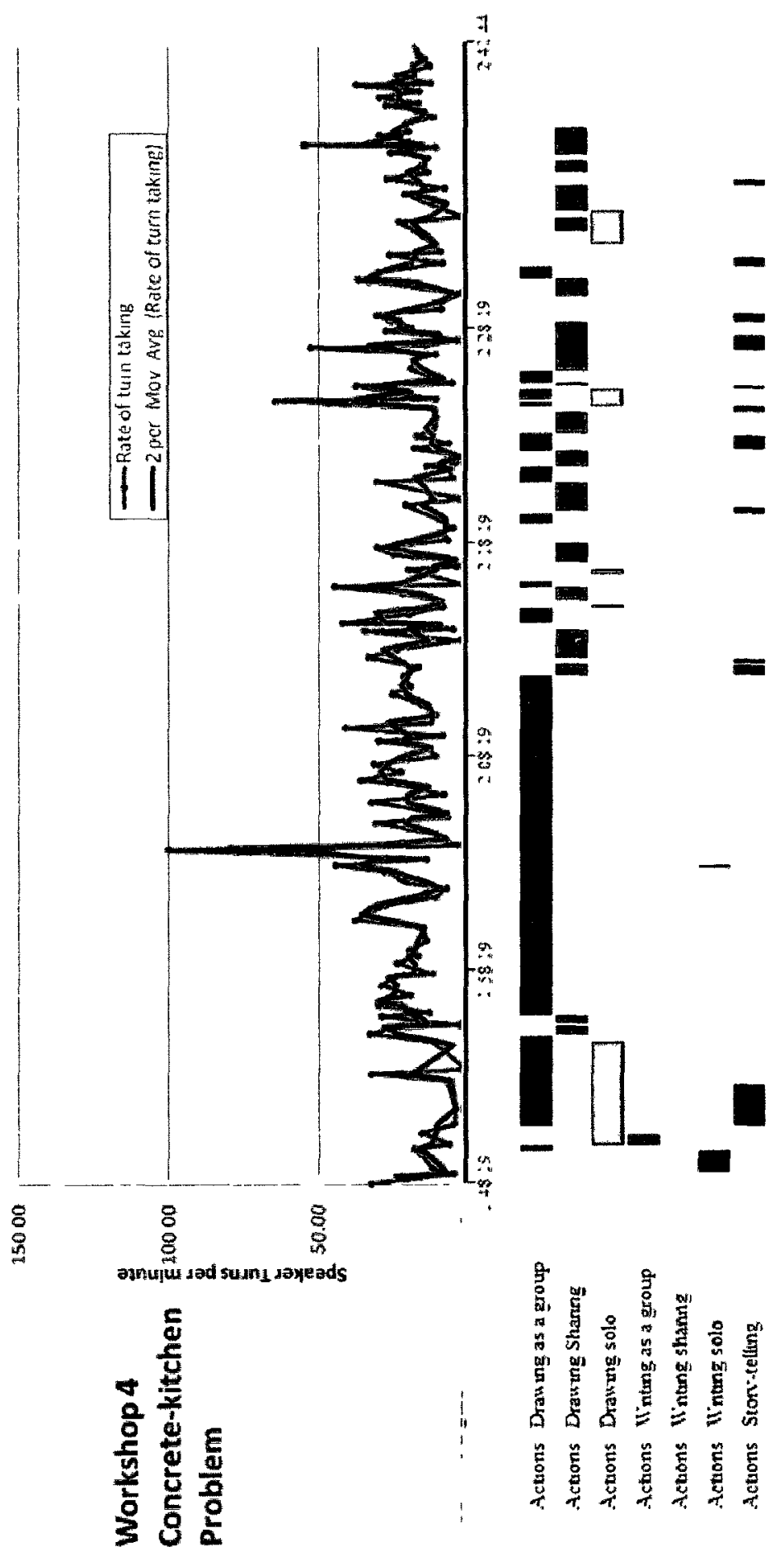

